Portland State University

PDXScholar

$1-1-2011$

\title{
Closed Loop Satisfaction Measurement: New Wine from Old Bottles
}

Michael Thomas O'Connell

Portland State University

Follow this and additional works at: https://pdxscholar.library.pdx.edu/open_access_etds Let us know how access to this document benefits you.

\section{Recommended Citation}

O'Connell, Michael Thomas, "Closed Loop Satisfaction Measurement: New Wine from Old Bottles" (2011). Dissertations and Theses. Paper 221.

https://doi.org/10.15760/etd.221

This Dissertation is brought to you for free and open access. It has been accepted for inclusion in Dissertations and Theses by an authorized administrator of PDXScholar. Please contact us if we can make this document more accessible: pdxscholar@pdx.edu. 


\title{
Closed Loop Satisfaction Measurement:
}

New Wine from Old Bottles

$$
\text { by }
$$

Michael Thomas O’Connell

A dissertation submitted in partial fulfillment of the requirements for the degree of

\author{
Doctor of Philosophy \\ in \\ Systems Science: Business Administration
}
Dissertation Committee:
Beverly Fuller, Chair
Alan Raedels
Richard Sapp
Wayne W. Wakeland
Timothy Anderson

Portland State University

(C) 2011 


\begin{abstract}
A field experiment examines within a financial services firm the impact of a customer satisfaction survey-based intervention that enables front-line employees to identify and contact less-than satisfied customers (less than 9 on a 10-point scale) to proactively prevent potential customer defections. The impact is measured using operational data from 28,000 new customers and their associated defection behavior over a period of eight years. The experiment applies binomial Z-tests of proportions to assess the difference in defection rates of targeted and non-targeted customers before and after the intervention.
\end{abstract}

The research finds that the use of closed loop satisfaction measurement reduces customer defections (by 40\%, $\mathrm{p}>.001$ ). Further, the research finds that the primary reduction is for non-targeted customers rather than for targeted customers, contrary to expectations. The research also provides additional support for the service recovery paradox wherein customers who are less-than satisfied who are satisfactorily resolved have reduced defection rates compared to customers that are satisfied (by $47 \%, \mathrm{p}=.016$ ). 
The primary limitation of the research is its reliance on data from a single company. Another limitation is the potentially confounding impact of the Great Recession on defections during the study period, which could threaten the validity of the analysis. Consequently, additional tests were performed to control for this and other potentially confounding factors. These tests show that the Great Recession and the host company's cost cutting reactions did impact defections and therefore data from these periods were eliminated from the analyses.

The primary theoretical contributions are the use of actual customer defections to measure the impacts and the use of a proactive rather than a reactive intervention. The contribution from a practitioner perspective is the relatively low cost of this intervention for improving customer retention. 


\section{ACKNOWLEDGEMENTS}

This dissertation is the result of a long and difficult journey for which I am grateful for the support of many faculty advisors and business colleagues, but most of all it would not have been possible for me to start this project, let alone complete the work, without the unwavering sacrifices from my beloved wife Katherine who dedicated herself to support me through very challenging times of illness and stress.

I'd like to thank my Committee Chair, Beverly Fuller, who faithfully and steadfastly steered my course to completion and my Systems Science Advisor, Wayne Wakeland, whose eye for academic excellence consistently challenged me to improve. At ABC Company, I want to thank Kerry Sharp and Ellen Steel, two business colleagues who believed in the value of this contribution and provided the opportunity to apply it at our company. Among my team members, I especially want to thank Fan Mo whose technical expertise and dedication produced the database tool that was crucial to the product and Phil Dolan who provided much support with the data analyses. 


\section{TABLE OF CONTENTS}

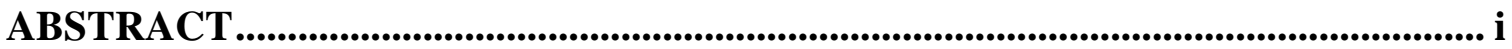

ACKNOWLEDGEMENTS .................................................................................................. iii

LIST OF TABLES

LIST OF FIGURES …........................................................................................... vii

CHAPTER 1: INTRODUCTION.............................................................................................1

CHAPTER 2: LITERATURE REVIEW .............................................................4

2-1: INTRODUCTION

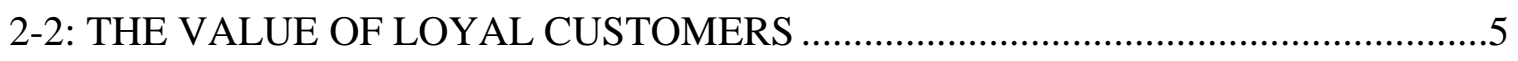

2-3: CUSTOMER SATISFACTION AND CUSTOMER LOYALTY .................................

2-4: EMPLOYEE - CUSTOMER “SATISFACTION MIRROR” …………….................14

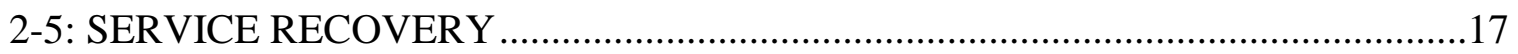

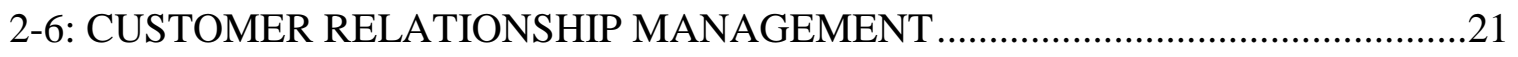

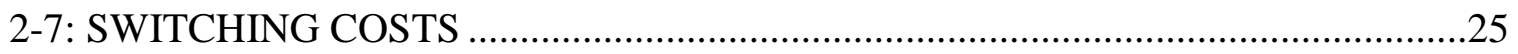

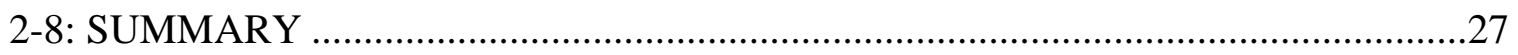

CHAPTER 3: RESEARCH METHODOLOGY ....................................................32

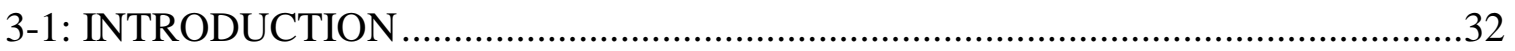

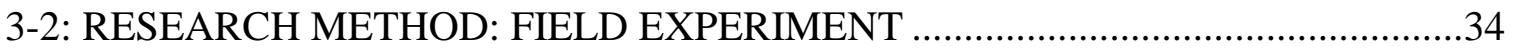

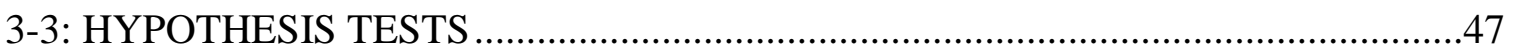

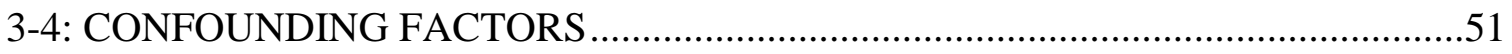

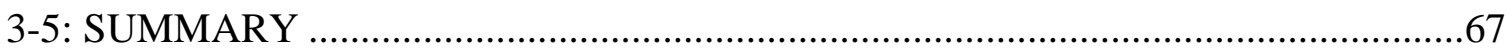

CHAPTER 4: RESEARCH FINDINGS ..................................................................69

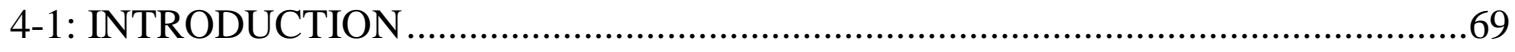

4-2: TEST RESULTS FOR RESEARCH QUESTION 1 ……………………..............69

4-3: TEST RESULTS CONTROLLING FOR CONFOUNDING FACTORS..................77

4-4: TEST RESULTS FOR RESEARCH QUESTION 2 .............................................98

4-5: TEST RESULTS FOR RESEARCH QUESTION 3 ….........................................104

4-6: TEST RESULTS FOR RESEARCH QUESTION 4 ….........................................107

4-6: TEST RESULTS FOR RESEARCH QUESTION 5..............................................111

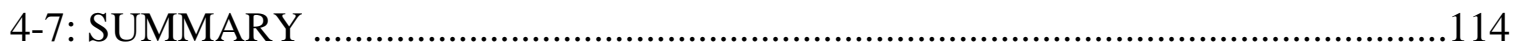


CHAPTER 5: DISCUSSION ...............................................................................................116

5-1: INTRODUCTION

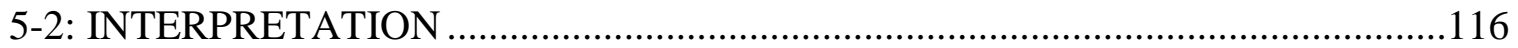

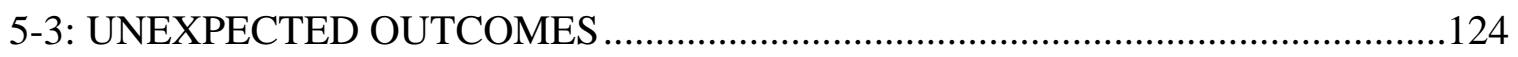

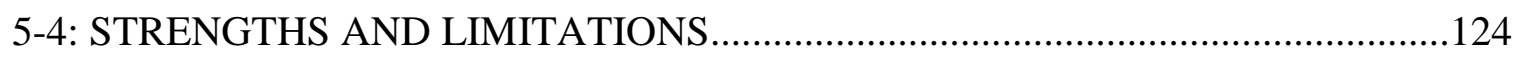

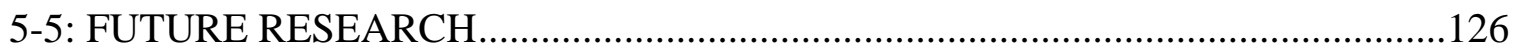

5-6: CONTRIBUTION TO THE LITERATURE ………................................................126

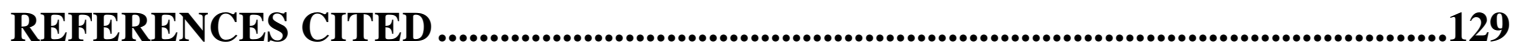




\section{LIST OF TABLES}

Table 2-1: List of Studies Examining the Relationship between Satisfaction, Loyalty, and

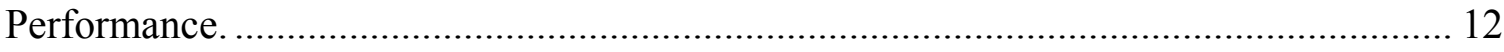

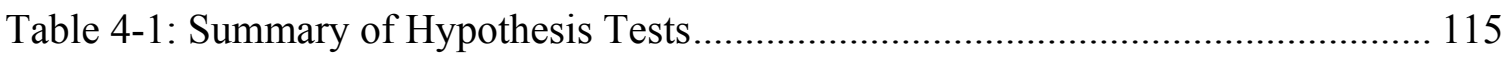

Table 5-1: Summary of Research Findings from the CLSM Intervention .................... 117 


\section{LIST OF FIGURES}

Figure 2-1: Service Profit Chain Source: Heskett, et al. (1997, 2008) ........................... 15

Figure 2-2: Satisfaction - Loyalty in a Competitive Environment, Source: Jones and

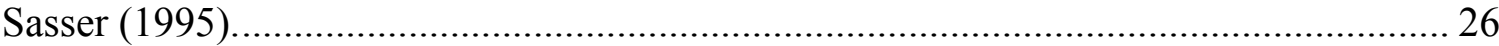

Figure 3-1: Customer Feedback Directs the Control Process of Continuous Process

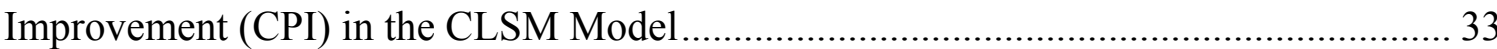

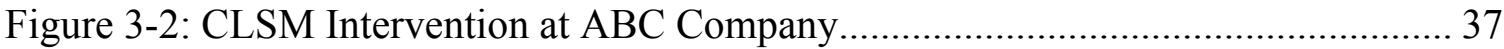

Figure 3-3: Customer Satisfaction Survey at ABC Company ........................................... 39

Figure 3-4: Survey Feedback and Employee Contact Interface at ABC Company .......... 41

Figure 3-5: Survey Responses and Issue Resolution Statuses ........................................... 43

Figure 3-6: ABC Company New Case Timeline and Great Recession Period.................. 54

Figure 3-7: Pre - Post Great Recession, Hola_............................................................. 55

Figure 3-8: Pre - During Great Recession, Holb and Post - During Great Recession,

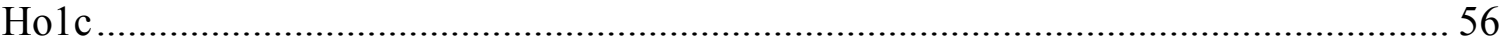

Figure 3-9 Pre and Post Great Recession combined and During Great Recession, Hold 57 Figure 3-10, ABC Company Proportion of 1st-Year Terminations and Cost-cutting

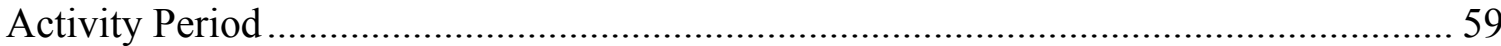

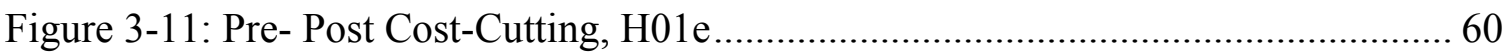

Figure 3-12: Pre and During Cost-Cutting, H01f; Post and During Cost-Cutting, H01g. 61

Figure 3-13: Pre and During Cost-Cutting Aggregated and During Cost-Cutting, H01h 62

Figure 3-14: Formula for One Sample Binomial Proportion Test Statistic ....................... 66

Figure 4-1: Pre-Post Intervention Binomial Single-proportion Significance Test

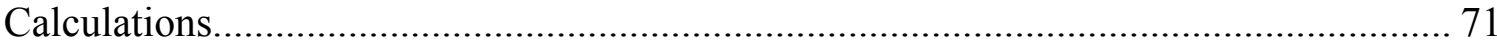

Figure 4-2: Pre-Post Intervention Binomial Two-proportion Significance Test

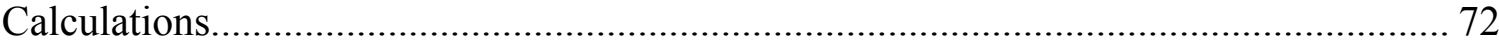

Figure 4-3: Pre-Post Intervention 1st-Year Terminations Confidence Intervals .............. 73

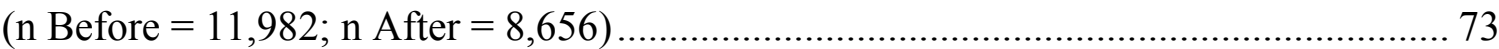

Figure 4-4: Adjusted Pre-Post Intervention Binomial Single-proportion Significance Test

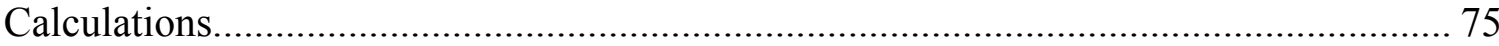

Figure 4-5: Pre-Post Intervention Binomial Two-proportion Significance Test

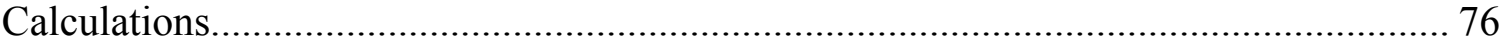

Figure 4-6: Pre-Post Intervention 1st-Year Terminations Confidence Intervals .............. 77

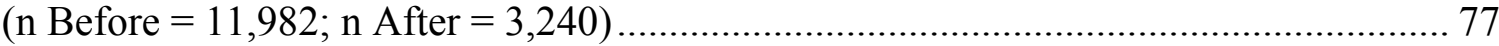

Figure 4-7: Pre-Post Great Recession, H01a Test Periods ............................................... 79 
Figure 4-8: Before and After the Great Recession Binomial Single-proportion Significance Test Calculations.

Figure 4-9: Before and After the Great Recession Binomial Two-proportion Significance

Test Calculations 81

Figure 4-10: Before and After Great Recession 1st-Year Terminations Confidence Intervals. 81

(n Before $=3,240 ;$ n After $=931)$ 81

Figure 4-11: Aggregated Before and After Proportion of 1st-Year Terminations and Great Recession, H01d, Test Periods.

Figure 4-12: During and Outside the Great Recession Binomial Single-proportion

Significance Test Calculations. 83

Figure 4-13: During and Outside the Great Recession Binomial Two-proportion

Significance Test Calculations. 84

Figure 4-14: During-Outside Great Recession 1st-Year Terminations Confidence Intervals. 85

(n During $=4,485 ; \mathrm{n}$ Outside $=4,171$ ) 85

Figure 4-15: Before and After Proportion of 1st-Year Terminations and Cost Cutting, H01d, Test Periods 86

Figure 4-16: Before and After Cost Cutting Binomial Single-proportion Significance Test Calculations.

Figure 4-17: Before and After Cost Cutting Binomial Two-proportion Significance Test Calculations. 88

Figure 4-18: Before-After Cost Cutting 1st-Year Terminations Confidence Intervals .... 88 (n Before $=2,815 ; \mathrm{n}$ After $=2,445$ ) 88

Figure 4-19: Proportion of 1st-Year Terminations Before and During Cost Cutting, H01f, Test Periods 89

Figure 4-20: Before and During Cost Cutting Binomial Single-proportion Significance Test Calculations.

Figure 4-21: Before and During Cost Cutting Binomial Two-proportion Significance Test Calculations.

Figure 4-22: Before-During Cost Cutting 1st-Year Terminations Confidence Intervals . 92 (n During $=3,841$; $\mathrm{n}$ Before $=2,815$ )

Figure 4-23: Proportion of 1st-Year Terminations After and During Cost Cutting, H01g, Test Periods 
Figure 4-24: After and During Cost Cutting Binomial Single-proportion Significance Test Calculations

Figure 4-25: After and During Cost Cutting Binomial Two-proportion Significance Test

Calculations 95

Figure 4-26: During-After Cost Cutting 1st-Year Terminations Confidence Intervals.... 95

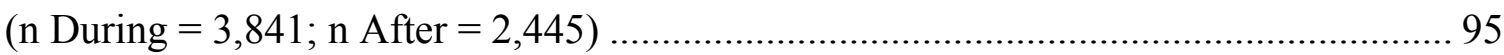

Figure 4-27: Study period with Confounding Factors .............................................. 97

Figure 4-28: Targeted and Non-targeted Before and After CLMS Intervention Binomial

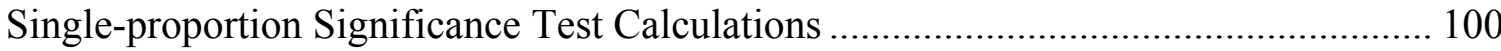

Figure 4-29: Targeted Customers Before and After CLMS Intervention Two-proportion

Significance Test Calculations................................................................................. 101

Figure 4-30: Pre-Post Intervention Confidence Intervals for Targeted Customers ........ 102

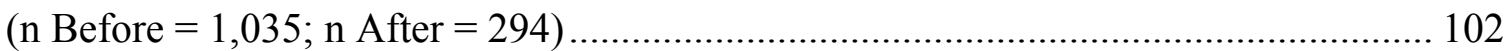

Figure 4-31: Non-targeted Customers Before and After CLMS Intervention Twoproportion Significance Test Calculations .............................................................. 103

Figure 4-32: Pre-Post Intervention Confidence Intervals for Non-Targeted Customers 103

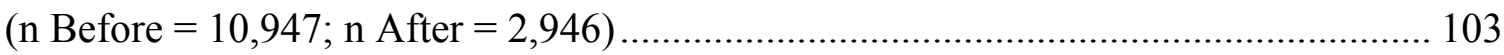

Figure 4-33: Before CLMS Intervention and "Resolved" After Binomial Singleproportion Significance Test Calculations.

Figure 4-34: All Customers Before and "Resolved" Customers After CLMS Intervention Two-proportion Significance Test Calculations

Figure 4-35: Pre-Intervention and Post-Intervention "Resolution" Customers Confidence

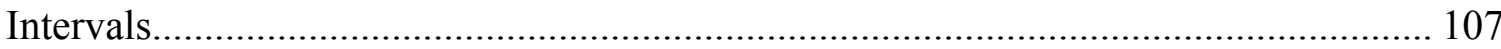

(n Before $=11,982 ; \mathrm{n}$ After $=205)$.

Figure 4-36: Before CLMS Intervention and "Not Resolved" Binomial Single-proportion

Significance Test Calculations

Figure 4-37: All Customers Before and "Not Resolved" Customers After CLMS

Intervention Two-proportion Significance Test Calculations.

Figure 4-38: Pre-Intervention and Post-Intervention Non-resolution Customers

Confidence Intervals

$(\mathrm{n}$ Before $=11,982 ; \mathrm{n}$ After $=96)$

Figure 4-39: "Satisfied" and "Resolved" Binomial Single-proportion Significance Test

Calculations. 
Figure 4-40: "Satisfied" and "Not Resolved" Customers After CLMS Intervention Twoproportion Significance Test Calculations............................................................ 113

Figure 4-41: Post-Intervention "Satisfied" and "Resolution" Customers Confidence

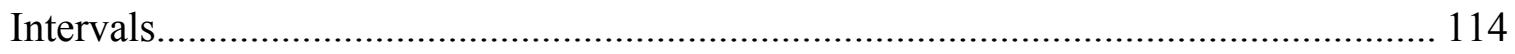

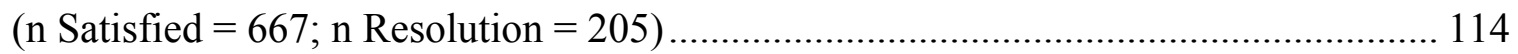

Figure 5-1: Counts of 1st-Year Termination by the Number of Months from a Contract's

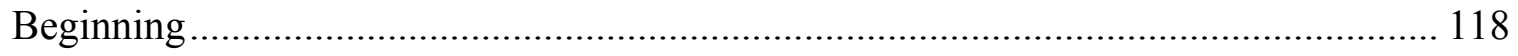




\section{CHAPTER 1: INTRODUCTION}

Since the 1980s American businesses have been collecting customer satisfaction surveys to understand customer expectations about a firm's products and services, inform continuous improvement, and measure performance. Because technology and the internet provide today's consumers with many options, competitiveness is increasing in the global marketplace. In response, businesses rely more and more on practices focused on retaining customers in order to reduce competitive pressure. Service Recovery and Customer Relationship Management are strategies to manage customer loyalty that emerged in the 1990s. Service Recovery identifies problems in service encounters and addresses customers' concerns in order to recover their loyalty after service failures. Customer Relationship Management promotes one-to-one relationships with customers through the use of technology and mass-customization.

In 2000, researchers recommended to extend the use of customer satisfaction surveys as a means to influence customers. This dissertation uses closed loop satisfaction measurement (CLSM) to answers their call. The CLSM system uses a customer satisfaction survey database to: (1) identify customers that are not completely satisfied, (2) empower employees to proactively affect customers' attitudes, (3) determine the cause of any dissatisfaction, and (4) provide a mechanism to avert potential customer defections. CLSM provides new functionality to survey practices that have continued for a long time. In this respect, CLSM is like new wine from old bottles. 
This research method is a field experiment at a financial services firm. The experiment analyzes the change in customer defections before and after a CLMS intervention. Results are measured by the proportion of first-year terminations of new contracts. The significance of the change in this metric is tested with binomial proportion z-tests.

The research contributes to the literature by providing empirical evidence of the value of using customer satisfaction survey feedback to reduce defections and responding to the call of other researchers to use survey feedback to influence customers. This approach is unique in that it is proactive instead of adaptive as is the common method of Service Recovery and it is far less expensive to implement than Customer Relationship Management because survey data is already available at most large firms. A strength of the research is that the effectiveness of the intervention is measured with actual customer defections rather than surveys of customer intent, which is the common approach.

Chapter 2 reviews the literature describing the value of loyalty, discusses the association between customer satisfaction and loyalty, and presents the loyalty strategies of Service Recovery and Customer Relationship Management. Chapter 3 defines the research methodology including the field experiment, the hypothesis tests, and the analyses of confounding factors. Chapter 4 presents results of the analyses, and Chapter 5 discusses 
and interprets the findings, summarizes the strengths and weaknesses of this research, and recommends opportunities for future work. 


\section{CHAPTER 2: LITERATURE REVIEW}

\section{2-1: Introduction}

The literature establishes customer loyalty as a valuable contribution to firm profitability, examines how retaining loyal customers creates additional value, and presents different methods for measuring the value of loyalty and targeting profitable, loyal, customers. Multiple empirical studies are available that analyze customer satisfaction's relationship as an antecedent of customer loyalty. In practice, customer satisfaction surveys are used to measure performance or inform continuous improvement. Some researchers argue that this practice limits the use of satisfaction surveys. McColl-Kennedy and Schneider (2000) point out that the customer survey transaction itself influences customers and recommend that survey process be used to consciously steer customers toward fulfilling a firm's strategy. However, this call has gone largely unheeded in the literature and subsequent research has failed to examine this purposeful use of customer satisfaction surveys to close the loop on customer feedback.

The literature review is presented as follows:

- Section 2-2 The Value of Loyal Customers

- Section 2-3 Customer Satisfaction and Customer Loyalty

- Section 2-4 Employee - Customer "Satisfaction Mirror"

- Section 2-5 Service Recovery

- Section 2-6 Customer Relationship Management

- Section 2-7 Switching Costs

- Section 2-8 Summary 


\section{2-2: The Value of Loyal Customers}

Customer loyalty has long been a goal pursued by businesses. The concept is straightforward and easy to understand. Loyal customers have higher retention rates; the longer they stay with the firm the more they are likely to buy. Furthermore, it is also far less costly to retain a loyal customer than it is to acquire a new one. The cost ratio of acquisition costs to the costs of retaining a customer is estimated to be 5:1 (Hart, et al. 1990) but firms continue to fail to retain customers. U.S. corporations on average lose half their customers in just five years (Reichheld, 1996).

Researchers use different indicators to predict loyalty including repurchase intention and recommend intention. Repurchase intention is a means to predict future purchasing behavior. Researchers find correlations between repurchase intentions and repurchase behavior (Morwitz, et al. 2005). However, repurchase intentions are influenced by "selfgenerated validity" that "inflate the association between intentions and behavior" (Chandon, et al. 2005, page 1) and are less reliable than empirical evidence from actual customer retention behavior.

Recommend intention and advocacy are also used as indicators of loyalty (Jones and Sasser, 1995). Reichheld (2003) contends that recommend intention is the one, best indicator of loyalty because a customer's recommendation incurs the risk of sacrificing one's reputation. He recommends a single metric as a leading indicator of customer 
loyalty- the Net Promoter Score. However, in subsequent critical analyses, different researchers rebut the validity of intent-to-recommend as the best indicator. Keiningham, et al. (2008) attempted to replicate Reichheld's statistical research in two different studies without success. They also extended their analyses to a subset of Reichheld's own data. In no case could Keiningham's research replicate Reichheld's results.

Furthermore, there is very little empirical research demonstrating that recommend intention actually leads to recommend behavior. "Recommendation intention (net promoters) and behavior (average number of recommendations) have little or no predictive value" of future business performance (Morgan and Rego, 2006, page 426). In separate studies, Sharp (2008) reports a "better correlation between satisfaction and retention" than between intent to recommend and customer retention. Pingitore, et al. (2007, page 10) find that "net metrics of any kind are usually not the strongest ... predictors of future business performance, and ... are so imprecise that they require huge sample sizes in comparison with ... measures of satisfaction."

Morgan and Rego (2006) compare the most commonly used customer feedback metrics to determine which are most valuable in predicting future business performance and argue that the most robust and empirically reliable measure of loyalty is customers' continued relationship with the firm. Keiningham, et al. (2007, page 364) define customer loyalty as a measure of customer retention behavior and state that, "For retail 
banks, it is continuing to maintain an account relationship with the bank. And for discount retailers, it is the continued repeat shopping with the retailer".

Customer loyalty adds value to a firm. The value of loyalty is not only derived from continued customer purchases, but as customers remain loyal to a firm, other factors contribute to the growth in profits. Reichheld and Sasser (1990) quantify the value of customer loyalty as the stream of customer profits from continued purchases over their life time and identify four additional ways that loyal customers add profit to a firm beyond base profitability (purchases - costs): increased annual buying rates, decreased operating expenses, referrals, and price premiums. In a subsequent work, Reichheld finds that "a 5-percentage point increase in customer retention increases the value of a customer by 75 percent" (Reichheld, 1996, page 56).

The literature identifies two principal methods for measuring the value of loyalty: Customer Account Profitability and Customer Lifetime Value. The Customer Account Profitability (Connolly and Asworth, 1994) method is based on verifiable, historical data. Profitability is measured with activity based costing (ABC) which relies on the analysis of resource and activity driver costs (Harrington, 1991; Miller, 1996; Kaplan and Cooper 1998). Such costs represent the consumption of resources by the activities required of the services expected by the customer. "The application of Activity Based Costing has provided insights into the relative profitability of customers by tracing costs and assets 
employed down to the individual products and services" (Kaplan and Norton, 1996, p55).

Stratton, et al. (2009) surveyed over 300 manufacturing and service companies worldwide and found that $\mathrm{ABC}$ continues to provide significant value from strategic and operational perspectives.

Another method used to measure the value of loyalty is "Customer Lifetime Value" (CLV) (Carpenter, 1995). CLV estimates the net present value of the customer by calculating the initial outlay to attract the customer and adding the annual revenues over the customers' lifetime. Ambler (2002) criticizes this method because it relies on forecasting future customer purchases and estimating the duration of customers' lifetimes. Never-the-less, Kumar and Rajan (2009) recommend using this method for segmenting and targeting customers.

Although customer loyalty is desirable, not all customers are sensible to retain; firms should seek to identify those that are. Reichheld (2006) proposes using surveys to segment a firm's customer base into three kinds of customers: promoters, passives, and detractors. A firm should seek to cultivate long-term relationships with promoters, discard detractors, and seek to convert passives into promoters. Aside from the problems associated with recommend intention as a viable measure of loyalty (discussed above), surveys seldom return $100 \%$ response rates rendering incomplete results and thus are unreliable for identifying all preferred customers. 
Porter $(1985,2008)$ recommends targeting and cultivating relationships with customers that depend on uniquely competitive activities that produce profits. He states that "the essence of strategy is in the activities - choosing to perform activities differently or to perform different activities" (Porter, 2008, page 41). Firms create competitive advantage by retaining loyal customers that rely on these activities.

This section establishes the value of loyalty and presents research describing how retaining loyal customers contributes value to a firm (Reichheld and Sasser, 1990, Carpenter, 1995) and profits from loyal customers increase over time (Reichheld, 1996). Actual customer defections are a reliable means of measuring loyalty (Morgan and Rego, 2006; Keiningham, et al. 2007). Reducing customer defections has a significant impact on profitability (Reichheld and Sasser, 1990; Jones and Sasser, 1995). Targeting and retaining specific customers creates competitive advantage (Porter, 1985, 2010). The next section discusses the association of loyalty with customer satisfaction.

\section{2-3: Customer Satisfaction and Customer Loyalty}

There has been a great deal of research about measures that predict customer loyalty behavior. Chief among the antecedents of loyalty is customer satisfaction which is typically measured with surveys. Managers frequently rely on customer surveys that 
include questions indicating customers' satisfaction, repurchase intentions, and

recommend intentions for measuring customer loyalty (Morgan and Rego, 2006).

The literature provides several examples of empirical studies that establish customer satisfaction as an antecedent to customer loyalty and its positive association with firm performance. Figure 2-1 is a synopsis of empirical research into the relationship of customer satisfaction, loyalty, and profitability.

\begin{tabular}{|c|c|c|c|}
\hline Subject / Title & Source & Research Approach & Findings \\
\hline $\begin{array}{l}\text { The antecedents and } \\
\text { consequences of customer } \\
\text { satisfaction for firms }\end{array}$ & $\begin{array}{l}\text { Anderson, Eugene, } \\
\text { Sullivan Mary, Marketing } \\
\text { Science, Vol } 12 \text { No } 2 \\
\text { Spring } 1993\end{array}$ & $\begin{array}{l}\text { Analysis of } 22,300 \\
\text { customers of } 114 \\
\text { companies in } 16 \text { major } \\
\text { product and service firms } \\
\text { in Sweden }\end{array}$ & $\begin{array}{l}\text { Findings show that high- } \\
\text { quality products produce } \\
\text { more satisfied customers } \\
\text { and customers likely to be } \\
\text { retained. }\end{array}$ \\
\hline $\begin{array}{l}\text { The relationships of } \\
\text { customer satisfaction, } \\
\text { customer loyalty, and } \\
\text { profitability: an empirical } \\
\text { study. }\end{array}$ & $\begin{array}{l}\text { Hallowell, Roger. } \\
\text { International Journal of } \\
\text { Service Industry } \\
\text { Management, 1996, Vol. } 7 \\
\text { Issue 4, }\end{array}$ & $\begin{array}{l}\text { OLS Regression of data } \\
\text { from one retail bank }\end{array}$ & $\begin{array}{l}\text { Findings support the theory } \\
\text { that customer satisfaction is } \\
\text { related to customer loyalty, } \\
\text { which in turn is related to } \\
\text { profitability. }\end{array}$ \\
\hline $\begin{array}{l}\text { Strengthening the } \\
\text { satisfaction-profit chain }\end{array}$ & $\begin{array}{l}\text { Anderson, Eugene and } \\
\text { Mittal, Vikas, Journal of } \\
\text { Service Research, } \\
\text { November } 2000\end{array}$ & $\begin{array}{l}\text { Correlation of data from } \\
\text { Swedish Customer } \\
\text { Satisfaction Barometer }\end{array}$ & $\begin{array}{l}\text { Findings conclude that, on } \\
\text { average, a } 1 \% \text { increase in } \\
\text { customer satisfaction is } \\
\text { associated with a } 2.37 \% \\
\text { increase in ROI whereas a } \\
1 \% \text { decrease in satisfaction } \\
\text { is associated with a } 5.08 \% \\
\text { drop in ROI }\end{array}$ \\
\hline $\begin{array}{l}\text { An empirical investigation } \\
\text { of an incentive plan that } \\
\text { includes non-financial } \\
\text { performance measures }\end{array}$ & $\begin{array}{l}\text { Banker, R. A., G Potter, } \\
\text { and D. Srinivasan, The } \\
\text { Accounting Review } 75 \text { (1): } \\
2000 \text { p 65-92. }\end{array}$ & $\begin{array}{l}\text { Longitudinal study over six } \\
\text { years }\end{array}$ & $\begin{array}{l}\text { Findings determine that } \\
\text { non-financial measures of } \\
\text { customer satisfaction are } \\
\text { significantly associated } \\
\text { with future financial } \\
\text { performance and contain } \\
\text { additional information not } \\
\text { reflected in the past } \\
\text { financial measures }\end{array}$ \\
\hline Theory, development and & Bruhn, Manfred, Grund, & Twenty industries within & Findings conclude that \\
\hline
\end{tabular}




\begin{tabular}{|c|c|c|c|}
\hline $\begin{array}{l}\text { implementation of national } \\
\text { customer satisfaction } \\
\text { indices: The Swiss Index of } \\
\text { Customer Satisfaction } \\
\text { (SWICS) }\end{array}$ & $\begin{array}{l}\text { Michael A., Total Quality } \\
\text { Management, September, } \\
2000\end{array}$ & $\begin{array}{l}\text { six business sectors, } 7,436 \\
\text { telephone interviews with } \\
3,845 \text { respondents in } \\
\text { German- speaking part of } \\
\text { Switzerland for average of } \\
\text { seventeen minutes with } \\
\text { each respondent; each } \\
\text { industry had roughly } 300 \text { - } \\
500 \text { respondents }\end{array}$ & $\begin{array}{l}\text { customer satisfaction is } \\
\text { crucial for customer } \\
\text { loyalty. They distinguish } \\
\text { between customer } \\
\text { satisfaction and customer } \\
\text { dialogue. The more } \\
\text { comparable products and } \\
\text { services are the more } \\
\text { important is customer } \\
\text { dialogue for customer } \\
\text { loyalty. }\end{array}$ \\
\hline $\begin{array}{l}\text { Personal Characteristics as } \\
\text { Moderators of the } \\
\text { Relationship Between } \\
\text { Customer Satisfaction and } \\
\text { Loyalty }\end{array}$ & $\begin{array}{l}\text { Homburg, Christian; } \\
\text { Annette Giering, } \\
\text { Psychology \& Marketing, } \\
\text { Jan2001, Vol. } 18 \text { Issue 1, } \\
\text { p43-66, 24p, }\end{array}$ & $\begin{array}{l}\text { Multiple - group causal } \\
\text { analysis in a consumer- } \\
\text { durables context. }\end{array}$ & $\begin{array}{l}\text { Findings show that the } \\
\text { strength of the relationship } \\
\text { between customer } \\
\text { satisfaction and loyalty is } \\
\text { strongly influenced by } \\
\text { characteristics of the } \\
\text { customer. }\end{array}$ \\
\hline $\begin{array}{l}\text { An empirical investigation } \\
\text { of customer satisfaction } \\
\text { and loyalty across two } \\
\text { divergent bank segments }\end{array}$ & $\begin{array}{l}\text { Pont, Marcin; McQuilken, } \\
\text { Lisa. Journal of Financial } \\
\text { Services Marketing, } \\
\text { Jun2005, Vol. } 9 \text { Issue 4, } \\
\text { p344-359 }\end{array}$ & $\begin{array}{l}\text { ANOVA, Pearson } \\
\text { Correlation Coefficient }\end{array}$ & $\begin{array}{l}\text { Findings determine that } \\
\text { there is no difference of the } \\
\text { effect of customer } \\
\text { satisfaction on behavior } \\
\text { between the two groups, } \\
\text { but did find a difference } \\
\text { with respect to loyalty and } \\
\text { switching costs. }\end{array}$ \\
\hline $\begin{array}{l}\text { An Empirical Examination } \\
\text { of the Influence of } \\
\text { Leadership Empowerment } \\
\text { Behavior on Customer } \\
\text { Satisfaction and } \\
\text { Performance }\end{array}$ & $\begin{array}{l}\text { Ahearne, Michael; } \\
\text { Mathieu, John; Rapp, } \\
\text { Adam. Journal of Applied } \\
\text { Psychology, Sep2005, Vol. } \\
90 \text { Issue } 5\end{array}$ & $\begin{array}{l}\text { ANOVA, Correlation, Chi } \\
\text { Square }\end{array}$ & $\begin{array}{l}\text { Findings indicate that } \\
\text { greater customer } \\
\text { satisfaction and sales } \\
\text { performance are associated } \\
\text { with leadership } \\
\text { empowerment behavior. }\end{array}$ \\
\hline $\begin{array}{l}\text { Customer satisfaction and } \\
\text { loyalty in a digital } \\
\text { environment: an empirical } \\
\text { test }\end{array}$ & $\begin{array}{l}\text { Donio, Jean; Massari, } \\
\text { Paola; Passiante, } \\
\text { Giuseppina. Journal of } \\
\text { Consumer Marketing, } \\
\text { 2006, Vol. } 23 \text { Issue } 7\end{array}$ & $\begin{array}{l}\text { Factor analysis, cluster } \\
\text { analysis, ANOVA, } \\
\text { canonical correlation } \\
\text { analysis, multiple } \\
\text { regression, path analysis, } \\
\text { and t-tests }\end{array}$ & $\begin{array}{l}\text { Findings conclude that } \\
\text { customer loyalty attitude is } \\
\text { positively and significantly } \\
\text { related to customer } \\
\text { profitability and customer } \\
\text { satisfaction is positively } \\
\text { and significantly related to } \\
\text { customer loyalty attitude. }\end{array}$ \\
\hline $\begin{array}{l}\text { An Empirical Investigation } \\
\text { on the Economic } \\
\text { Consequences of Customer } \\
\text { Satisfaction }\end{array}$ & $\begin{array}{l}\text { Sui-Hua Yu. Total Quality } \\
\text { Management \& Business } \\
\text { Excellence, Jul2007, Vol. } \\
18 \text { Issue 5, p555-569, 15p }\end{array}$ & $\begin{array}{l}\text { ANOVA, Pearson } \\
\text { Correlation Coefficient }\end{array}$ & $\begin{array}{l}\text { Findings indicate that } \\
\text { several dimensions of } \\
\text { customer satisfaction are } \\
\text { positively associated with } \\
\text { individual customers' } \\
\text { repurchase intentions. }\end{array}$ \\
\hline $\begin{array}{l}\text { Understanding customer } \\
\text { satisfaction and loyalty: An } \\
\text { empirical study of mobile } \\
\text { instant messages in China }\end{array}$ & $\begin{array}{l}\text { Deng, Zhaohua; Lu, } \\
\text { Yaobin; Wei, Kwok Kee; } \\
\text { Zhang, Jinlong. } \\
\text { International Journal of } \\
\text { Information Management, } \\
\text { Aug2010, Vol. } 30 \text { Issue 4, } \\
\text { p289-300 }\end{array}$ & $\begin{array}{l}\text { Factor analysis, ANOVA, } \\
\text { correlation analysis, } \\
\text { multiple regression }\end{array}$ & $\begin{array}{l}\text { Findings show that trust, } \\
\text { customer satisfaction and } \\
\text { switching cost directly } \\
\text { enhance customer loyalty. }\end{array}$ \\
\hline
\end{tabular}




\begin{tabular}{|l|l|l|l|}
$\begin{array}{l}\text { Customer value } \\
\text { anticipation, customer } \\
\text { satisfaction and loyalty: An } \\
\text { empirical examination }\end{array}$ & $\begin{array}{l}\text { Flint, Daniel J.; Blocker, } \\
\text { Christopher P.; Boutin, } \\
\text { Philip J. Industrial } \\
\text { Marketing Management, } \\
\text { Feb2011, Vol. 40 Issue 2, } \\
\text { p219-230, }\end{array}$ & $\begin{array}{l}\text { Structural equation } \\
\text { modeling }\end{array}$ & $\begin{array}{l}\text { Customer value } \\
\text { anticipation is a strong } \\
\text { driver of satisfaction and } \\
\text { loyalty, with satisfaction } \\
\text { acting as a mediator for } \\
\text { loyalty. }\end{array}$ \\
\end{tabular}

Table 2-1: List of Studies Examining the Relationship between Satisfaction, Loyalty, and Performance.

Companies that produce high quality products create greater customer satisfaction, loyalty, and retention (Anderson and Sullivan, 1993; Bruhn and Grund, 2000; Yu, 2007; Flint, et al. 2011). Customer satisfaction is affected by the customer relationship and employee empowerment (Homburg and Giering, 2001; Aheame, et al. 2005). Customer loyalty is positively associated with high switching costs (Pont and McQuilken, 2005; Deng, et al. 2010). Customer satisfaction is also associated with positive firm performance (Hallowell, 1996; Anderson and Mittal, 2000; Banker, et al. 2000; Donio, et al. 2006). These studies provide substantial empirical evidence that customer satisfaction is positively associated with service quality, customer loyalty, and firm performance. The trend in all of these examples of empirical research is to establish associations among antecedents. This synopsis of studies indicates that research is based on a linear model:

Service Quality $\rightarrow$ Customer Satisfaction $\rightarrow$ Customer Loyalty $\rightarrow$ Firm Performance

The predominant use of customer satisfaction surveys is for performance measurement (Naumann and Giel, 1995: Vavra, 1997; Chakrapani, 1998; Kessler, 1996). In business practice, the most commonly used metric for performance from the customers' 
perspective $^{1}$ is customer satisfaction (Gupta and Zeithaml, 2007; Keiningham, 2007).

Zeithaml, et al. 2006 (p. 170) observe that this is "because it is generic and can be universally gauged for all products and services.

The second most common use of customer satisfaction surveys is for total quality management (TQM). TQM practitioners, who are solidly committed to a customer focus, assert that the principal use of customer satisfaction surveys is to "provide the focus on business improvement activities” (Yang, 2003, page 920). Both performance measurement and improvement activities are introspective uses of customer satisfaction surveys. This is a myopic and narrow use of customer satisfaction feedback.

The literature overlooks the use of customer satisfaction surveys as a purposeful means for influencing the customer. This oversight has resulted in a call to use customer satisfaction surveys proactively and not just for performance measurement or merely as a quality tool. As McColl-Kennedy and Schneider recommend:

The procedure of customer satisfaction measurement is no neutral act. It should not merely be a measure of past performance as is commonly practiced, but a means to create the future and influence customers according to vision and strategy (McColl-Kennedy and Schneider. 2000, p. 894).

\footnotetext{
${ }^{1}$ The Balanced Scorecard (Norton and Kaplan, 1996) presents financial and non-financial metrics in four perspectives: financial, customer, internal processes, and learning and growth.
} 
Customer satisfaction surveys provide opportunities to affect customer attitudes and shape their image of the firm. Research is lacking regarding the effect of using customer satisfaction surveys to contact customers and influence retention behavior. This paucity presents an important gap in the literature.

\section{2-4: Employee - Customer "Satisfaction Mirror"}

The system dynamics that produce growth in customer satisfaction, loyalty, and profits are recursive and circular as described by the Service Profit Chain (SPC) (Heskett, et al. 1997, 2008). The SPC is based upon empirical and anecdotal evidence that explains how highly satisfied customers drive growth and profitability (Reichheld and Sasser, 1990; Barber, et al. 1999; Hallowell, 1996; Anderson and Mittal, 2000; Banker, et al. 2000), enhance internal service quality (Roth, 1993; Huselid, 1995, Swanson, 1998), raise employee satisfaction (Schlesinger and Zornitsky, 1991; Gostick, 2000; Pfau and Kay, 2002), fuel employee loyalty and productivity (Cohen, et al. 1997; Davis and Landa, 2000), boost external service value (Hallowell, et al. 1996; Maister, 2000), and thereby increase customer satisfaction and loyalty (Jones and Sasser, 1995; Wisner and Feist, 2001). Figure 2-2 illustrates SPC as a causal loop diagram. 


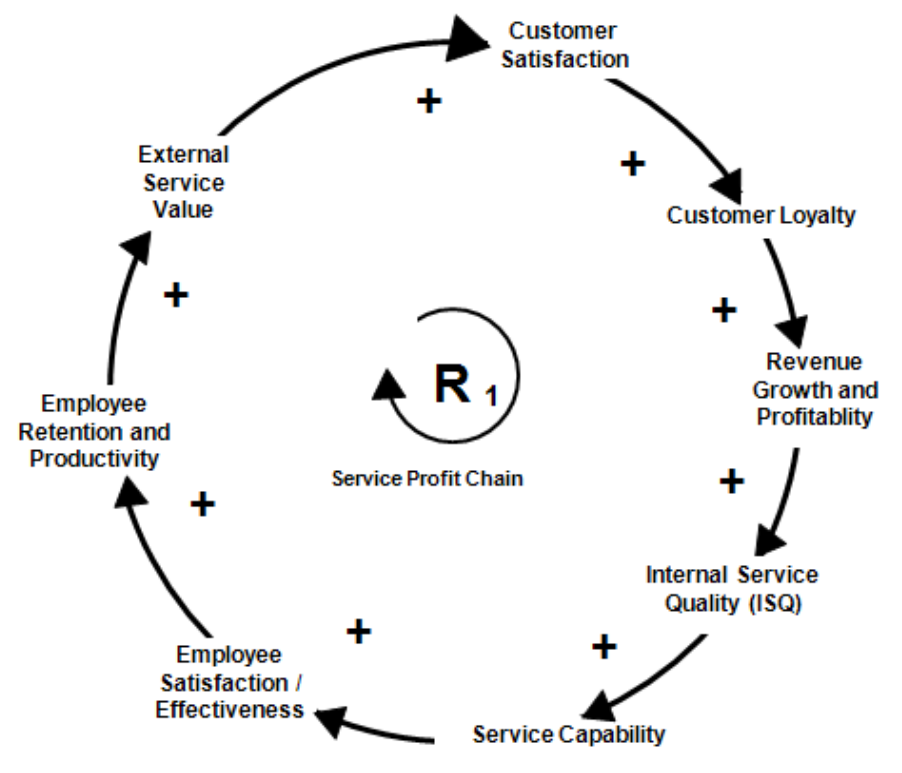

Figure 2-1: Service Profit Chain Source: Heskett, et al. $(1997,2008)^{2}$

The SPC forms a continuous loop of inter-dependent causalities. It is a closed system and, as such, it is recognizable from system dynamics theory as a reinforcing feedback loop. It is well known that reinforcing causal loop structures create exponential growth (Forrester, 1968; Richmond, 1993, 2004; Sterman, 2000). Each component within the structure influences successive elements in the same, reinforcing manner repeatedly over time. In a reinforcing structure, actions are amplified.

\footnotetext{
${ }^{2}$ The notation in this causal loop diagram follows Sterman's conventions (Sterman, 2000). The " $\mathrm{R}$ " in the center indicates that this feedback loop generates reinforcing (exponential) dynamic behavior. The "+" sign indicates that, all else being equal, when the preceding component increases (decreases) then the successive component increases (decreases) above (below) what it otherwise would have been.
} 
Within the SPC system, Heskett, et al. (1997, page 99) propose that external customer satisfaction is affected by interactions between satisfied employees and customers with a construct termed "the employee / customer satisfaction mirror." Employees' realization that they are empowered and successful in meeting their customers' needs increases their level of satisfaction (Swanson, 1998; Schlesinger and Zornitsky, 1991; Gostick, 2000). To the extent that employees perceive that they can successfully meet customer expectations (or surpass them) produces the most consistent measure of their customers' own satisfaction (Schneider and Bowen, 1985, 1999; Koys, 2001). Hallowell, et al. (1996) also finds that internal service quality and capability links to customer satisfaction. As employees' sense of capability, increases so does the appreciation of the jobs and tenure with the firm (Schlesinger and Zornitsky, 1991). Loyalty engenders additional efficiencies and, in turn, promotes customer satisfaction and loyalty (Schlesinger and Heskett, 1991). Yee, et al. (2009, page 624) investigate the relationships of the SPC constructs including the employee / customer satisfaction mirror, and find that contact between employees and customers have a "moderating effect on the link between employee loyalty and customer perception of service quality."

These sections discussed customer satisfaction; how researchers have examined it as an antecedent to customer loyalty, how practitioners have used it for performance measurement and business improvement, and how some researchers have called for its further use to influence customers. Customer satisfaction is also associated with employee satisfaction via the employee - customer "Satisfaction Mirror." In the next 
section, the proactive use of survey feedback is contrasted and compared with two other common management practices to increase customer loyalty, Service Recovery and Customer Relationship Management. This is followed by a discussion of the non-linear impact of switching costs on customer loyalty and its implication for setting the bar for a CLSM intervention.

\section{2-5: Service Recovery}

Customers are satisfied when their expectations are met. Expectations, in turn, are determined by advertising, prior experience, personal needs, word of mouth (Parasuraman, et al. 1985), the image of the service provider (Gronroos, 1984) and other factors. Disconfirmation of service expectations caused by service failures leads to customer dissatisfaction (Parasuraman, et al, 1985), customer defection (Reichheld, 1996), and negative word of mouth about the firm's products and services (Richins, 1983).

Service recovery is the artful practice of turning a common business mistake into an opportunity to win a customer for the long-term (Hart, et al. 1990). "Service recovery involves those actions designed to resolve problems, alter negative attitudes of dissatisfied consumers and to ultimately retain these customers" (Miller, et al. 2000, page 387). In essence, service recovery encompasses all actions taken by a service provider in 
order to try to resolve the problem a customer has with their organization (Gronroos, 1990). ${ }^{3}$

Two seminal studies explore the relationship between service failure and loyalty. First, a study conducted by Clark, et al. 1992, illustrates that, of the customers who received poor service in various industries and whose complaints were not responded to by the company, $52 \%$ intended to switch to a substitute service. Another study, conducted by the US Office of Consumer Affairs (1986) indicates that only 19\% of customers would remain loyal to their suppliers if they were not happy with the service failure resolution.

The literature identifies two principal elements required for service recovery: a service failure (perceived or not perceived by the customer) and a recovery attempt. Service recovery occurs after a "service failure and usually a complaint" (Johnston and Mehra, 2002, page 145). Recovery success or failure is usually measured by surveys of customer intent or direct observation at the service transaction (Michel, 2001; Johnston and Mehra, 2002, page 151).

McCollough and Bharadwaj (1992, page 119) identify what they termed the "service recovery paradox." It is defined as "a situation in which a consumer has experienced a

\footnotetext{
${ }^{3}$ In contrast, CLSM goes beyond the problem resolution approach of service recovery and reaches out to survey respondents with relatively high satisfaction scores ( $<=8$ on a 10-point scale).
} 
problem which has been satisfactory resolved, and where the consumer subsequently rates their satisfaction to be equal to or greater than that in which no problem had occurred." Conversely, customers who experience additional failures as a firm attempts to recover from a service mishap, tend to rate their satisfaction worse than had no recovery been attempted. The service recovery paradox on customer satisfaction is found in several studies (Maxham and Netemeyer, 2002; Smith and Bolton, 1998).

Service recovery differs from complaint management in its focus on service failures and the company's immediate reaction to it. Complaint management is a sub-set of service recovery and is based on customer complaints which may be triggered by service failures. However, since most dissatisfied customers are reluctant to complain (Andreasen and Best, 1977; Singh, 1990), service recovery attempts try to solve problems at the service encounter, before customers complain or before they leave the service encounter dissatisfied, Both complaint management and service recovery are considered customer retention strategies (Halstaed, et al. 1996).

Most empirical research into service recovery either: 1) collects accounts of actual critical incidents from respondents (Chung and Hoffman, 1998; Edvardsson, et al. 2000;), 2) describes hypothetical scenarios to respondents (Kelley and Davis, 1994; Smith, et al. 1998) or 3) uses written complaints (Tax, et al. 1998). Research into service recovery is 
reactive, following a service failure (identified by a customer complaint or an employee observation) or hypothetical.

Davidow (2003) provides a comprehensive examination of 53 different research studies between 1982 and 2001 linking organizational response dimensions of redress (the actions a firm takes to mollify a customer complaint) to post-complaint behavior. Of these, 24 use surveys that measure customer intent, 8 use the critical incident technique (CIT) of directly observing customer behavior at the service encounter, 19 conduct experiments and one uses a mathematical model. The types of experiments reported in the literature include:

- Measuring the effect of redress action on customer satisfaction (Blodgett and Tax, 1993),

- Determining the effect of redress with compensation on intent to remain with the service provider (Boshoff, 1997; Smith, Bolton, and Watner, 1999; Goodwin and Ross, 1992), and

- Analyzing the effect of redress with free services on intent to repurchase (Brown, et al. 1996).

Customer retention is studied as a redress outcome by only two research teams in Davidow (2003). They are: Kelley, Hoffman, and Davis (1993) and Hoffman and Chung (1999) who examine retention as an outcome from a compensatory redress. Both studies 
collect reports from subjects about continued patronage after a service failure and both observe customer behavior at the critical incident.

None of the research, described by Davidow, uses customer satisfaction results to prompt a proactive recovery attempt, nor do they measure the result empirically with actual customer defections. These studies measure the effect of redress after a service failure. Only two experiments consider customer retention as an outcome, both measure it with surveys of customer intent (Kelley, et al. 1993; Hoffman and Chung, 1999).

The service recovery literature is dominated by studies of firm's reacting to and resolving customer complaints. There are few examinations of proactive activities based upon customer satisfaction survey scores measured with empirical evidence of subsequent customer defections. This presents a significant gap in the literature.

\section{2-6: Customer Relationship Management}

Another strategy for managing customer retention and loyalty is Customer Relationship Management (CRM). According to Stone, et al. (1996) CRM is the use of a wide range of marketing, sales, communication, service and customer care technologies that identify customers, create long-term relationships, and manage the relationships to the mutual benefit of customer and firm. The intent is to increase customer retention, loyalty and profitability. Battista and Verhun (2000, page 34) state that "retaining customers ranks as the number-one objective of CRM efforts." CRM represents a break with past marketing strategies that focus on product. CRM focuses on the customer - firm relationship and is 
made possible by the leveraging of three technologies: database, interactivity, and mass customization (Harvard Management Update, 2000).

In contrast to CLSM where survey data is already available at most large firms, CRM is an expensive undertaking and requires a significant investment in technology. Battista and Verhun (2000, page 37) report that, "To many technology-focused individuals, CRM is synonymous with large databases and data mining. However, a much broader range of technologies is involved. Many general technology issues need to be addressed to support any customer relationship management initiative, including bandwidth, powerful workstations, web infrastructure, and computer telephony integration issues. Other technologies are more specifically linked to CRM initiatives. These include advanced algorithms, cookies, intelligent agents, middleware, neural networks, online analytical processing, and push technologies. These technologies represent some of the nuts and bolts of any sophisticated CRM infrastructure."

CRM is often misunderstood as only a technology solution, but a much broader range of technologies is also involved. "CRM requires company-wide, cross-functional, customer-focused business process re-engineering. Although a large portion of CRM is technology, viewing CRM as a technology-only solution is likely to fail. Managing a successful CRM implementation requires an integrated and balanced approach to technology, process, and people" (Chen and Popovich, 2003, page 672). 
The claims that CRM increases customer loyalty, retention, and profitability (Stone, et al. 1996; Wright, et al. 2002; Chen and Popovich, 2003) were not supported in the early literature. Early reports of its effectiveness were not encouraging. Ambler (2002) reports that the metrics on customer satisfaction and loyalty associated with CRM are barely measurable (36\% and $51 \%$ of the companies respectively) and when there is an association, it is unclear if the association can be understood. Johnson (2004) predicted that through 2006, more than 50 percent of all CRM implementations will be viewed as failures from a customer's point of view and 55-75 percent of all CRM projects will fail to meet their objectives.

However, later studies paint a different picture. Boulding, et al. (2005) present a set of nine articles and two essays that advance the science and practice of CRM. Eight of the ten studies find associations between CRM and firm performance. For example, Mithas, et al. (2005) uses a cross-section of CRM practicing U.S. firms to find a positive association with improved customer knowledge and improved customer satisfaction. Srinvasan and Moorman (2005) find that firms with at least moderate on-line experience are better able to leverage CRM into superior customer satisfaction outcomes than bricksand-mortar firms with little or no experience. Ryals (2005) researches two longitudinal case studies in the financial services industry that demonstrate customer management strategies change as more is learned from the lifetime value of customers affected by CRM and these changes lead to better firm performance based upon lifetime value. 
Peerman, et al. (2008, page 466) apply structural equation modeling to examine eight CRM award winning companies to evaluate the effectiveness of CRM components upon CRM success. In the study results, CRM success is determined by individual company strategy, customer satisfaction and loyalty are "intermediary metrics" that are not directly, empirically, determined to improve as a result of CRM but which improvement is inferred by the "related latent variables that all have a positive impact on CRM metrics."

Wann-Yih and Cheng-Hung (2007, page 194) employ LISREL models to data collected from ten direct selling companies that use CRM and find that "favorable consumer purchase intentions often result from the consumer-company identification." The consumer-company identification is the cognitive link between the organization and the individual's self that is enhanced by CRM.

Customer satisfaction survey results undoubtedly reside somewhere in the data warehouses of CRM systems and may thus be considered a subset of CRM because information in the surveys informs the relationship management process. However, none of the research into the effectiveness of CRM investigates the specific use of survey results to proactively contact customers and CRM research does not relate survey 
feedback to customer retention. This gap in the literature is not addressed by CRM research.

\section{2-7: Switching Costs}

Service recovery and CRM are important strategies for retaining loyal customers, but switching costs also contribute to customer loyalty. Analysis of banking customers demonstrates that switching costs are key factors in the decision-making process as to whether to remain with a service provider (Colgate, 2001).

In their seminal work, Jones and Sasser (1995) illustrate that where market competition is intense, alternatives are more available and switching costs are lower. In this environment, there is a tremendous difference between the loyalty of satisfied and completely satisfied customers. However, in markets where the firm exerts near complete control over customer choice creating high switching costs, customers remain loyal at very low levels of satisfaction. Figure 2-3 depicts the non-linear relationship of satisfaction to loyalty in competitive environments. 


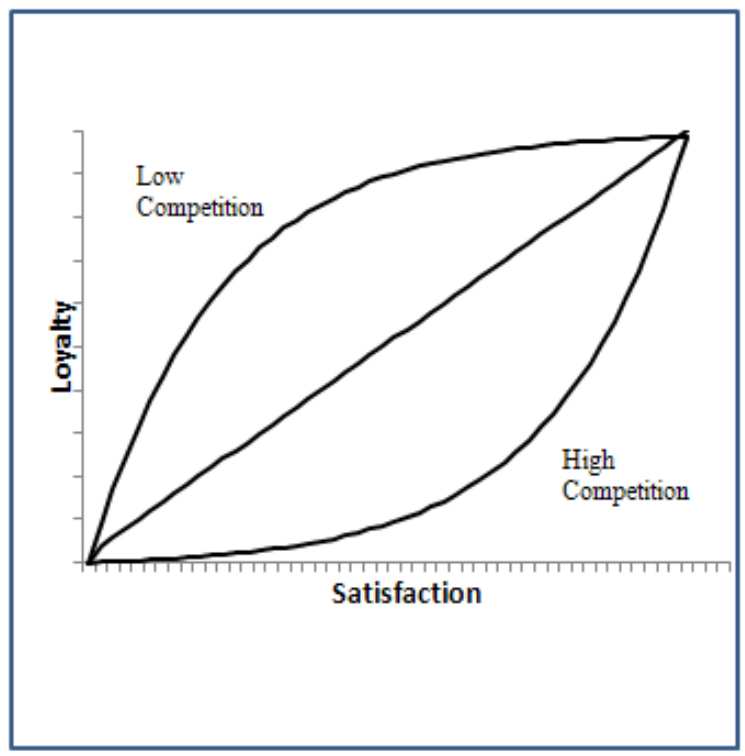

Figure 2-2: Satisfaction - Loyalty in a Competitive Environment, Source: Jones and Sasser (1995).

A merely "satisfied" customer, except in rare instances, does not represent a "loyal" customer. Complete satisfaction is the key for ensuring a customer's loyalty when competitive forces are high and offer multiple alternatives. This is increasingly true the higher the level of market competition in the company's industry. Conversely, a customer may be very frustrated with the local cable provider and report low satisfaction, but still not switch to satellite TV because there are few alternatives.

Wang (2010) finds that high switching costs also impact customer perceived value and corporate image thereby decreasing customer loyalty. Bell, et al. (2005) find that, as customer relationships with a service provider deepen, customers increase their own expertise in dealing with the provider. This increases their emotional investment in the 
provider and hence, increases their switching costs. Bell concludes that customer relationship factors that create switching costs have a greater impact upon loyalty than even service quality. Kelley (1994) demonstrates that the degree of customer's investment in a commitment to a service provider contributes to recovery expectations and loyalty predictability because loyal customers that expect certain outcomes are more likely to give the business an opportunity to recover after a service failure. Likewise, customers with higher perceived service quality expectations possess higher retention expectations (Kelley, 1994; Halstead, et al. 1993). Jones, et al. (2000) find that the influence of core-service satisfaction on repurchase intentions decreases under conditions of high switching barriers when satisfaction is low.

The ferocity of competition in a firm's market and the importance of switching costs imposed on (or by) customers affect the level of satisfaction where customers are more likely to remain loyal. The assessment of competition and customer satisfaction levels are considerations a firm should take into account in determining the degree of satisfaction firms consider for targeting customers that are potentially at risk of defection. The target should set the bar for proactive intervention actions to contact customers and ensure that they remain highly satisfied and loyal to the firm.

\section{2-8: Summary}

Today's global marketplace offers customers many opportunities to find alternatives and customer loyalty is a goal pursued by many companies. It is less costly to retain current 
customers than it is to attract new ones and the profitability of loyal customers increases over time. Some customers are more profitable than others and firms should strategically target those profitable customers that depend on the activities that create a competitive advantage for the firm.

Service Recovery and CRM are two principal retention strategies practiced by firms today. Service Recovery is reactive and is used to respond to service failures. However, recovery efforts can be risky and backfire. If the recovery is not successful it brings to bear the service recovery paradox (McCollough and Bharadwaj, 1992) that results in greater customer dissatisfaction than if no recovery was attempted. CRM employs technology to acquire knowledge about the customers to cultivate long-term relationships. However, the technology needed to implement CRM requires large investments in both information technology and organizational change. Both practices have their proponents and there is evidence that they improve firm performance.

In contrast to Service Recovery and CRM, CLSM is proactive and inexpensive. It uses customer satisfaction surveys to purposefully and proactively influence customers to prevent defections rather than reactively respond to service failures. It is inexpensive because most firms already survey customers and collect satisfaction data. Although customer satisfaction surveys are ubiquitous, there is little discussion in the literature about proactively using them to avert potential problems or affect customer attitudes 
despite the fact that some researchers have recommended that they be similarly used to influence customers. This dissertation responds to this gap in the literature by analyzing the effect of CLSM upon customer defections. The first question that this research seeks to answer is whether or not a closed loop intervention can successfully decrease customer defections. Specifically,

Research Question 1: Does a proactive closed loop approach using customer satisfaction survey responses to influence customers reduce customer defections?

The literature recommends that a firm's unique activities create competitive advantage and firms should seek to align their activities to the strategy and the needs of targeted customers. The second question this research seeks to answer is whether or not CLSM decreases defections of targeted customers more than others.

Research Question 2: Does a proactive closed loop approach using customer satisfaction survey responses to influence customers decrease defections of targeted customers versus non-targeted customers?

Service recovery acts to resolve problems caused by service mistakes. CLSM proactively influences less-than satisfied customers with satisfaction scores below 9 and attempts to 
resolve problems whenever they are found. The third question this research seeks to answer is whether or not the successful use of CLSM to proactively resolve customer problems actually decreases customer defections.

Research Question 3: Does the proactive closed loop approach using customer satisfaction survey responses to resolve customer problems decrease customer defections?

The service recovery paradox cautions that unsuccessful attempts to ameliorate customer issues exasperate customers and result in increased defections. The fourth question this research seeks to answer is whether or not the unsuccessful attempts of CLSM to proactively resolve customer problems actually increases customer defections.

Research Question 4: Does the unsuccessful use of the proactive closed loop approach using customer satisfaction survey responses to resolve customer problems increase customer defections?

The service recovery paradox also advises that successful attempts to resolve customer issues improves customer satisfaction to at least or greater than expected if there were no issues to resolve. 
Research Question 5: Does the successful use of the proactive closed loop approach using customer satisfaction survey responses to resolve customer problems decrease customer defections?

In the next chapter, the methodology used in this research to determine the effectiveness of CLSM is presented, the CLSM intervention at ABC Company is described, and the hypothesis tests used to answer the research questions are posed. 


\section{CHAPTER 3: RESEARCH METHODOLOGY}

\section{3-1: Introduction}

This chapter describes the method used in this dissertation to answer the four research questions presented in chapter 2 . The research method is a field experiment. The field experiment provides a research environment to gather empirical evidence about the impact of a CLSM intervention on customer defection rates. This research examines the effectiveness of the CLSM model.

The CLSM model is built upon the construct of the Service Profit Chain (SPC) although not all of the SPC links are explained in this dissertation. The SPC produces the reinforcing growth dynamic of the customer - employee "Satisfaction Mirror" (Section 2-4). However, reinforcing behavior can produce growth or decay. A balancing mechanism is required to ensure that the SPC maintains a positive growth orientation. ${ }^{4}$ This control loop is provided in CLSM by the survey feedback used to initiate continuous process improvement (CPI). Figure 3-1 illustrates the CLSM model in a causal loop diagram.

\footnotetext{
${ }^{4}$ The reinforcing loop in CLSM is based on the Service Profit Chain (SPC) (Heskett, et al. 1997). In their model, the SPC authors introduce a number of policies in their model that would balance their system including measurement and control (p. 34 -37), understanding customer needs (p. 46), service recovery (p. 68 ), and managing the customer-employee satisfaction mirror (p.98-110).
} 


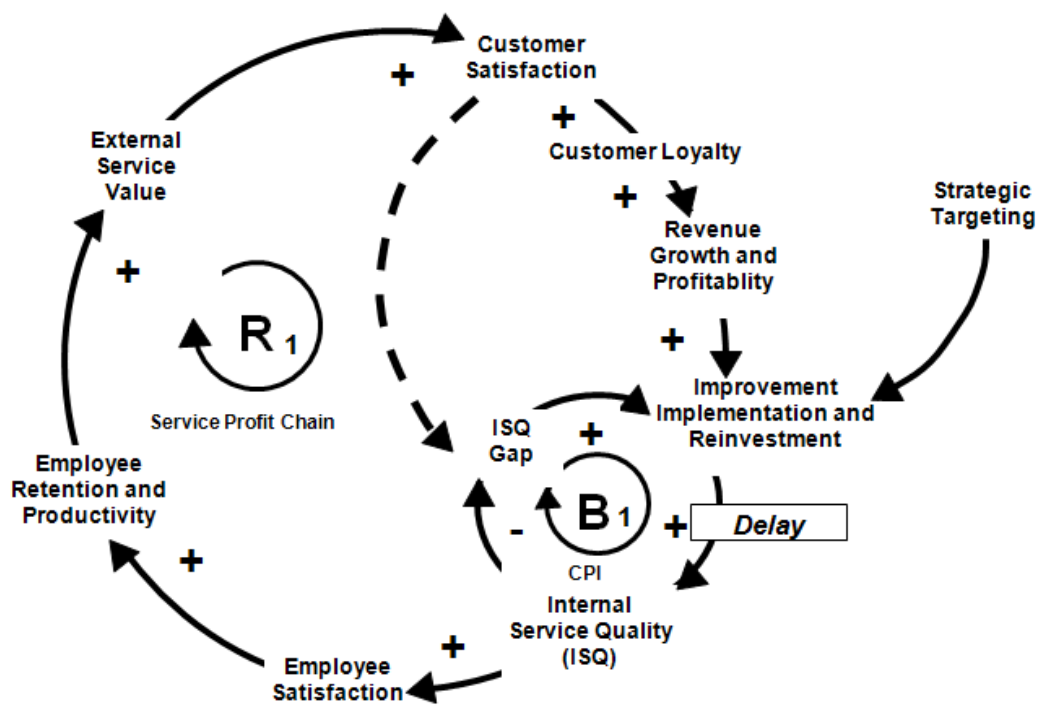

Figure 3-1: Customer Feedback Directs the Control Process of Continuous Process Improvement (CPI) in the CLSM Model ${ }^{5}$

The outer circle contains the relationships described by SPC. CLSM adds the dotted information flow to the CPI process. This represents the empowerment of employees to initiate improvements based upon interactions with customer satisfaction survey

feedback. Continuous process improvement is never immediate and the model includes a delay. System Dynamics models of CPI (Repenning and Sterman, 2001, Repenning and Sterman, 2002; Keating, et al. 1999) represent delays from CPI with the improvement half-life discovered by Schneiderman (1988). The improvement half-life states that CPI decreases defects by half within a predictable amount of time based upon the scope and complexity of the process improvement; modest improvements to single manufacturingline processes require three months, enterprise wide improvements require five years.

\footnotetext{
${ }^{5}$ The "B" in the center of the CPI Feedback loop indicates that this structure generates balancing dynamic behavior. The "-" sign indicates that, ceteris paribus (all else being equal), if the preceding component increases (decreases) then the successive component decreases (increase) below (above) what it otherwise would have been.
} 


\section{3-2: Research Method: Field Experiment}

The research method in this dissertation is a field experiment where a) pre-intervention data is captured, b) an intervention is implemented, and c) post intervention data is gathered and analyzed. The CLSM intervention was implemented at ABC Company in 2006, within the company's new contract process. The pre-intervention data was collected from existing databases at the host organization. The post-intervention data was gathered with two new tools provided to the host organization as part of this research: a customer survey and a CLSM database.

ABC Company is a large, national financial service company employing more than 2,000 people and generating annual revenues of $\$ 15$ billion, $\$ 2$ billion of which is contributed by the departments examined. To be more successful in its very competitive business to business (B2B) market, ABC Company installed a new management system in 2006 to increase customer loyalty by re-engineering the Sales and Operations departments into a cross-functional process for producing new contracts. The metric for the increase in customer loyalty is the decrease in the proportion of $1^{\text {st }}$ year terminations for new customer contracts. $\mathrm{ABC}$ Company recovers its cost of gaining new customers in the first year, making the proportion of $1^{\text {st }}$ year terminations a reasonable measure.

Four years of data before the intervention was gathered to establish a reliable performance benchmark. The population from before the CLMS intervention consists of 11,982 customers spanning the period 10/1/2002 - 10/31/2006. This four-year period 
follows a major data integrity effort conducted at the host organization that significantly enhanced the reliability and data integrity of the company's computer systems. The integrity enhancement was in response to the Sarbanes-Oxley Act of 2002 (SOX) requiring reliable internal controls.

SOX was a congressional response to certain notable financial scandals that occurred during 2001 and 2002 by Enron, Tyco International, Adelphia, and WorldCom. SOX was put into law on July 30, 2002. It established a public company accounting oversight board to monitor the audit of public companies that are subject to US securities laws. The board oversees the practice of public accounting firms and can revoke their licenses and impose fines up to $\$ 15,000,000$, upon violators of the act.

The act also requires CEOs and CFOs of publicly traded corporations to certify each annual and quarterly report filed with the Security Exchange Commission by stating that $\mathrm{s} /$ he reviewed it, the report fairly presents, in all material respects, the financial condition and results of operations. The signing officers are responsible for maintaining a system of internal controls and identifying all significant deficiencies or material weaknesses to the company's auditors. SOX imposes fines and imprisonment of up to 20 years on signing corporate officers that are found to have committed fraud under the act. 
ABC Company's senior management accepts the serious responsibilities imposed by SOX and diligently enforces its provisions for assuring adequate internal controls including assuring the integrity of computer data. Because of these efforts, the four years of data prior to the intervention provide a reliable measure the company's performance and establish a benchmark to measure the effects of the CLSM intervention.

The CLSM intervention begins with surveys that are sent to all new customers who engage in a financial services contract with ABC Company. As customers respond to the survey, the responses are updated into a specialized CLSM database and made available to front-line staff. Front-line employees are required to proactively reach out to customers and attempt to resolve less -than-satisfied customer issues. The success of this issue resolution is then updated in the CLSM database to inform the CPI process and develop improvement initiatives. This process is illustrated below in figure 3-2. 


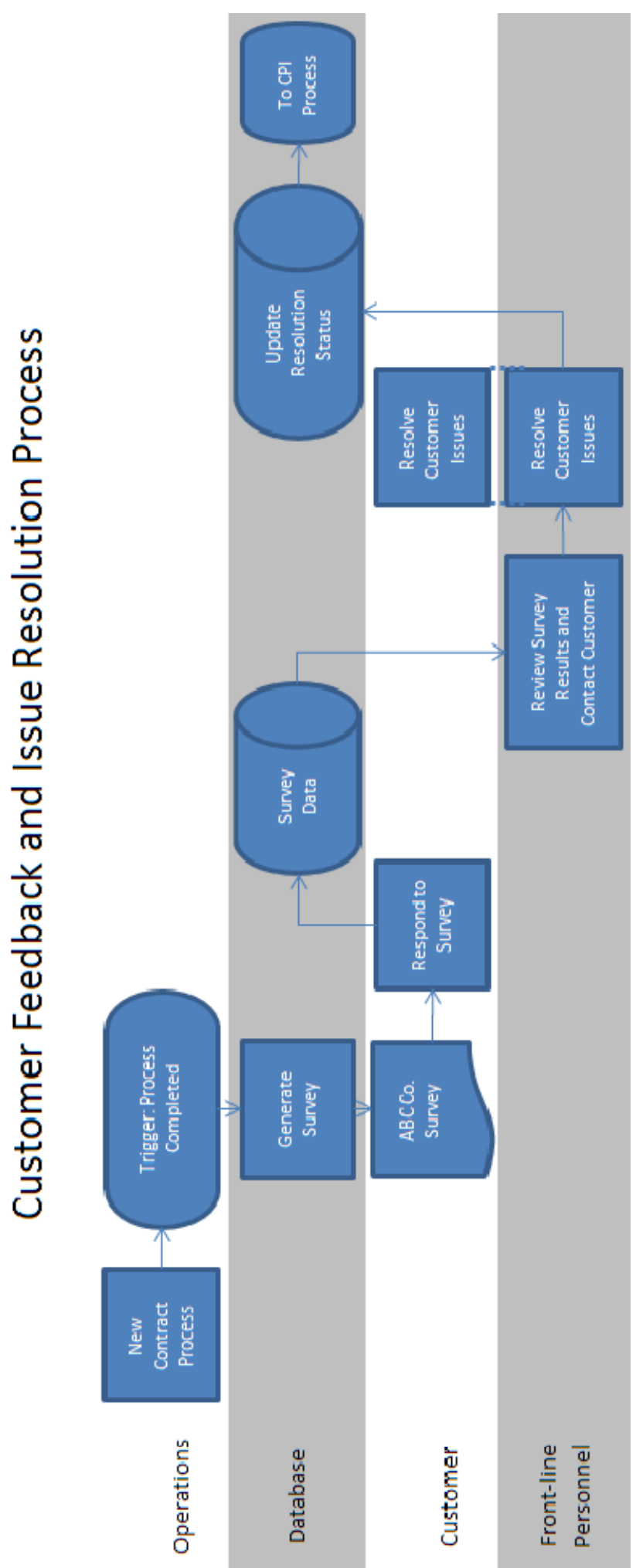

Figure 3-2: CLSM Intervention at ABC Company 
Feedback from surveys provides front-line personnel with customer satisfaction information. Questions for the survey were suggested by teams from Marketing and the Operations departments. All members were aware of their department services and also were intimately knowledgeable of the new contract process. After many discussions, questions were presented to management, who reviewed the recommendations from the cross-functional teams and made the final determination as to what quality attributes to include in the survey.

The survey measures a discrete set of attributes to gauge the satisfaction of a new customer's experience with the new contract transaction. Over a period of three years since adoption of this process, 15,000 new customers have been sent the survey. Figure 3-3 shows the new contract survey used by ABC Company. 


\begin{tabular}{|c|c|c|}
\hline Service experience & $\begin{array}{c}\text { Level of Satisfaction } \\
\text { From } 1 \text { (low) to } 10 \text { (high) }\end{array}$ & $\begin{array}{c}\text { Level of Importance } \\
\text { From } 1 \text { (low) to } 10 \text { (high) }\end{array}$ \\
\hline 1. Timeliness of policy delivery. & 12345678910 & 12345678910 \\
\hline 2. Timeliness of initial billing statement delivery. & 12345678910 & 12345678910 \\
\hline 3. Accuracy of initial billing statement. & 12345678910 & 12345678910 \\
\hline 4. Overall effectiveness of communications. & 12345678910 & 1233456789910 \\
\hline 5. Ease of doing business with $A B C$ Co. & 12345678910 & 12345678910 \\
\hline $\begin{array}{l}\text { 6. What other aspects of service were important } \\
\text { in vour organization's experience with The }\end{array}$ & & \\
\hline a. & 1233456789910 & 1233456789910 \\
\hline b. & 1223456789910 & 12345678910 \\
\hline $\begin{array}{l}\text { 7. Please rate your organization's overall level } \\
\text { of saticfartion with your recent experience } \\
A B C \text { Co. }\end{array}$ & 12345678910 & \\
\hline
\end{tabular}

Comments:

Figure 3-3: Customer Satisfaction Survey at ABC Company

The survey is intentionally brief to ensure a high response rate, as short questionnaires tend to generate a higher response rate than long ones. This questionnaire consists of seven questions. Questions 1-5 measure the quality attributes (Vavra, 1997) included by management. Question 6 is an open ended question asking for other aspects of service experience that are important to the new customer. This question can provide rich insights into customers' likes and dislikes. Question 7 asks for an overall measure of satisfaction. By intentionally designing a brief questionnaire, ABC Company has achieved a $20 \%$ response rate. 
Responses to the questions are of two types - the level of satisfaction and level of importance with the different aspects of services (Parasuraman, et al. 1988). These responses are measured on a 10-point scale for degree of satisfaction and importance with 1 low and 10 high. The results are analyzed to identify those customers who are "lessthan-satisfied" as measured by an average of 8 or below for all of the questions. These customers then are contacted by front-line personnel to proactively identify potential problems, communicate the company's commitment to quality, and avert potential defections before service problems (if any) can affect customer behavior.

When the new customers are interviewed, the front-line personnel address any issues alluded to by the customer. Some are resolved and employees record the contact status as "Resolution." Employees record unresolved issues as "Contact." For those customers who were not successfully contacted, employees report these as "No Contact" in the CLSM database. Anecdotal data reports that many customers do not consider a satisfaction score below 8 to indicate service problems, but are impressed by the company's commitment to quality and post-survey engagement. Figure 3-4 (below) illustrates the survey feedback and customer contact interface. 


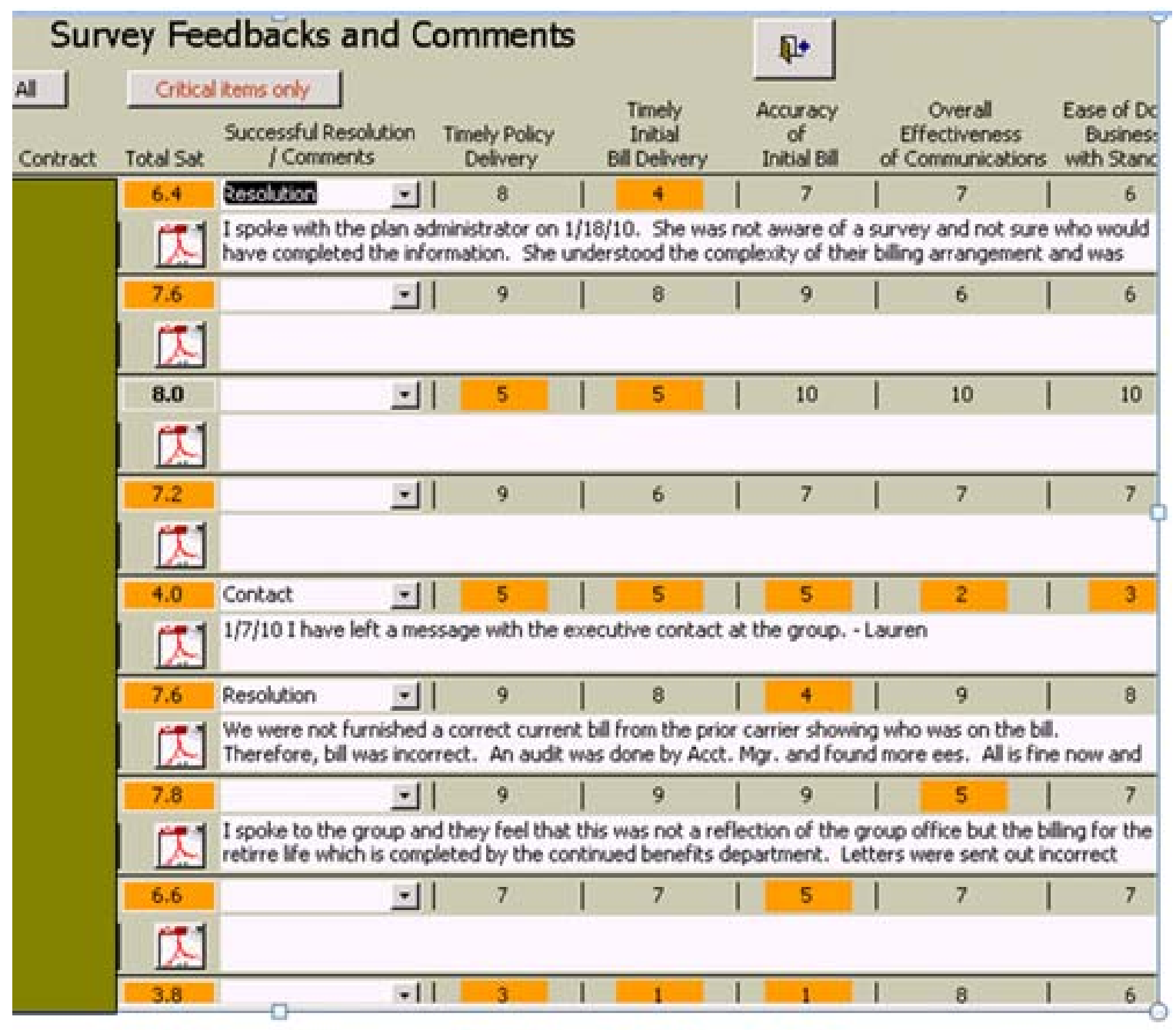

Figure 3-4: Survey Feedback and Employee Contact Interface at ABC Company

Highlighted scores indicate less-than-satisfied responses and require employees to make proactive contact with the customer. Employees record the status of the contact and enter comments into the interface. 


\section{$\underline{\text { Survey Responses }}$}

As customers respond, survey response feedback is expedited directly to the front-line personnel responsible for servicing these customers. Of the over 15,000 new customers who received surveys about 3,000 responded. Figure 3-5 illustrates the proportion of responses from $\mathrm{ABC}$ Company customers. 


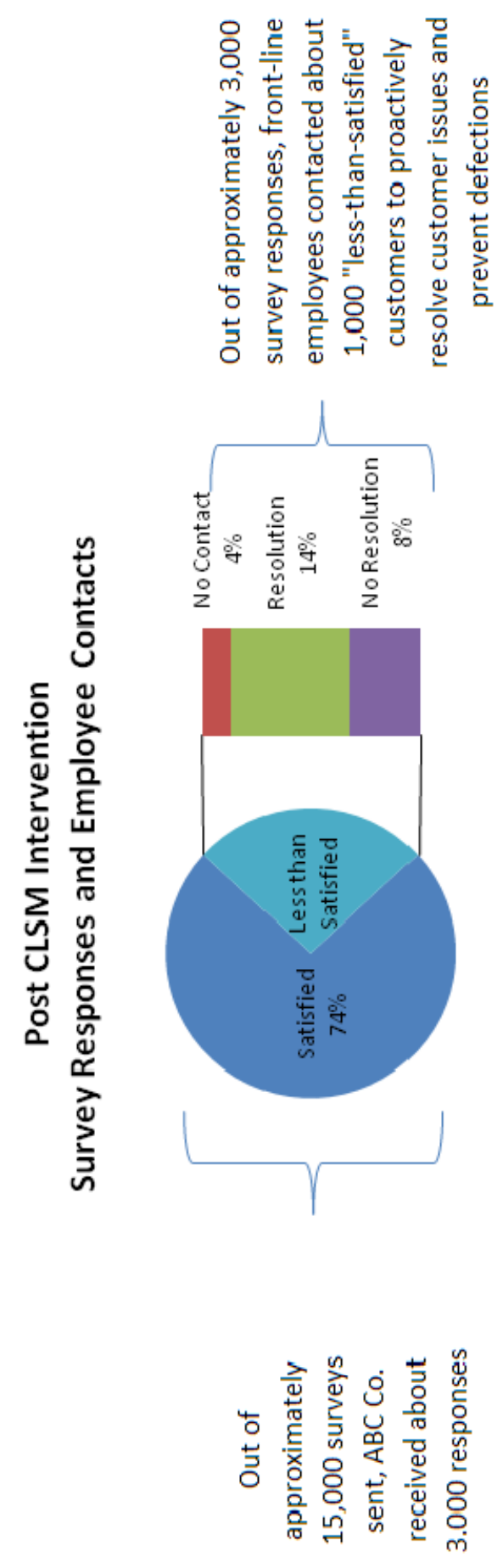

Figure 3-5: Survey Responses and Issue Resolution Statuses 
In figure $3-5,74 \%$ of the survey respondents are considered satisfied. The remaining $26 \%$, the less-than-satisfied customers, were contacted by front-line personnel to resolve issues. From this remaining 26\%, 14\% were resolved satisfactorily, $8 \%$ were not resolved, and $4 \%$ were not contacted.

Issue Resolution / Less-than-satisfied Customers Defined

Front-line staff is required to resolve all customer issues when respondent surveys report less-than-satisfied. A less-than-satisfied score is established by management policy to be 8 or below for overall satisfaction (Question 7) or an average below 8.5 for the first five service quality attribute questions (Questions 1-5) on a 10-point scale.

There needn't be any customer complaint to prompt a contact. Employees contact the customers when their satisfaction scores meet management policy criteria as less-thansatisfied. They inquire about any issues or concerns and attempt to resolve any problems the customers mention. The employees record into the CLSM database whether: 1) the customer issues are resolved to the customers' satisfaction, 2) the customer is contacted, or 3) no customer contact is made. 


\section{Post Intervention Data Gathering}

This research tested the hypothesis that CLSM increases customer loyalty by measuring the change in the proportion of 1 st-year terminations. Data from the CLSM was joined with other company databases to create a data set containing:

1. policy effective and termination dates,

2. targeted customer flags,

3. survey respondents,

4. survey respondents contacted,

5. contacted survey respondent s with "Resolution" status, and

6. contacted survey respondents without "Resolution" status.

The data was then filtered into subsets for performing hypothesis tests. A discussion of the research variables used to test the hypotheses follows.

\section{Customer Loyalty}

The metric used to determine customer loyalty is the proportion of 1st-year terminations. ABC Company management is particularly concerned about this measure because conventional wisdom states that, it requires at least one year for the company to recover the contract's initial investment in acquiring the contract. The company's financial service contracts usually specify a one-year term, but ABC Company relies upon its core service capability, i.e., to solve customer problems, and expects customers to renew their contracts annually. Customer loyalty is measured as follows: 
The proportion of 1 st-year terminations equals the count of individual contracts where the duration between effective date and termination date is less than or equal to 1-year divided by the total number of contracts in a data set.

Data sets are defined by the parameters specified by the hypothesis tests. For instance, to determine the proportion of 1 st-year terminations in the pre-intervention period, the count of contracts terminating in one year or less in years prior to the intervention is divided by all contracts effective in the same years prior to the intervention.

\section{$\underline{\text { Targeted Customers }}$}

ABC Company segments its customer base into targeted and non-targeted sub groups based on their demographics, their demand for core services, and their profitability. These customers, more than others, rely upon the core services that differentiate ABC Company from its competition. The requirements of this customer group complement the company's core competencies. The CLSM relational database joins to ABC Company's other databases to identify targeted customers and separates them from the rest of the population for analyses.

\section{$\underline{\text { Survey Respondents }}$}

ABC Company can segment its less-than-satisfied survey respondents into two subsets within the CLSM database: 1) contacted with "Resolution" and 2) contacted without "Resolution." Front-line employees are required to contact less-than-satisfied customers 
to proactively attempt to resolve potential problems. These employees record the results of in the database in free-text fields describing the details of the contact and record the status of the contact as being successful by selecting the "Resolution" status. If the "Resolution" status is not recorded, the contact is considered to be not resolved for this analysis.

\section{$\underline{\text { Summary }}$}

This research determines the effectiveness of the CLSM intervention to increase customer loyalty at $\mathrm{ABC}$ Company. It measures the increase (decrease) of the loyalty of targeted customers, and the loyalty of less-than-satisfied customers where front-line employee contacts resolved or failed to resolve customer issues. The variable, customer loyalty, is measured by the proportion of 1st-year terminations. Targeted customers are identified with a targeted flag in the CLSM database. Resolved and non-resolved customer issues by front-line employee contacts are identified with the "Resolution" status in the CLMS database. The next section describes the specific hypothesis tests performed.

\section{3-3: Hypothesis Tests}

In this section, hypothesis tests determine if there is a difference in customer defections before and after the CLSM intervention, but because the research method is a field experiment there are confounding factors that necessitated additional hypotheses to 
determine their effect on the data. If confounding factors do affect the measure of loyalty, then the analysis must be adjusted to control for these effects.

Research questions $1 \& 2$ ask if CLSM, in general, decreases customer defections. The following hypotheses determine the answer.

\section{$\underline{H}_{0} \underline{1}$ Pre / Post Intervention}

Null hypothesis $\mathrm{H}_{\mathrm{o}} 1$ is associated with research question one. The test for $\mathrm{H}_{0} 1$ determines if the difference in customer defections from before and after the introduction of CLSM is statistically significant. This null hypothesis states:

$\mathrm{H}_{\mathrm{o}}$ 1: The proportion of 1st-year terminations of all new customers in the four years before the CLSM intervention is less than or equal to the proportion of 1st-yr. terminations of new customers in the three years after the CLSM intervention began.

\section{$\underline{\mathrm{H}}_{0} 2$ Targeted / Non-targeted Customer Defections}

Null hypothesis $\mathrm{H}_{0} 2$ is associated with research question two. The test for $\mathrm{H}_{0} 2$ determines if the difference in customer defections of targeted versus non-targeted customers is statistically significant. This null hypothesis states: 
$\mathrm{H}_{\mathrm{o}}$ 2a: The proportion of 1st-year terminations of all new targeted customers in the preintervention period is less than or equal to the proportion of 1st-yr. terminations of all other new targeted customers in the post-intervention period. ${ }^{6}$

$\mathrm{H}_{\mathrm{o}} 2 \mathrm{~b}$ : The proportion of 1st-year terminations of all new non-targeted customers in the pre-intervention period is less than or equal to the proportion of 1st-yr. terminations of all other new non-targeted customers in the post-intervention period. ${ }^{6}$

Research questions 3, 4 \& 5 ask if the successful (or unsuccessful) use of customer satisfaction feedback decreases (or increases) customer defections. The following hypotheses determine the answer.

\section{$\underline{\mathrm{H}}_{0} 3$ Successful use of Customer Satisfaction Measurement \#1}

Null hypothesis $\mathrm{H}_{0} 3$ is associated with research question three. The test for $\mathrm{H}_{0} 3$ determines if the difference in the defections of customer satisfaction survey respondents to the defections of all customers before the intervention is statistically significant. This null hypothesis states:

${ }^{6}$ The post intervention period is the measurement period after the CLSM intervention in 11/06 adjusted for confounding factors. 
$\mathrm{H}_{\mathrm{o}} 3$ : The proportion of 1st-year terminations of all new customers in the preintervention period is less than or equal to the proportion of 1st-yr. terminations of post intervention less-than satisfied customers who were contacted by employees to proactively resolve potential problems and whose issues were considered resolved in the CLSM database.

\section{$\underline{\mathrm{H}_{0}} \underline{4}$ Unsuccessful use of Customer Satisfaction Measurement}

Null hypothesis $\mathrm{H}_{0} 4$ is associated with research question four. The test for $\mathrm{H}_{0} 4$ determines if the difference in customer defections of survey respondents (who were contacted but whose status did not indicate "Resolution") to the defections of all customers before the intervention is statistically significant. This null hypothesis states:

Ho 4: The proportion of 1st-year terminations of all new customers in the preintervention period is less than or equal to the proportion of 1st-yr. terminations of new customer survey respondents in the post-intervention period that were contacted by employees, but whose status did not indicate "Resolution."

\section{$\underline{\mathrm{H}_{0}} \underline{5 \text { Successful use of Customer Satisfaction Measurement \#2 }}$}

Null hypothesis $\mathrm{H}_{0} 5$ is associated with research question five. The test for $\mathrm{H}_{0} 5$ determines if the difference in the defections of less-than satisfied survey respondents (score $<9$ ) to the defections of satisfied customers (score $>8$ ) after the intervention is statistically significant. This null hypothesis states: 
$\mathrm{H}_{\mathrm{o}}$ 5: The proportion of 1st-year terminations of all satisfied customers is less than or equal to the proportion of 1 st-yr. terminations of post intervention less-than satisfied customers who were contacted by employees to proactively resolve potential problems and whose issues were considered resolved in the CLSM database.

\section{3-4: Confounding Factors}

Determining whether a difference occurs before and after an intervention in a field experiment is not sufficient without considering the possibility of other potential causalities that might obscure the interpretation of the research findings. Unlike controlled experiments conducted in a laboratory, field experiments take place in an open environment where confounding factors may be unavoidable.

Confounding factors are factors that may lessen the experiment's accuracy and / or repeatability, or the analysts' ability to interpret results. Researchers must identify and control for confounding factors. As stated earlier, H01 does not control for the influential events that might affect customer behavior independent from the intervention. The "before group" may have made its defection decisions during a robust and growing economy, whereas the "after group" may be affected by a severe economic downturn, or some customers may be impacted by ABC Company management actions (other than the CLSM). 
There are two major events that may have impacted the post-intervention group and not the pre-intervention group, thereby compromising validity of the uncontrolled $\mathrm{H}_{0} 1$ hypothesis test. The first is the Great Recession, the worst downturn in financial markets since the depression of the 1930s. The second is management's implementation of a costcutting policy, the largest front-line personnel reduction in ABC Company's history.

The effect of both of these events are tested by isolating the period affected by the confounding factors and applying additional hypothesis tests to determine if any differences in the defection rates are statistically significant. If there is a statistically significant difference, the sample is adjusted to control for the effect of the confounding factor.

\section{Great Recession Effect}

According to the National Bureau of Economic Research, the Great Recession began December, 2007 and ended June, 2009.7 It is necessary to control for the impact of the Great Recession in $\mathrm{H}_{0} 1$ if it has a significant effect upon customer defections.

In order to determine if the significant differences of the pre/post-intervention test actually result from the CLSM exclusively or are influenced by the Great Recession 
effect, it is necessary to determine if the Great Recession itself impacts the measurement of customer loyalty. The following figure 3-6 depicts a time line of the proportion of $1^{\text {st }}$-year terminations each month at ABC Company from four years prior to the intervention, the beginning of the intervention, and during the Great Recession. 


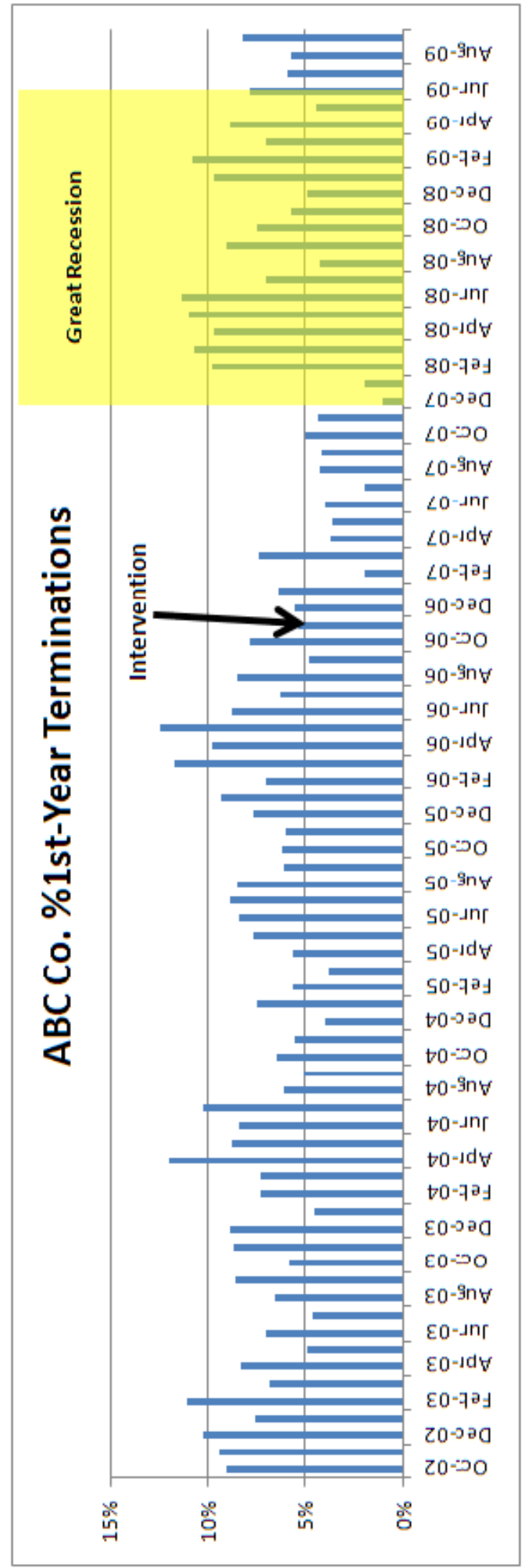

Figure 3-6: ABC Company New Case Timeline and Great Recession Period 
Since the CLSM intervention spans a time frame from November, 2006 to September 2010 , it is possible to isolate and examine customer behavior outside of the recession period. The analysis can test customer defections during the intervention period before the recession and after it to determine if the recession had a significant impact on customer defections. Figure 3-7 below illustrates the two periods after the intervention examined in the next hypothesis test.

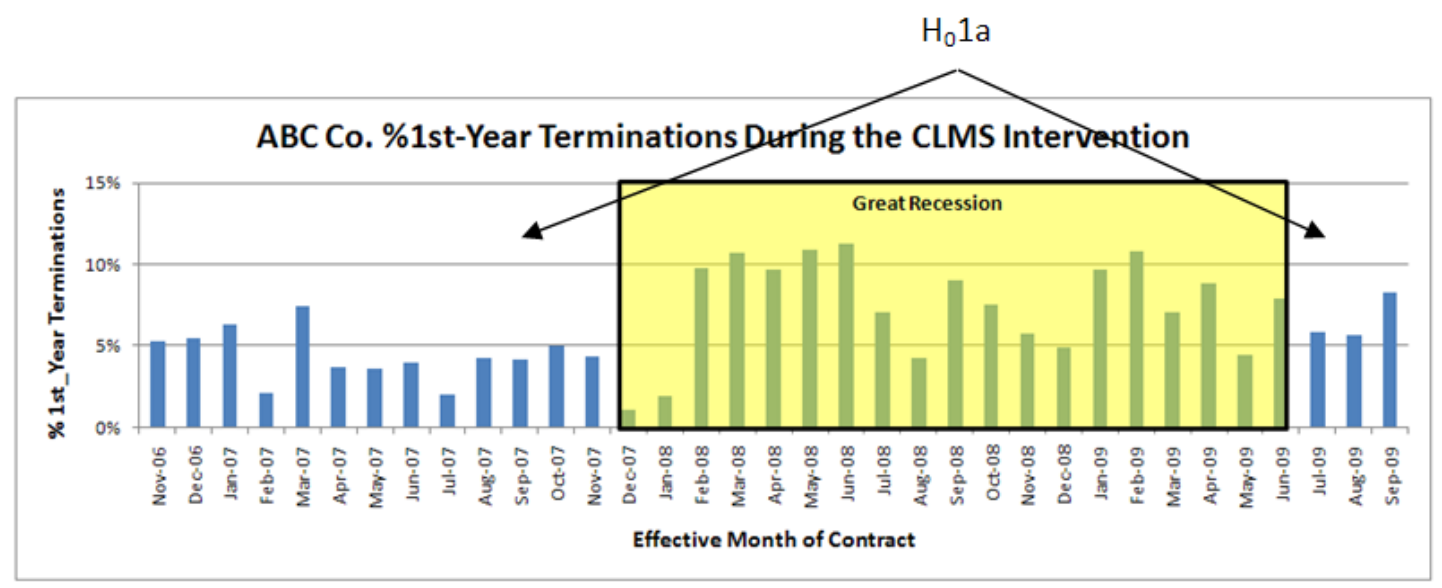

Figure 3-7: Pre - Post Great Recession, $\mathrm{H}_{\mathrm{o}} 1 \mathrm{a}$

The following hypothesis test determines if customer loyalty behavior is consistent among ABC Company's customers after the intervention, but outside of the recession period.

\section{$\underline{H}_{0} \underline{1 \text { a Pre-Post Great Recession }}$}

$\mathbf{H}_{\mathbf{0}} \mathbf{1 a}$ The proportion of 1st-year terminations before the recession equals the proportion of 1st-yr. terminations after the recession. 
Should it be found that there is a statistically significant difference in the proportion of 1st-year terminations between the periods before and after the recession, then each period is tested to determine if either the before or after periods differ statistically from the recession period itself. Figure 3-8 below illustrates the two periods examined in the next two hypothesis tests.

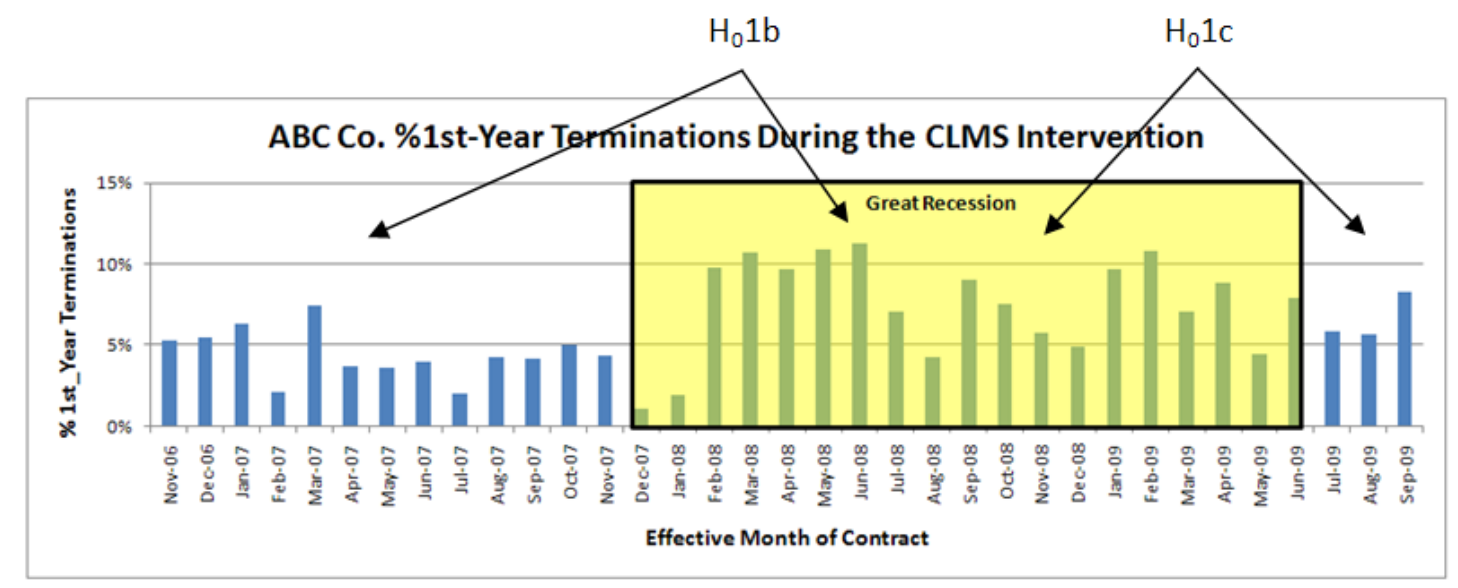

Figure 3-8: Pre - During Great Recession, $\mathrm{H}_{\mathrm{o}} 1 \mathrm{~b}$ and Post - During Great Recession, $\mathrm{H}_{\mathrm{o}} 1 \mathrm{c}$

The two hypotheses $\mathrm{H}_{0} 1 \mathrm{~b}$ and $\mathrm{H}_{0} 1 \mathrm{c}$ determine if customer loyalty behavior is consistent among $\mathrm{ABC}$ Company's customers after the intervention, but before and during the recession period $\left(\mathrm{H}_{0} \mathrm{lb}\right)$ and after and during the recession period $\left(\mathrm{H}_{0} 1 \mathrm{c}\right)$.

\section{$\underline{\mathrm{H}}_{0} \underline{1 \mathrm{~b} \text { Pre-Great Recession - During Great Recession }}$}

$\mathbf{H}_{\mathbf{0}} \mathbf{1 b}$ The proportion of 1st-year terminations during the Great Recession equals the proportion of 1st-year terminations before the Great Recession. 


\section{$\underline{H}_{0} \underline{1 c}$ Post-Great Recession - During Great Recession}

$\mathbf{H}_{\mathbf{0}}$ 1c The proportion of 1st-year terminations during the Great Recession equals the proportion of 1st-year terminations after the Great Recession.

\section{Inside-Outside the Great Recession}

If, however, there is no statistically significant difference between the before and after recession periods, then the two periods may be aggregated to test the following hypothesis. Figure 3-9 below illustrates the periods examined in the next test.

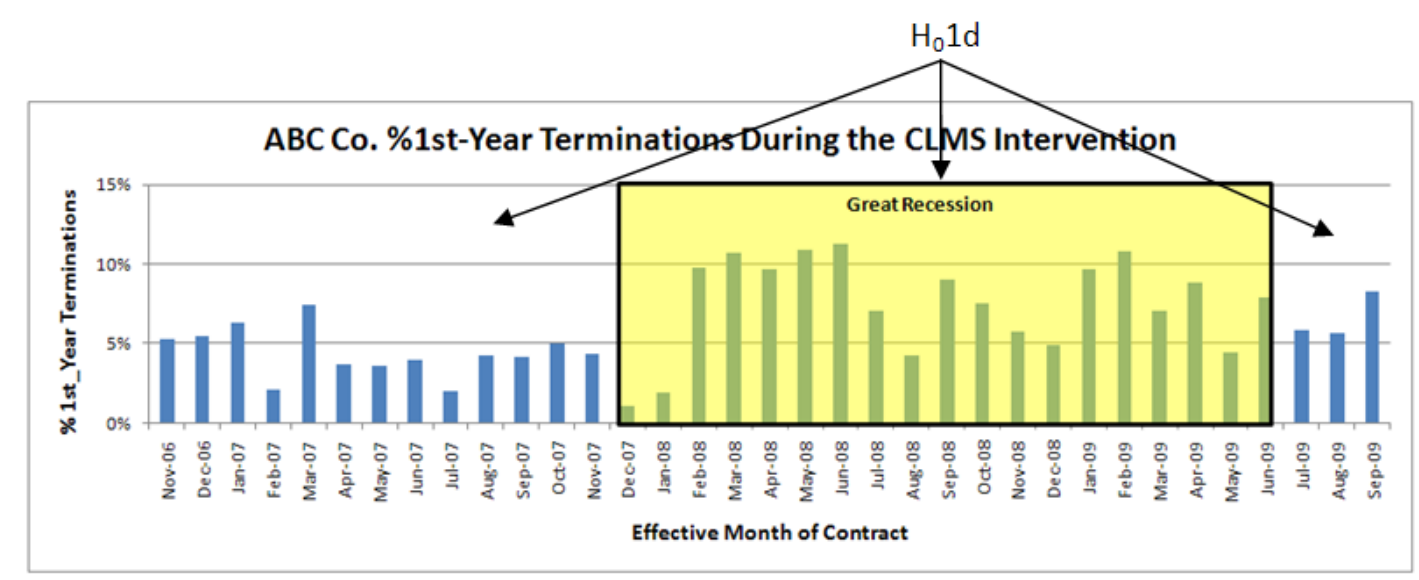

Figure 3-9 Pre and Post Great Recession combined and During Great Recession, $\mathrm{H}_{\mathrm{o}} 1 \mathrm{~d}$

\section{$\underline{\mathrm{H}}_{0} \underline{1 \mathrm{~d} \text { Outside-Great Recession - During Great Recession }}$}

$\mathbf{H}_{\mathbf{0}} \mathbf{1 d}$ The proportion of 1st-year terminations during the recession equals the proportion of 1st-yr. terminations outside of the recession. 


\section{Summary}

In the preceding paragraphs, four hypothesis tests are described that will determine if the Great Recession significantly affects customer loyalty. The results from $\mathrm{H}_{0} 1 \mathrm{a}-\mathrm{H}_{0} 1 \mathrm{~d}$ determine if customer loyalty is affected by the Great Recession and identify which periods should be excluded from this research to control for the Great Recession effect. In the next section similar hypotheses are proposed to determine if ABC Company's cost cutting policy affects customer loyalty.

\section{Cost Cutting Effect}

The second potential confounding factor is management's cost-cutting policy. In line with a long-term plan to increase efficiencies at ABC Company, management took actions to eliminate redundancies in its sales operations by eliminating a large number of front-line staff in the field performing activities that are more efficiently performed by functional experts at the home office. The disruption of activities in the offices principally responsible for providing local service and support directly to customers may impact customer terminations and be found to be another confounding factor.

It is necessary to control for the effect of this cost-cutting program if it had a significant impact upon customer loyalty. In order to determine if the significant differences of the pre/post-intervention test actually result from the CLSM, or were influenced by the cost- 
cutting effect, the analysis determines if management cost-cutting actions affect the measurement of customer loyalty.

Since the cost-cutting effect occurred between $9 / 1 / 08-3 / 30 / 09,{ }^{8}$ it is possible to isolate and examine customer behavior outside of the policy change period. The research can test customer loyalty during the intervention period prior to the cost cutting and after it to determine if it had a significant impact on customer loyalty. The following figure 3-10 depicts the time line by contract effective month of the proportion of $1^{\text {st }}$-year terminations at $\mathrm{ABC}$ Company indicating the beginning of the intervention and duration of the costcutting actions by management.

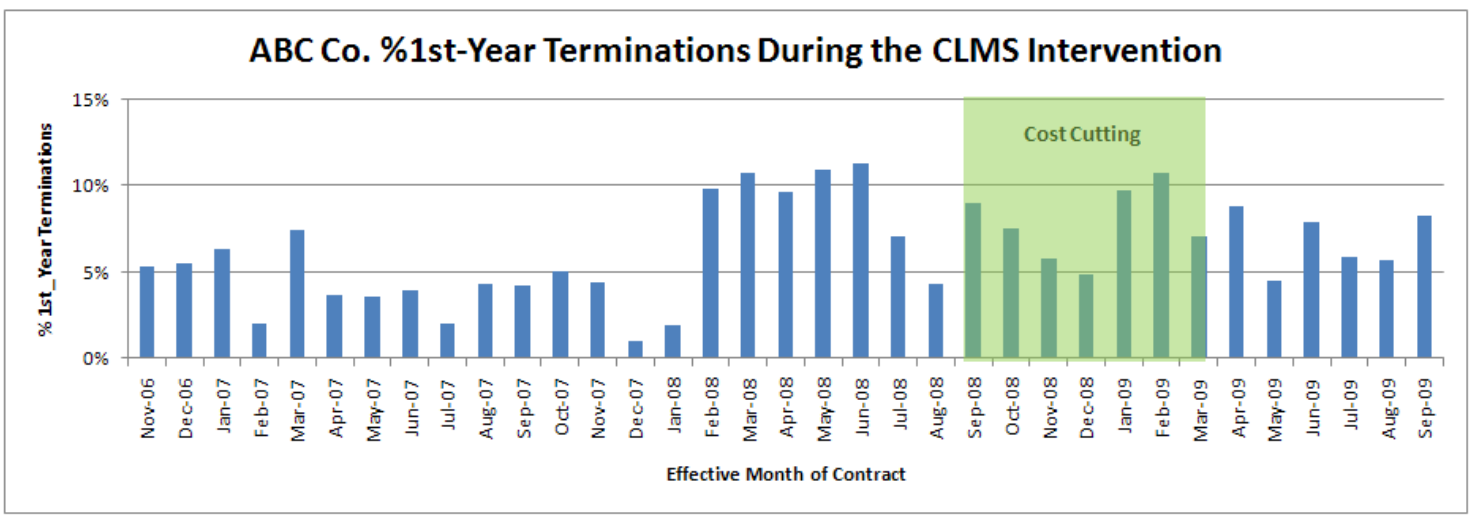

Figure 3-10, ABC Company Proportion of 1st-Year Terminations and Cost-cutting Activity Period

\footnotetext{
${ }^{8}$ Actual staffing reductions occurred from 9/1/08 - 11/30/08. Management expects the policy to affect customers for an additional four months during the transition to the new policy.
} 
The next hypothesis test determines if customer loyalty behavior is consistent among ABC Company's customers outside of the cost-cutting period. Figure 3-11 illustrates the periods examined by the next hypothesis test.

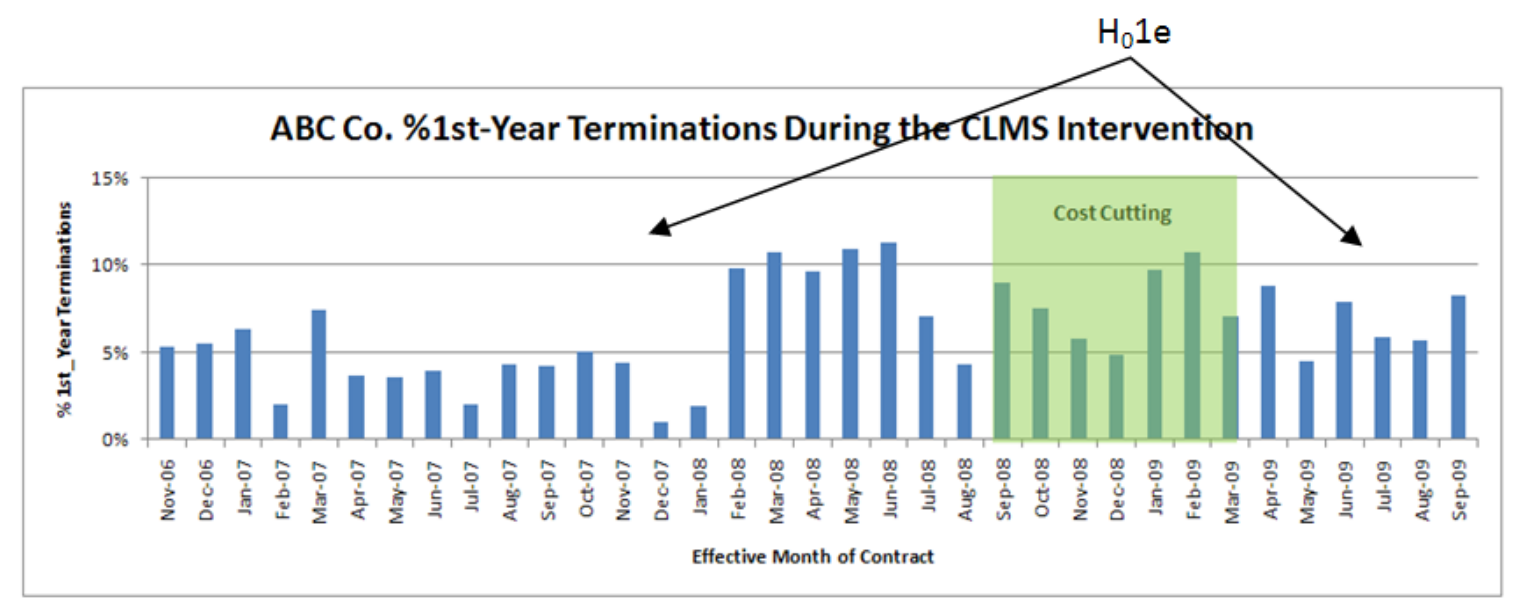

Figure 3-11: Pre- Post Cost-Cutting, $\mathrm{H}_{0} 1 \mathrm{e}$

\section{$\underline{\mathrm{H}}_{\mathrm{o}} \underline{\mathrm{e} \text { Pre-Post Cost Cutting }}$}

$\mathbf{H}_{\mathbf{0}} 1 \mathbf{e}$ The proportion of 1st-year terminations before the cost cutting policy equals the proportion of 1st-year terminations after the cost-cutting policy.

Should it be found that there is a statistically significant difference between the periods before and after the cost-cutting policy period, and then each period will be tested to determine if either differs statistically from the cost-cutting period and the following two hypotheses are tested. Figure 3-12 illustrates the periods examined by the next two hypothesis tests. 


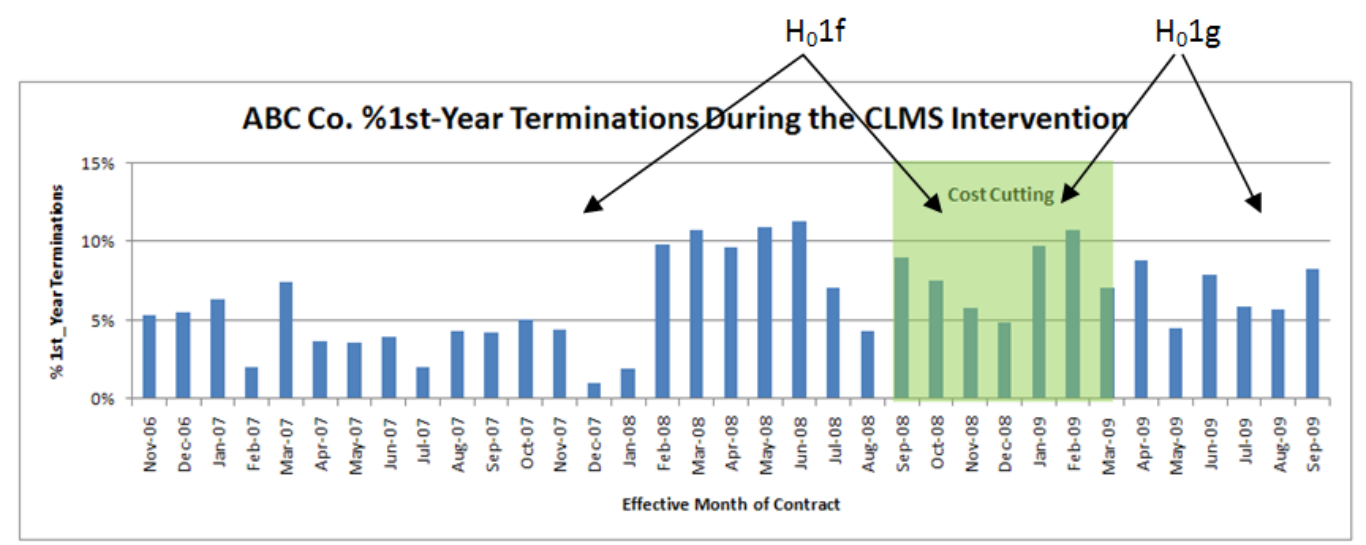

Figure 3-12: Pre and During Cost-Cutting, $\mathrm{H}_{0} 1 \mathrm{f}$; Post and During Cost-Cutting, $\mathrm{H}_{0} 1 \mathrm{~g}$

\section{$\underline{\mathrm{H}}_{\mathrm{o}} \underline{1 \mathrm{f} \text { Pre Cost-cutting -During Cost-cutting }}$}

$\mathbf{H}_{\mathbf{0}}$ 1f The proportion of 1st-year terminations during the cost-cutting policy equals the proportion of 1st-year terminations before the cost-cutting policy.

\section{$\underline{H}_{0} \underline{1 g}$ Post Cost Cutting - During Cost Cutting}

$\mathbf{H}_{\mathbf{0}} \mathbf{1 g}$ The proportion of 1st-year terminations during the cost-cutting policy equals the proportion of 1st-year terminations after the cost-cutting policy.

If, however, there is no statistically significant difference in the Proportion of 1st-year terminations between the before and after cost-cutting periods, then the two periods may be aggregated and tested against the cost-cutting period. Figure 3-13 below illustrates the periods examined by the next hypothesis test. 


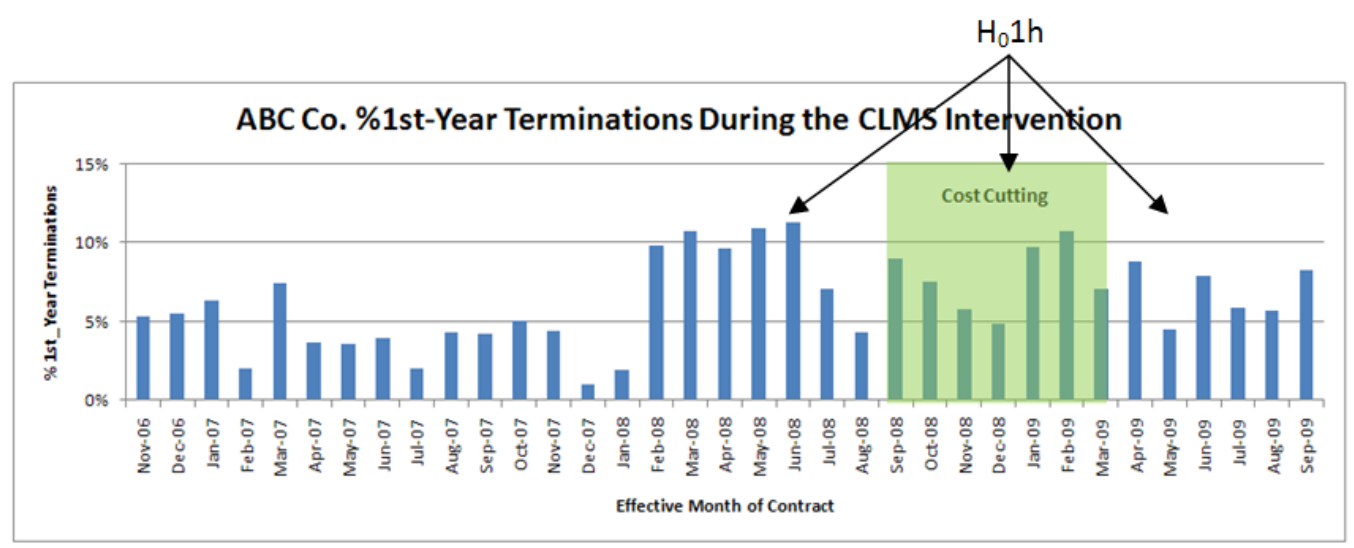

Figure 3-13: Pre and During Cost-Cutting Aggregated and During Cost-Cutting, $\mathrm{H}_{0} 1 \mathrm{~h}$

\section{$\underline{\mathrm{H}}_{\mathrm{o}} \underline{\mathrm{h} \text { Inside-Outside the Cost Cutting }}$}

$\mathbf{H}_{\mathbf{0}} \mathbf{1 h}$ The proportion of 1st-year terminations during the cost cutting policy equals the proportion of 1st-yr. terminations outside cost cutting policy.

\section{$\underline{\text { Summary }}$}

In the preceding paragraphs, the effects of confounding factors are discussed. There are two possible confounding factors that could lessen the experiment's accuracy and / or repeatability or obscure the interpretation of results. They are the Great Recession and cost-cutting activities at ABC Company. Should analysis of either of these two events find them to be confounding factors, i.e., differ significantly from the remainder of the sample, then the sample will be adjusted to control for the confounding effect(s) by 
eliminating the data from the sample and the following hypotheses are used to answer research questions $1-4$.

\section{$\underline{H_{0}} \underline{1}$ (controlled) Pre / Post Intervention}

$\mathbf{H}_{\mathbf{0}} \mathbf{1}$ (controlled) The proportion of 1 st-year terminations of all new customers before the CLSM intervention equals the proportion of 1st-yr. terminations of new customers in the period after the CLSM intervention controlled for the confounding factor(s).

\section{Hypothesis for Research Question 2}

Research question 2 asks if the CLSM intervention increased the loyalty of targeted customers (by decreasing defections) over all others. Transactions occur contemporaneously among targeted and non-targeted customers in the post intervention period. The environment, in which these transactions occur, although possibly affected by confounding factors, would influence the behavior of customers similarly and therefore data in periods impacted by confounding factors were not eliminated. To answer research question 2 , the following hypothesis test is used.

\section{$\underline{\mathrm{H}_{0}} \underline{2}$ Targeted / Non-targeted Customers}

$\mathbf{H}_{\mathbf{0}} \mathbf{2}$ The proportion of 1st-year terminations of all new targeted customers in the postintervention is greater than or equal to the proportion of 1 st-yr. terminations of all other new non-targeted customers in the post-intervention period. 


\section{$\underline{\text { Hypotheses for Research Question } 3}$}

Research question 3 asks if the CLSM intervention increased the loyalty of customer survey respondents (by decreasing customer defections) whose issues were resolved by employee contacts. These survey respondents were determined by their survey response scores to be less-than-satisfied customers, were contacted by front-line employees, and the "Resolution" status indicating a successful problem resolution was reported in the CLSM database.

Examination of the CLSM intervention's effect on customers who were contacted and whose issues were resolved is compared against customers not impacted at all by the intervention, the pre-intervention customers. Because these groups are not contemporaneous, the post-intervention examination period will necessarily be modified by removing data impacted by either confounding factor discussed above.

\section{$\underline{H}_{0} \underline{3 \text { Resolved Contacts }}$}

$\mathbf{H}_{\mathbf{0}} 3$ The proportion of 1st-year terminations of all new customers in the preintervention period is less than or equal to the proportion of 1 st-year terminations of new customers in the post-intervention period controlled for confounding factors who 
were contacted by front-line personnel and whose issues were reported as resolved in the CLSM database.

\section{Hypotheses for Research Question 4}

Research question 4 asks if the CLSM intervention decreased the loyalty (by increasing customer defections) of customer survey respondents whose issues were not resolved by employee contacts. These survey respondents were determined by their survey response scores to be less-than-satisfied customers, were contacted by front-line employees, and the "Resolution" status did not indicate a successful problem resolution in the CLSM database.

Examination of the CLSM intervention's effect on customers who were contacted and whose issues were not resolved was compared against customers not impacted at all by the intervention, the pre-intervention customers. Because these groups are not contemporaneous, the post-intervention examination period will necessarily be modified by removing data impacted by either confounding factor discussed above.

\section{$\underline{\mathrm{H}_{0}} \underline{4} \underline{\text { Unresolved Contacts }}$}

$\mathbf{H}_{\mathbf{0}} 4$ The proportion of 1st-year terminations of all new customers in the pre- intervention period is greater than or equal to the proportion of 1 st-year terminations of new customers in the post-intervention period controlled for confounding factors who were 
contacted by front-line personnel and whose issues were not reported as resolved in the CLSM database.

\section{Binomial Proportion Z-tests}

This research uses binomial proportion z-tests in the analysis. The test determines whether the hypothesized difference between a benchmark, i.e. non-intervention proportion, differs significantly from a sample (intervention) proportion (figure 3-13 below).

$$
\text { Test Statistic }=\frac{\hat{p}-P H_{0}}{\sqrt{\frac{P H_{0} *\left(1-P H_{0}\right)}{n-1}}}
$$

Figure 3-14: Formula for One Sample Binomial Proportion Test Statistic

Where $\hat{\mathrm{p}}$ is the proportion from sampled (intervention) data, $\mathrm{PH}_{0}$ is the proportion of the null hypothesis (benchmark), and $\mathrm{n}=$ the sample size. If the $\mid$ Test Statistic $\mid>$ critical zvalue, reject the null hypothesis. This analysis applies a confidence level of $95 \%$ and uses both one-tailed and two-tailed tests (depending on the null hypothesis) and infinite degrees of freedom. 
It is appropriate to use the two-proportion z-test when the populations are independent, when $\mathrm{n}=>30$, and $\mathrm{P} * \mathrm{n}>4$ and $(1-\mathrm{P}) * \mathrm{n}>4$, (McDaniel and Roger, 2005). These conditions are met for all hypothesis tests described in this section.

\section{3-5: Summary}

This research methodology uses a measure of customer loyalty $\left(1^{\text {st }}\right.$-year terminations $)$ in a field experiment to answer four research questions:

1. Does CLSM decrease customer defections?

2. Does CLSM decrease the defections of targeted customers more than that of other customers?

3. Does the successful use of CLSM to proactively resolve potential customer issues decrease defections?

4. Does the unsuccessful use of CLSM to proactively resolve potential customer issues increase defections?

The analysis applies the binomial z-test of proportions to the Proportion of 1st-year terminations to test the hypotheses. The tests reject or fail to reject the null hypotheses that:

1. There is a difference in customer defections from before and after the CLSM intervention, 
2. There is a difference in defections during periods impacted by confounding factors,

3. There is a difference in post-intervention defections among targeted and nontargeted customers,

4. There is a difference in customer defections among contacted customer survey respondents whose issues were resolved, and

5. There is a difference in customer defections among contacted customer survey respondents whose issues were not resolved. 


\section{CHAPTER 4: RESEARCH FINDINGS}

\section{1: Introduction}

The previous chapter described the method used to answer five research questions about the CLSM model. This chapter presents the results from the hypothesis tests used to answer these questions. The analysis applied a z-test of proportions to determine if the proportion of 1 st-fear terminations was changed by the intervention. The discussion of these test results is organized around the four research questions:

1. Does CLSM decrease customer defections?

2. Does CLSM decrease defections of targeted customers over that of all other, nontargeted customers?

3. Does the successful use of CLSM to resolve customer problems decrease customer defections?

4. Does the unsuccessful use of CLSM to resolve customer problems increase customer defections?

Each section that follows includes:

1. the hypothesis,

2. the results are presented including a confidence interval diagram; and

3. a brief summary.

\section{4-2: Test Results for Research Question 1}

Hypothesis tests associated with research question 1 were initially applied to the pre-post intervention differences without adjusting the data to control for confounding factors. 
This is followed by the same test but with data adjusted to eliminate the effect of confounding factors.

The first hypothesis test is:

$\mathbf{H}_{\mathbf{0}} \mathbf{1}$ The Proportion of 1 st-year terminations of all new customers before the CLSM intervention is less than or equal to the proportion of 1 st-year terminations of new customers in the period after the CLSM intervention.

Findings: The null hypothesis is rejected. The analysis found that there was a statistically significant difference in the metric before and after the intervention. The CLSM intervention produced a statistically significant lower proportion of 1st-year terminations than was measured before the intervention. The proportion of 1st-year terminations from the pre-intervention period $(10 / 1 / 2002-10 / 31 / 2006)$ is $\mathrm{P}=7.5 \%$, but afterward, from $11 / 1 / 2006-8 / 31 / 2009$, the proportion of 1 st-year terminations was $\widehat{\mathrm{p}}=6.0 \%$. The $\mid$ Test Statistic $\mid$ is 5.36. This is greater than the critical z-value 1.64 , the level of a statistical significance with a $95 \%$ confidence interval for a one-tail test (figure 4-1, below). 


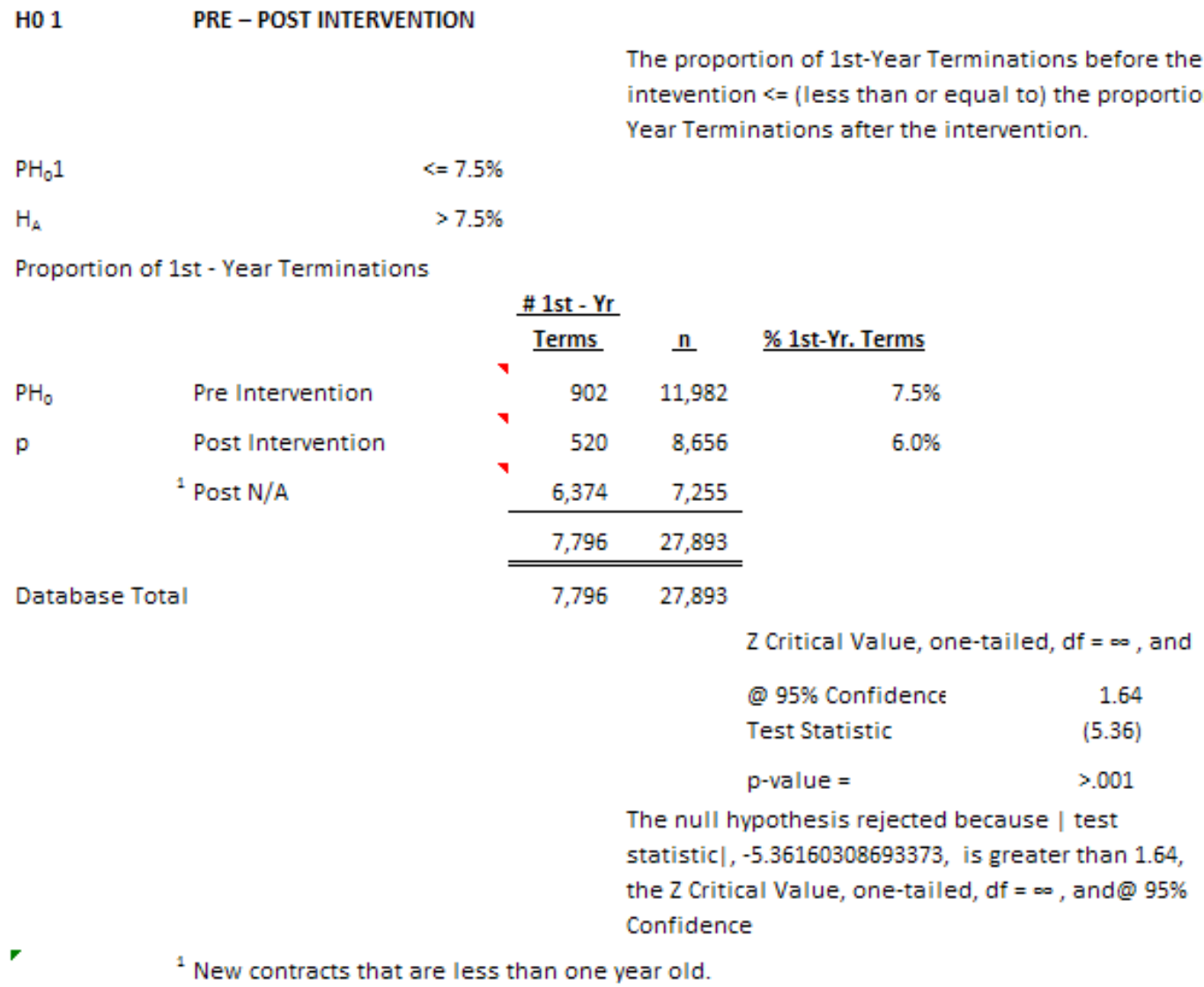

Figure 4-1: Pre-Post Intervention Binomial Single-proportion Significance Test Calculations

Because the data from both the pre and post intervention period contain variability, a second binomial proportion z-test is applied that accounts for variability within the proportions taken from two independent samples (figure 4-2, below). 


\section{Two-proportion z-test}

$\begin{array}{llll}\mathrm{H}_{0} & \mathrm{p}_{1} & <= & \mathrm{p}_{2} \\ \mathrm{H}_{\mathrm{a}} & \mathrm{p}_{1} & > & \mathrm{p}_{2} \\ \text { Level of Significance }= & 0.05 & & \end{array}$

Pre Intervention

\section{Post Intervention}

$\begin{array}{lrr}\mathrm{n} & 11,982 & 8,656 \\ \mathrm{p} & 7.5 \% & 6.0 \%\end{array}$

$$
\begin{array}{lc}
\mathrm{p}= & 0.068902025 \\
\mathrm{SE}= & 0.003572928 \\
\mathrm{z}= & 4.255795495 \\
\mathrm{p} \text {-value }= & 1.04154 \mathrm{E}-05 \\
& \text { Reject the Null Hypothesis }
\end{array}
$$

Figure 4-2: Pre-Post Intervention Binomial Two-proportion Significance Test Calculations

In figure 4-3 below, the confidence interval diagram illustrates the range of values that estimated the pre-intervention (Before) population proportion of 1st-year terminations and was compared with the CLMS post-intervention (After) population proportion estimate.

All of the following confidence interval graphs report the range of values from a minimum value to a maximum value based on the following formulae:

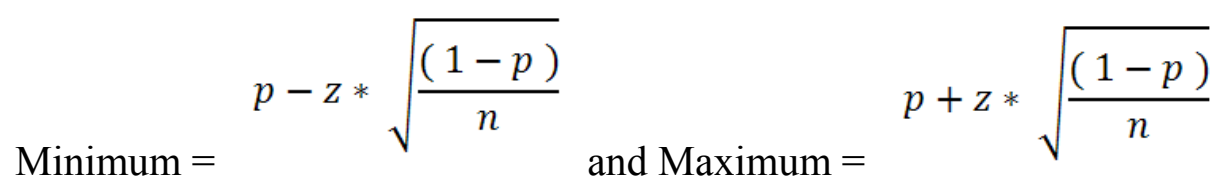


Where $\mathrm{p}=$ the proportion of the sample; $\mathrm{z}=$ the $\mathrm{z}$-critical value (1.64 for one-tailed tests with .05 significance and 1.96 for two-tailed test with .05 significance) and $n=$ the sample size.

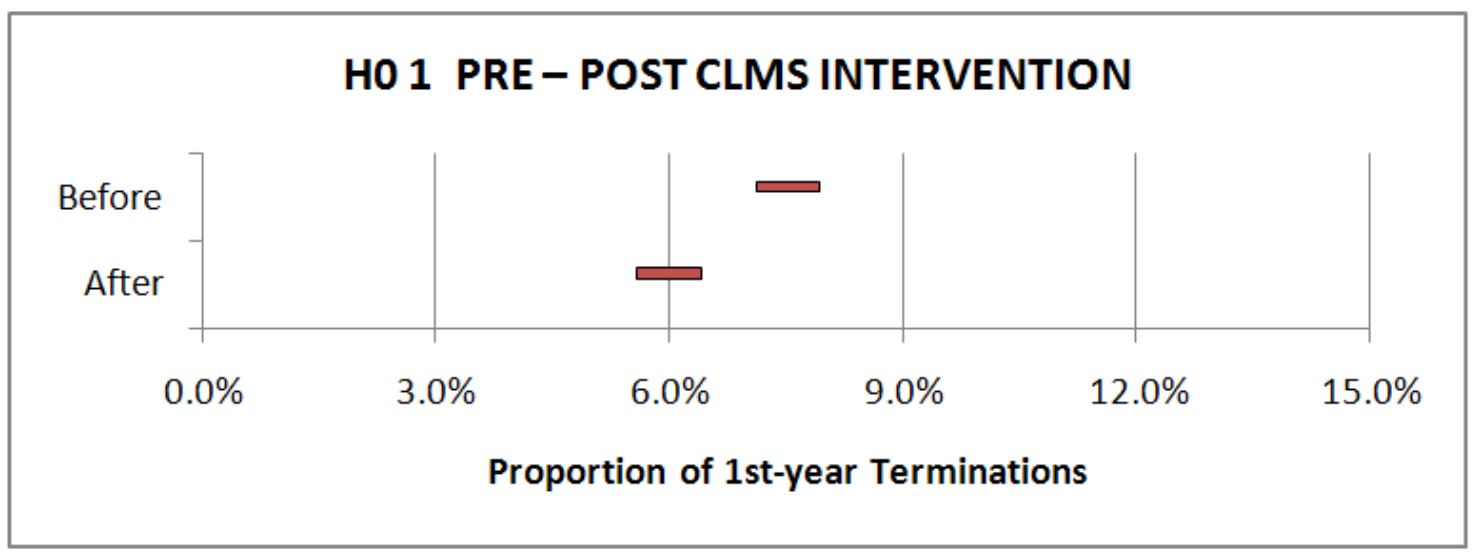

Figure 4-3: Pre-Post Intervention 1st-Year Terminations Confidence Intervals

$$
\left(\mathrm{n}_{\text {Before }}=11,982 ; \mathrm{n}_{\text {After }}=8,656\right)
$$

The estimated range of values for the proportion of $1^{\text {st }}$-Year Termination for new customers affected by CLSM was less than the estimate for new customers before CLSM.

Next, the same hypothesis test is presented, but this time the analysis controls for confounding factors. The tests that determined the data correction used to control for confounding factors is discussed in the next section.

$\mathbf{H}_{\mathbf{0}} \mathbf{1}$ (controlled): The proportion of 1st-year terminations of all new customers before the CLSM intervention is less than or equal to the proportion of 1 st-year terminations 
of new customers in the period after the CLSM intervention controlling for confounding factors.

Findings: The null hypothesis is rejected. The analysis found that there is a statistically significant difference in the metric before and after the intervention.

The CLSM intervention produced a statistically significant lower Proportion of 1st-year terminations than was measured before the intervention. The proportion of 1 st-year terminations from the pre-intervention period $(10 / 1 / 2002-10 / 31 / 2006)$ is $\mathrm{PH}_{0}=7.5 \%$, but afterward, from $11 / 1 / 06-11 / 30 / 2007$, the proportion of 1 st-year terminations was $\widehat{p}=4.5 \%$. The $\mid$ Test Statistic $\mid$ is 6.52 . This is greater that the critical z-value 1.64 , the level of a statistical significance with a $95 \%$ confidence interval for a one-tail test (figure 4-4, below). 


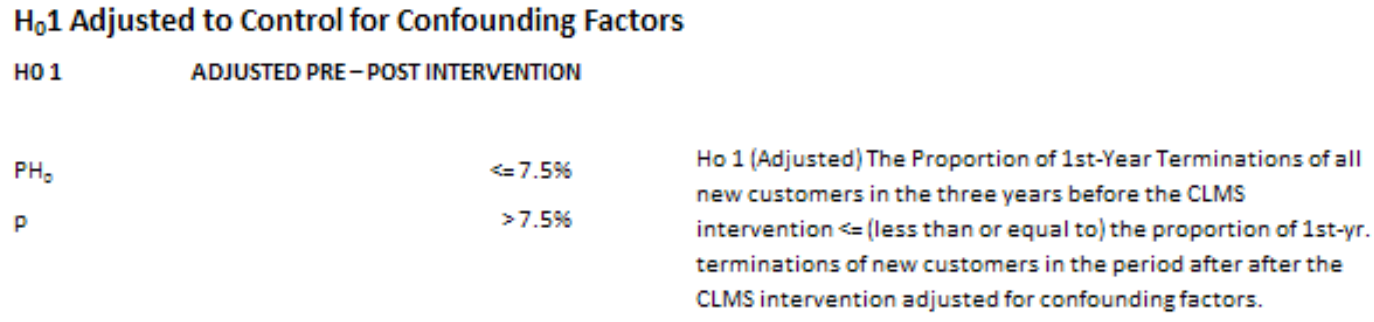

Figure 4-4: Adjusted Pre-Post Intervention Binomial Single-proportion Significance Test Calculations

Because the data from both the pre and post intervention period contain variability, a second binomial proportion z-test is applied that accounts for variability within the proportions taken from two independent samples (figure 4-5, below). 


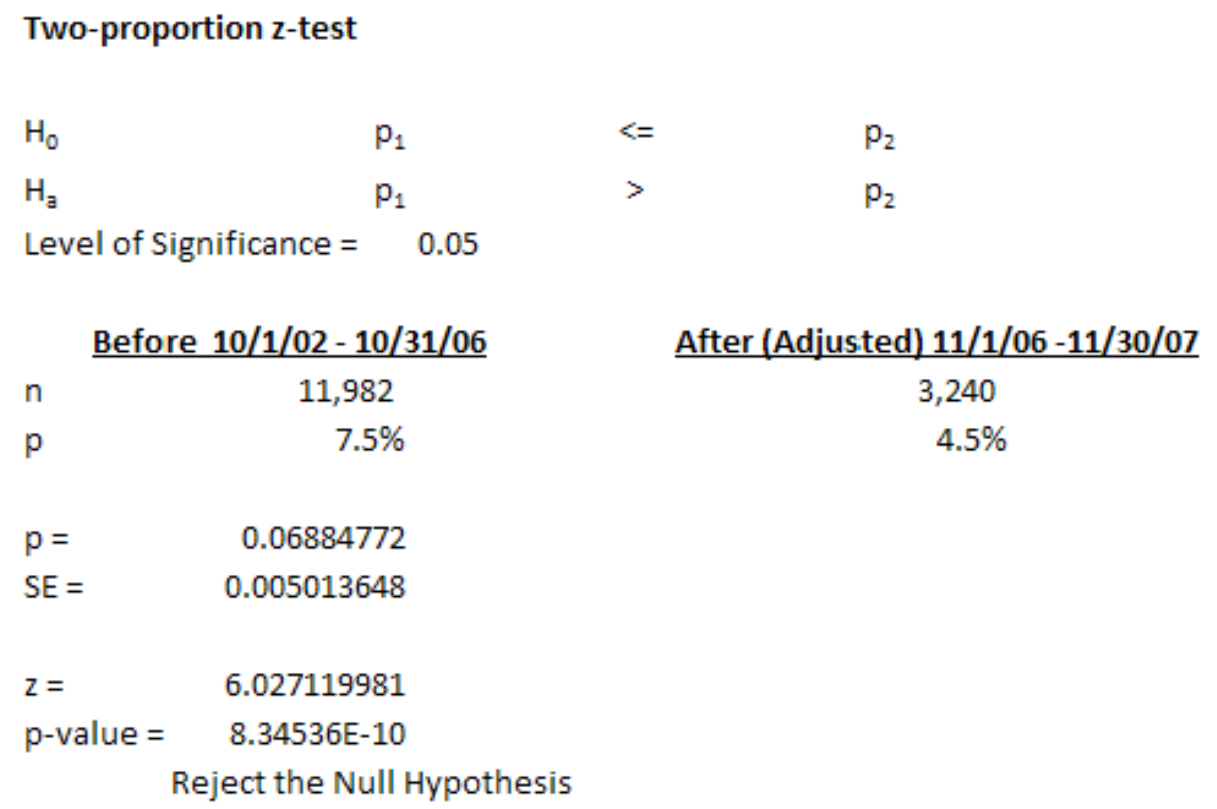

Figure 4-5: Pre-Post Intervention Binomial Two-proportion Significance Test Calculations

In figure 4-6 below, the confidence interval diagram illustrates the range of values that estimated the controlled pre-intervention (Before) population proportion of 1st-year terminations compared with the CLSM post-intervention (After) population proportion estimate. 


\section{HO 1 ADJ PRE - POST INTERVENTION CONTROLLED FOR CONFOUNDING FACTORS}

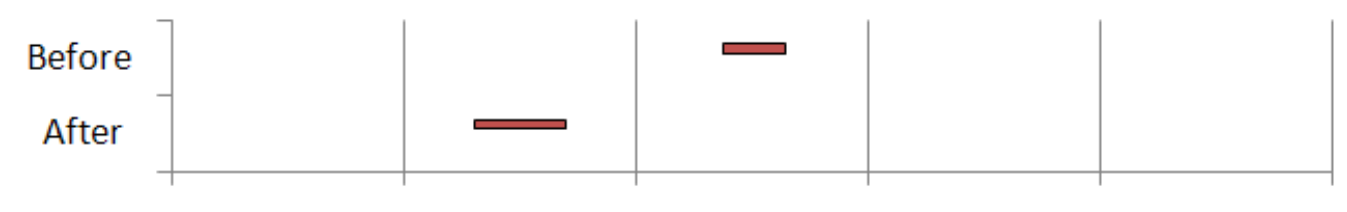
$0.0 \%$
$3.0 \%$
$6.0 \%$
$9.0 \%$
$12.0 \%$
$15.0 \%$
Proportion of 1st-year Terminations

Figure 4-6: Pre-Post Intervention 1st-Year Terminations Confidence Intervals

$$
\left(\mathrm{n}_{\text {Before }}=11,982 ; \mathrm{n}_{\text {After }}=3,240\right)
$$

The estimated range of values for the proportion of $1^{\text {st }}$-year termination for new customers affected by the CLSM was less than the estimate for new customers before the CLSM intervention.

\section{4-3: Test Results Controlling for Confounding Factors}

As discussed in chapter 3, because this research is based upon data collected from a field experiment, a potential validity threat results from the impact of confounding factors upon the data. Two events were identified during the research as possible confounding factors, the Great Recession and the cost-cutting activity.

To compensate for this potential risk, the post intervention data is analyzed to determine if the proportion of $1^{\text {st }}$-year terminations metric is significantly affected by either or both events. If a significant difference was found, the data was removed from the post 
intervention period to control for the confounding factor. Following is a discussion of the analysis applied to these events.

\section{Great Recession}

To determine if the Great Recession was a confounding factor, hypothesis tests were applied to determine if a difference exists in the proportion of $1^{\text {st }}$-year terminations before and after, but not during the Great Recession period $\left(\mathrm{H}_{0} 1 \mathrm{a}\right)$.

\section{Pre-Post Great Recession}

$\mathbf{H}_{\mathbf{0}}$ 1a: The proportion of 1st-year terminations of all new customers in the period during the CLSM intervention, but before the recession is equal to the proportion of 1st-yr. terminations of new customers during the CLSM intervention, but after the recession. 
Figure 4-7 below illustrates the periods tested:

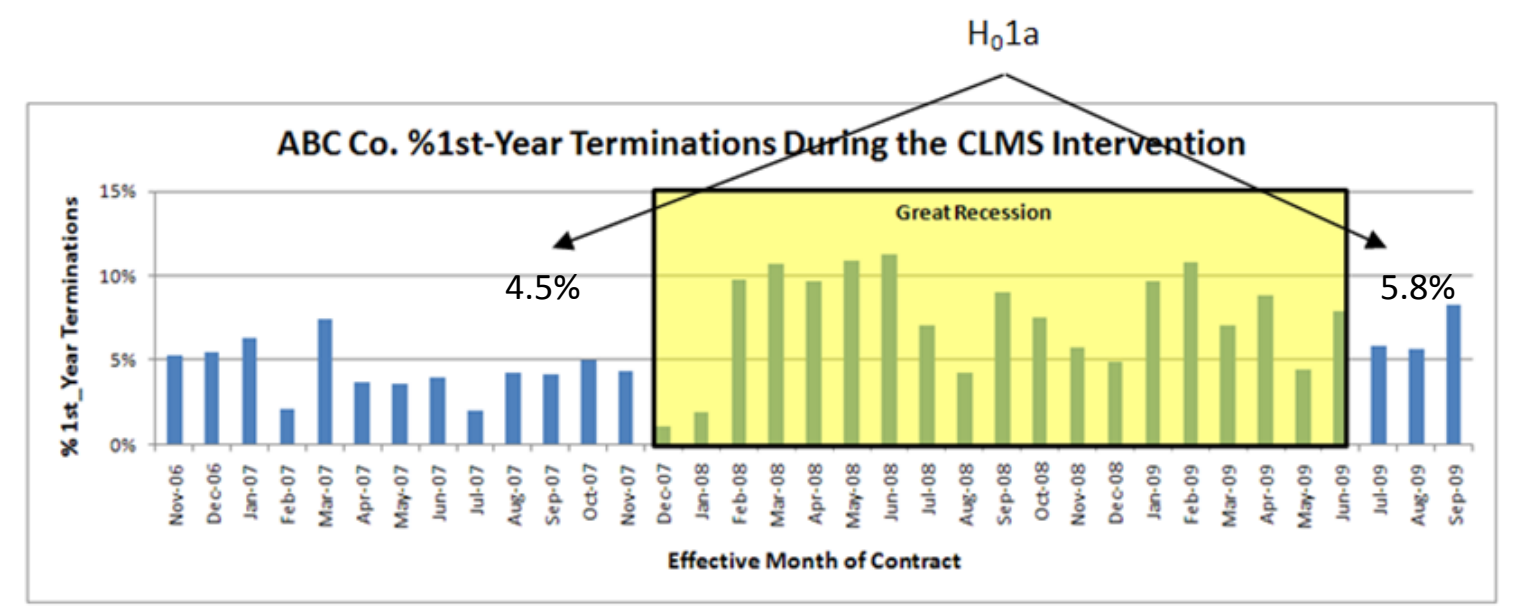

Figure 4-7: Pre-Post Great Recession, $\mathrm{H}_{0} 1 \mathrm{a}$ Test Periods

Findings: The null hypothesis is not rejected. The analysis found that there is no statistically significant difference in the metric before and after the recession. The proportion of 1 st-year terminations from the pre-recession period is $\mathrm{PH}_{0}=4.5 \%$. After the recession, the proportion of 1 st-year terminations is $\hat{p}=5.8 \%$. The $\mid$ Test Statistic $\mid$ is 1.90. This is not greater that the critical z-value 1.96, the level of a statistical significance with a $95 \%$ confidence interval for a two-tail test (figure $4-8$, below). 


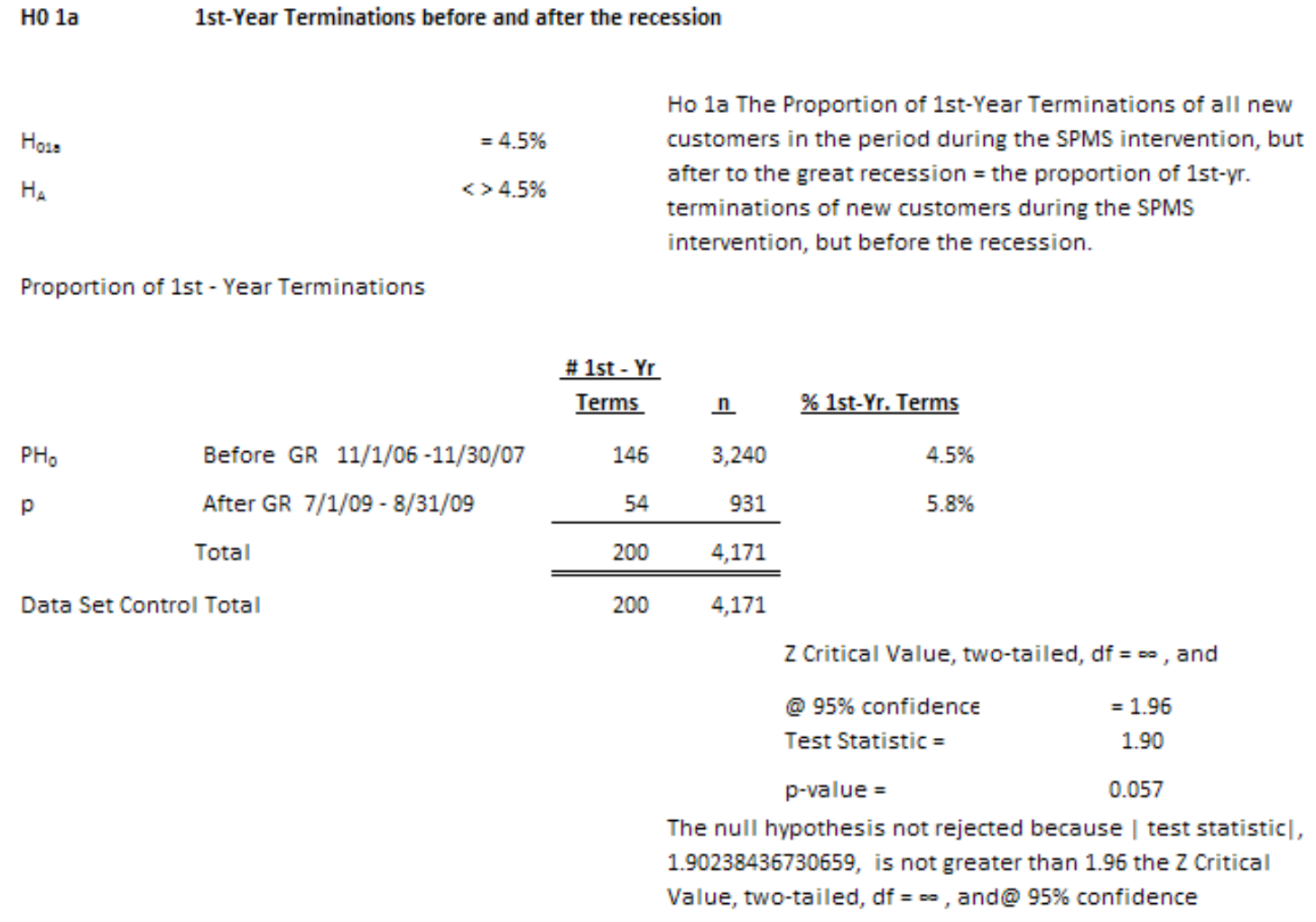

Figure 4-8: Before and After the Great Recession Binomial Single-proportion Significance Test Calculations

Because the data from both before and after the Great Recession contain variability, a second binomial proportion z-test is applied that accounts for variability within the proportions taken from two independent samples (figure 4-9, below). 
Two-proportion z-test

$\begin{array}{llll}\mathrm{H}_{0} & \mathrm{p}_{1} & = & \mathrm{p}_{2} \\ \mathrm{H}_{\mathrm{a}} & \mathrm{p}_{1} & < & \mathrm{p}_{2} \\ \text { Level of Significance }= & 0.05 & & \end{array}$

$\begin{array}{lcc}\text { Before GR } 11 / \mathbf{1 / 0 6 - 1 1 / 3 0 / 0 7} & \text { After GR } 7 / \mathbf{1 / 0 9 - 8 / 3 1 / 0 9} \\ \mathrm{n} & 3,240 & 931 \\ \mathrm{p} & 4.5 \% & 5.8 \%\end{array}$

$\mathrm{p}=\quad 0.047950132$

$\mathrm{SE}=\quad 0.007945066$

$z=\quad-1.628736638$

p-value $=0.103368783$

Cannot Reject the Null Hypothesis

Figure 4-9: Before and After the Great Recession Binomial Two-proportion Significance Test Calculations

In figure 4-10 below, the confidence interval diagram illustrates the range of values that estimate the proportion of 1st-year terminations before and after the Great Recession.

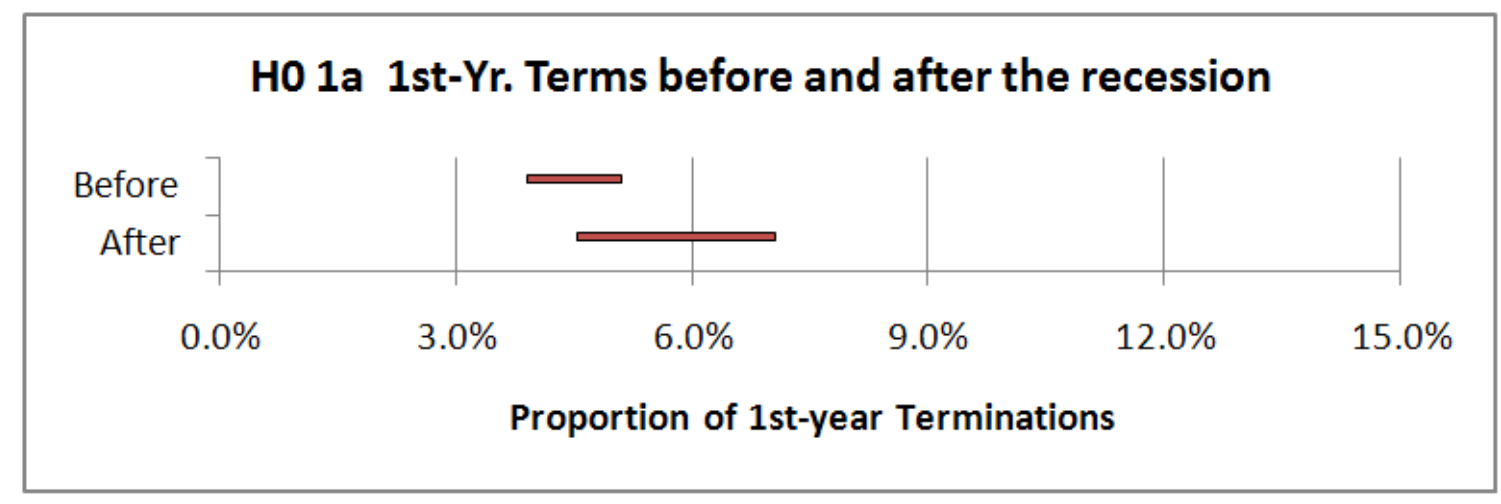

Figure 4-10: Before and After Great Recession $1^{\text {st }}$-Year Terminations Confidence Intervals $\left(\mathrm{n}_{\text {Before }}=3,240 ; \mathrm{n}_{\text {After }}=931\right)$ 
Because this test fails to reject Hola, the difference is not statistically significant; data from both the periods before and after the recession is aggregated. The hypothesis tests, $\mathrm{H}_{0} 1 \mathrm{~b}$ and $\mathrm{H}_{0} 1 \mathrm{c}$, described in chapter 3 , analyze the before period and after period separately against the Great Recession period, are unnecessary. The aggregated data set is used in the following hypothesis test to determine if the Great Recession is a confounding factor.

Customer Loyalty During and Outside the Great Recession

$\mathbf{H}_{\mathbf{0}} 1 \mathrm{~d}$ : The proportion of 1st-year terminations during the recession is equal to the proportion of 1st-yr. terminations outside of the recession.

Figure 4-11 below illustrates the periods tested:

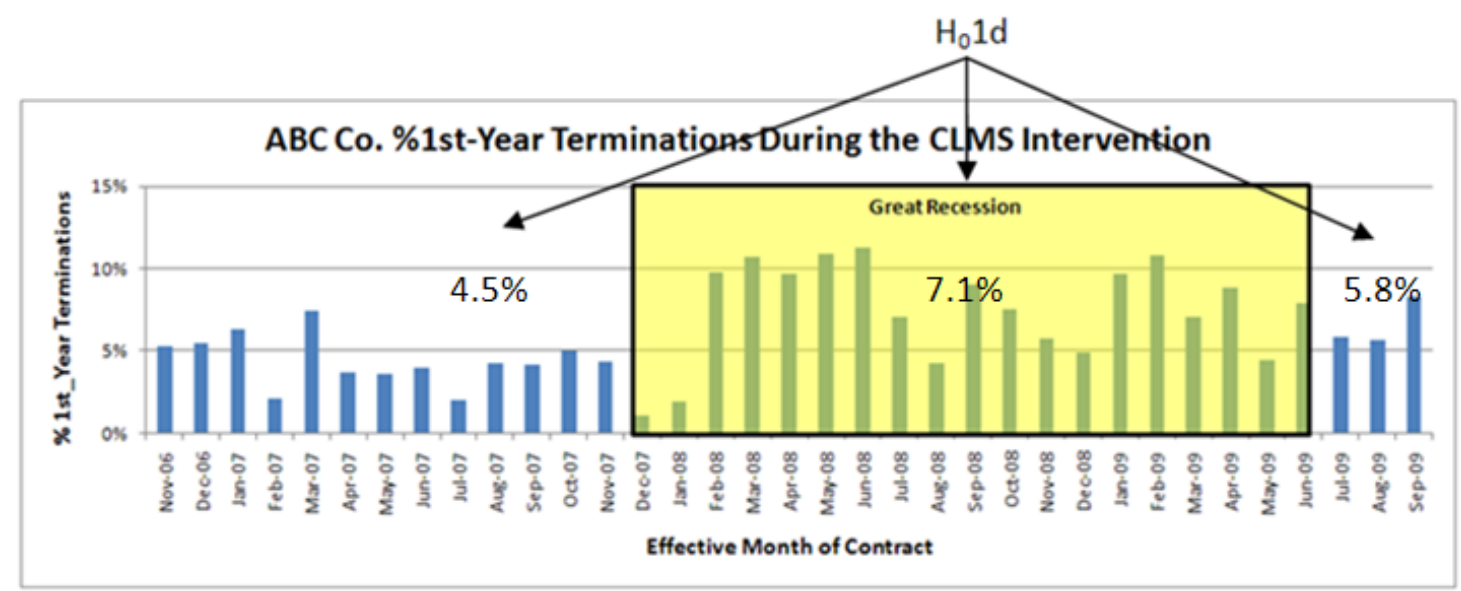

Figure 4-11: Aggregated Before and After Proportion of $1^{\text {st }}$-Year Terminations and Great Recession, H01d, Test Periods 
Findings: The null hypothesis is rejected. The analysis finds that there is a statistically significant difference in the metric during the recession period and outside it. Aggregating the data before the recession (4.5\%) with the data afterward (5.8\%) gives a combined proportion of $1^{\text {st }}$ year terminations from the aggregated non-recession periods of $\hat{p}=4.8 \%$. During the recession, the proportion of 1 st-year terminations is $\mathrm{PH}_{0}=7.1 \%$. The $\mid$ Test Statistic| is 5.87. This is greater that the critical z-value 1.96, the level of a statistical significance with a 95\% confidence interval for a two-tail test (figure 4-12, below).

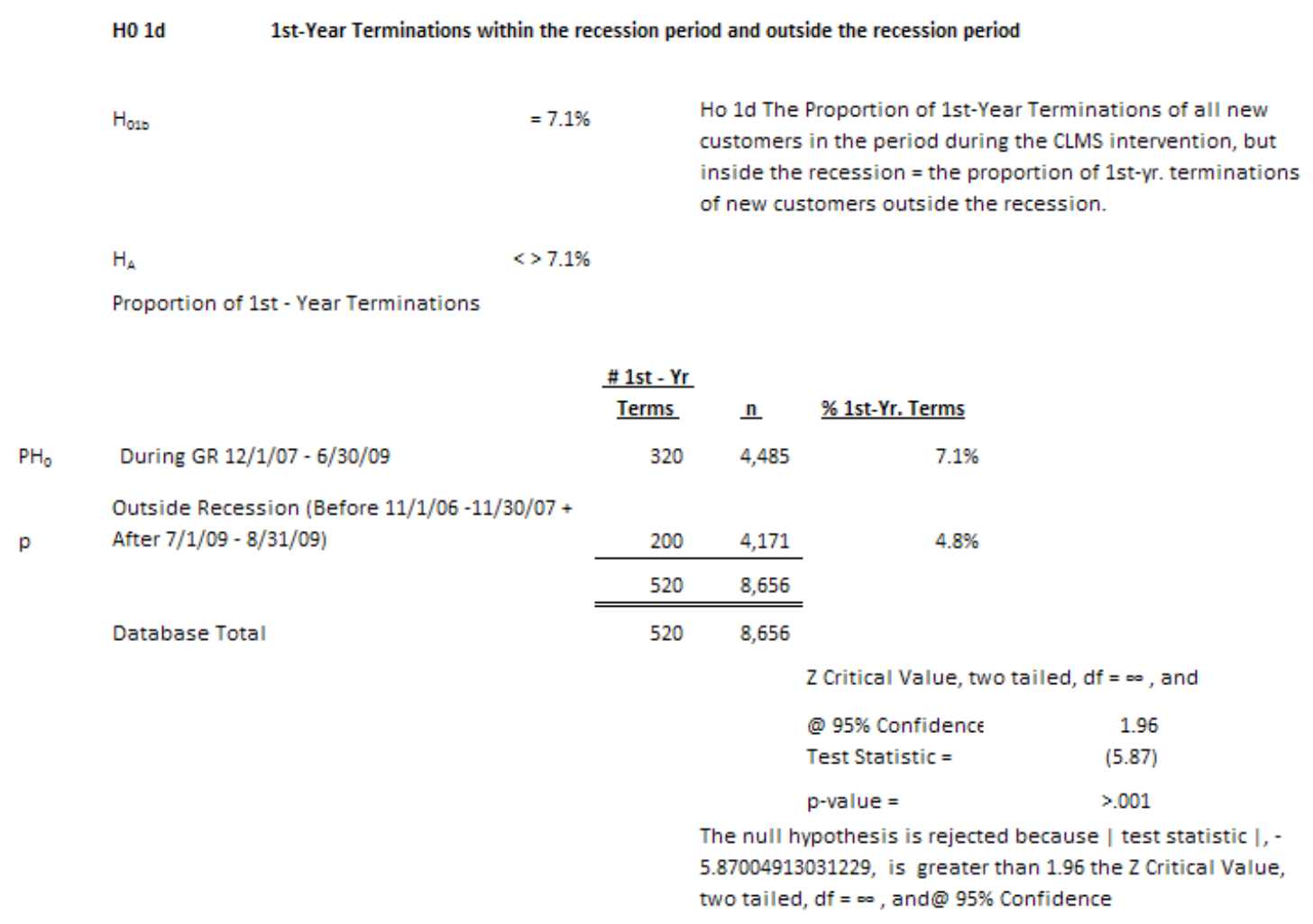

Figure 4-12: During and Outside the Great Recession Binomial Single-proportion Significance Test Calculations 
Because the data from both during and outside the Great Recession contain variability, a second binomial proportion z-test is applied that accounts for variability within the proportions taken from two independent samples (figure 4-13, below).

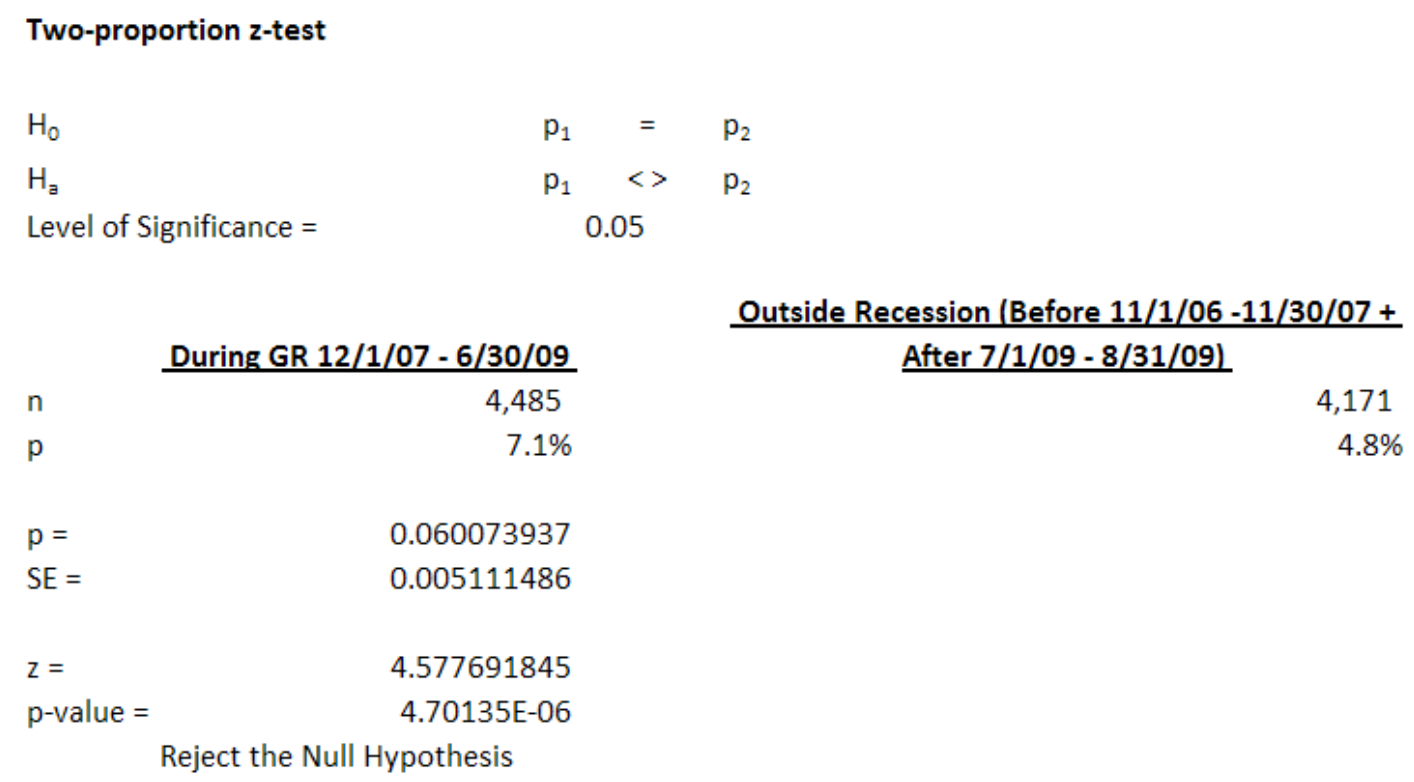

Figure 4-13: During and Outside the Great Recession Binomial Two-proportion Significance Test Calculations

In figure 4-14 below, the confidence interval diagram illustrates the range of values that estimate the proportion of 1st-year terminations during and outside the Great Recession. 


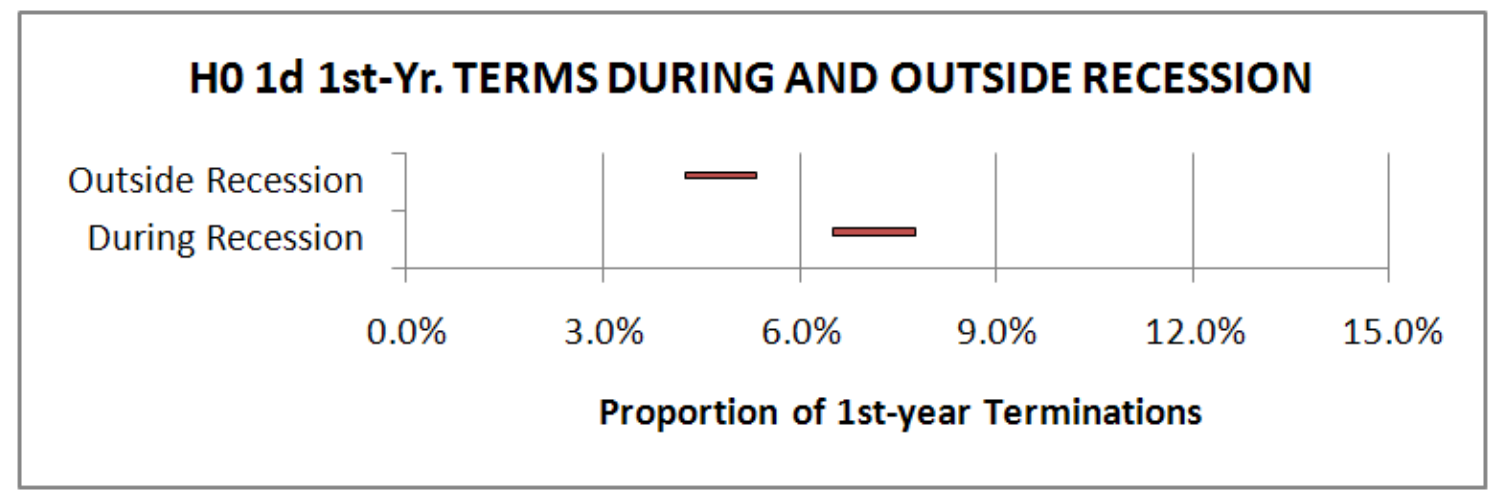

Figure 4-14: During-Outside Great Recession $1^{\text {st }}$-Year Terminations Confidence Intervals $\left(\mathrm{n}_{\text {During }}=4,485 ; \mathrm{n}_{\text {Outside }}=4,171\right)$

Summary

Rejecting the null hypothesis, $\mathrm{H}_{0} 1 \mathrm{~d}$, means that the customer loyalty behavior during the Great Recession is statistically different from the behavior before and after it. Therefore, the Great Recession was a confounding factor and that data was eliminated from the field experiment.

\section{Cost-cutting}

The second possible confounding factor requiring investigation is the effect of costcutting actions that ABC Company's management implements in September, 2008 March, 2009. The next hypothesis test determines if there is a statistically significant difference in customer loyalty in periods before and after the cost-cutting policy. As with the previous tests of the Great Recession, this hypothesis test determined if the data from these two periods may be aggregated (fail to reject $\mathrm{H}_{0}$ ) or treated separately (reject $\mathrm{H}_{0}$ ). 


\section{Customer Loyalty Before and After the Cost-cutting Policy}

$\mathbf{H}_{\mathbf{0}}$ 1e: The proportion of 1st-year terminations of all new customers before the cost cutting is equal to the proportion of 1 st-year terminations of all new customers after the cost-cutting. Figure 4-15 below illustrates the periods tested:

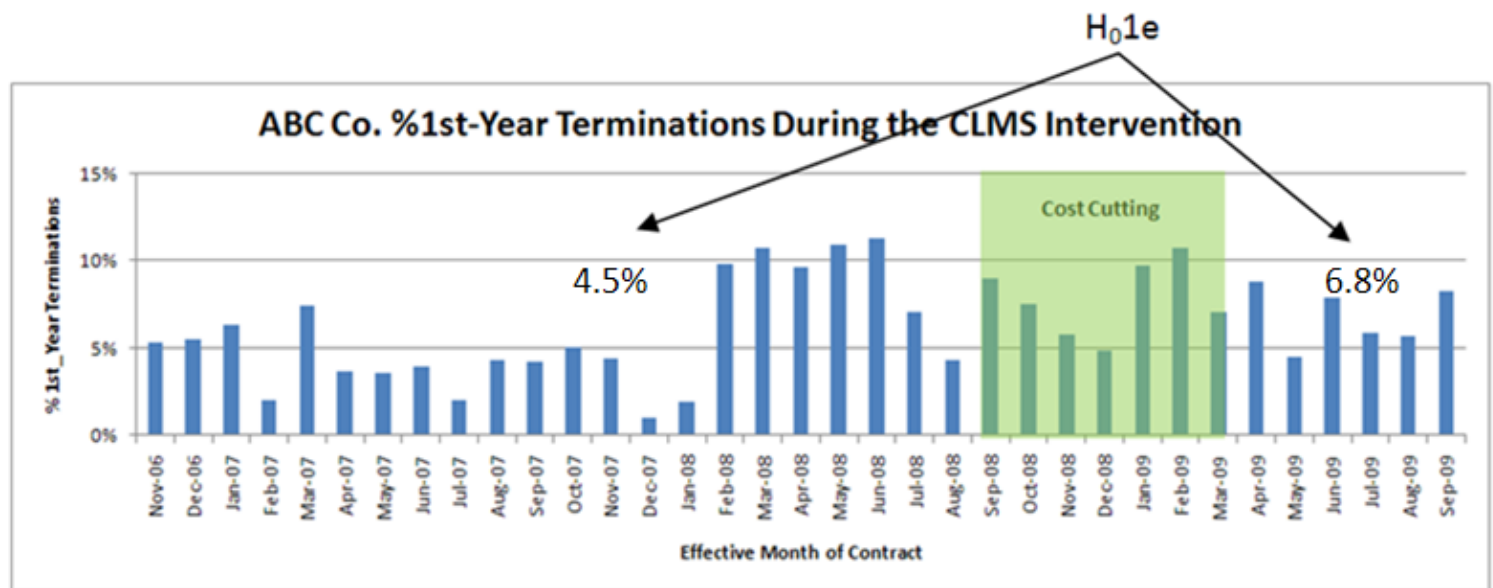

Figure 4-15: Before and After Proportion of $1^{\text {st }}$-Year Terminations and Cost Cutting, H01d, Test Periods

Findings: The null hypothesis is rejected. The analysis finds that there is a statistically significant difference in the metric from before the cost-cutting period and after it. The proportion of 1 st-year terminations after the policy was $\hat{p}=6.8 \%$. Before the cost-cutting policy, the proportion of 1st-year terminations was $\mathrm{PH}_{0}=4.5 \%$. This was a statistically significant difference. The $\mid$ Test Statistic $\mid$ is 5.53 . This is greater that 
the critical z-value 1.96 , the level of a statistical significance with a $95 \%$ confidence interval for a two-tail test (figure 4-16, below).

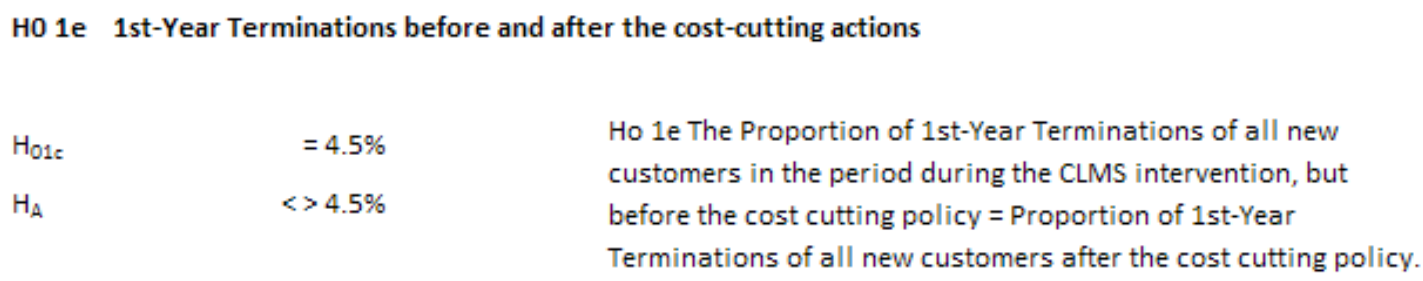

Figure 4-16: Before and After Cost Cutting Binomial Single-proportion Significance Test Calculations

Because the data from both before and after the cost cutting activities contain variability, a second binomial proportion z-test is applied that accounts for variability within the proportions taken from two independent samples (figure 4-17, below). 


\section{Two-proportion z-test}

$\begin{array}{lcc}\mathrm{H}_{0} & \mathrm{p}_{1}= & \mathrm{p}_{2} \\ \mathrm{H}_{\mathrm{a}} & \mathrm{p}_{1} \quad \mathrm{p}_{2} \\ \text { Level of Significance }= & 0.05 & \end{array}$

$\begin{array}{lrr} & \begin{array}{lr}\text { Before Cost- } \\ \text { cutting }\end{array} & \frac{\text { After Cost- }}{\text { cutting }} \\ \mathrm{n} & 2,815 & 2,445 \\ \mathrm{p} & 4.5 \% & 6.8 \% \\ \mathrm{p}= & 0.055513308 & \\ \mathrm{SE}= & 0.006330102 & \\ \mathrm{z}= & -3.654514093 \\ \mathrm{p}-\text {-value }= & 0.00025767 \\ & \text { Reject the Null Hypothesis }\end{array}$

Figure 4-17: Before and After Cost Cutting Binomial Two-proportion Significance Test Calculations

In figure 4-18 below, the confidence interval diagram illustrates the range of values that estimate the proportion of 1 st-year terminations before and after the cost-cutting policy.

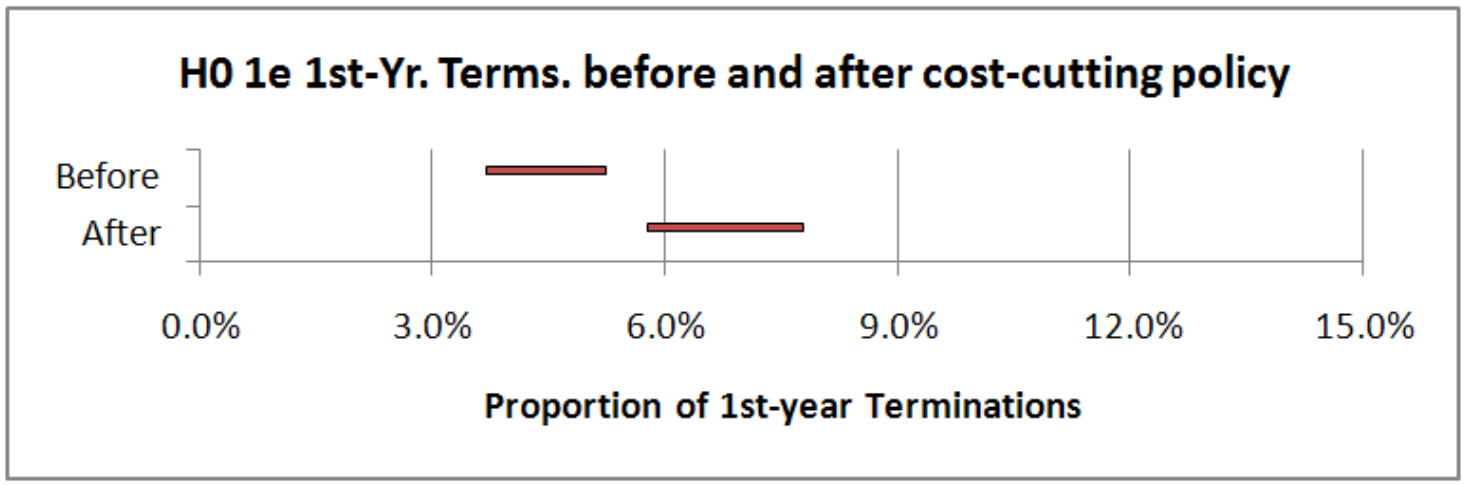

Figure 4-18: Before-After Cost Cutting $1^{\text {st }}$-Year Terminations Confidence Intervals $\left(\mathrm{n}_{\text {Before }}=2,815 ; \mathrm{n}_{\text {After }}=2,445\right)$ 
Having established that the proportion of $1^{\text {st }}$-year terminations significantly increased (loyalty decreased) in the period following the cost cutting policy from the measure before the cost-cutting, the next hypothesis test seeks to determine if there was a difference in the proportion of 1st-year terminations before and during the cost cutting policy.

Customer Loyalty Before and During the Cost-cutting Policy

$\mathbf{H}_{\mathbf{0}}$ 1f: The proportion of 1st-year terminations of all new customers before the cost cutting is equal to the proportion of 1st-year terminations of all new customers during the cost-cutting. Figure 4-19 below illustrates the periods tested:

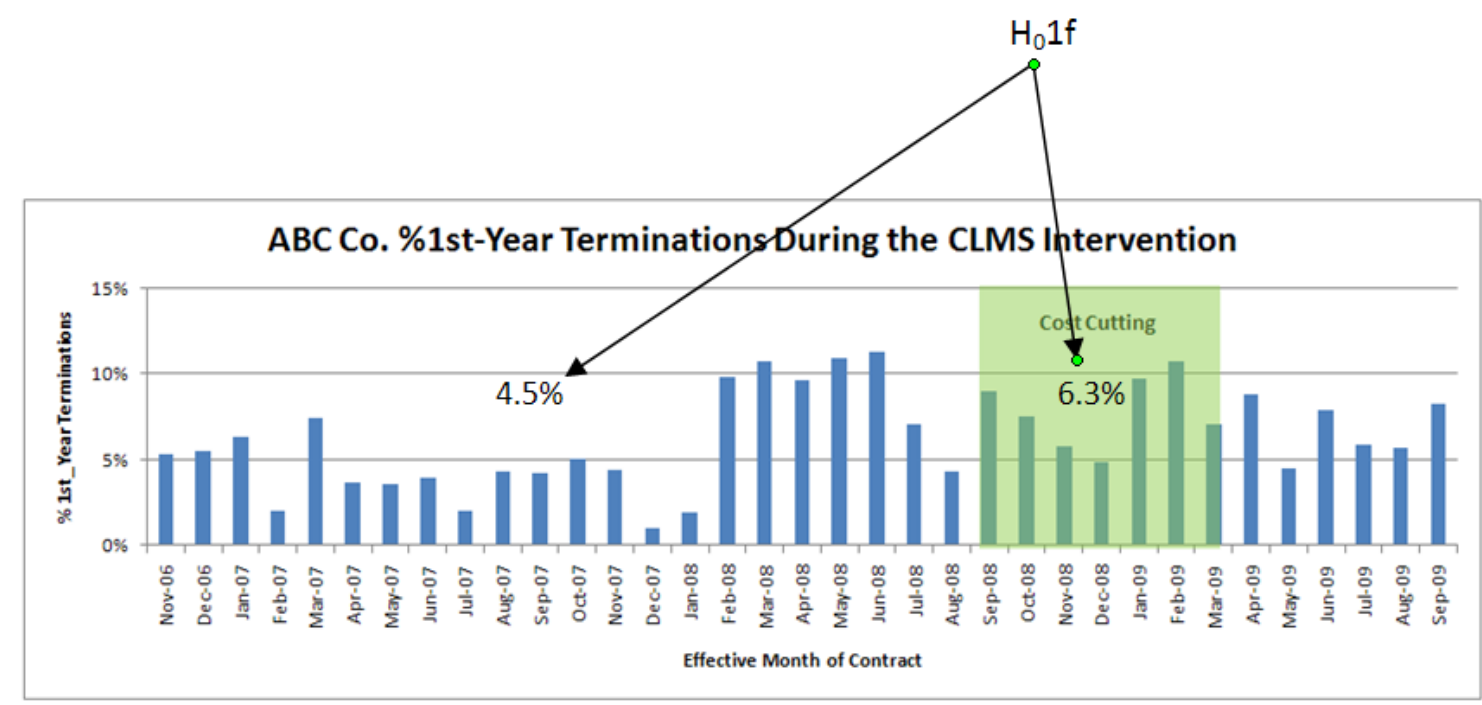

Figure 4-19: Proportion of $1^{\text {st }}$-Year Terminations Before and During Cost Cutting, H01f, Test Periods

Findings: The null hypothesis is rejected. The analysis finds that there is a statistically significant difference in the metric from before the cost-cutting period and 
during it. The Proportion of 1st-year terminations in the period before the cost-cutting is $\hat{p}=4.5 \%$. During the cost-cutting policy, the proportion of 1 st-year terminations is $\mathrm{P}=$ $6.3 \%$. This was a statistically significant difference. The $\mid$ Test Statistic $\mid$ is 3.93. This is greater that the critical z-value 1.96, the level of a statistical significance with a $95 \%$ confidence interval for a two-tail test (figure 4-20, below).

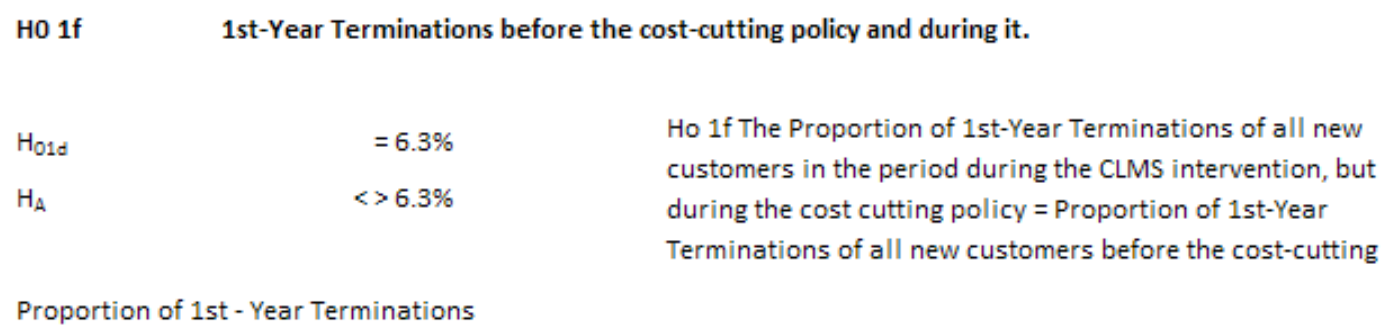

Figure 4-20: Before and During Cost Cutting Binomial Single-proportion Significance Test Calculations 
Because the data from both before and during the cost cutting activities contain variability, a second binomial proportion z-test is applied that accounts for variability within the proportions taken from two independent samples (figure 4-21, below).

\section{Two-proportion z-test}

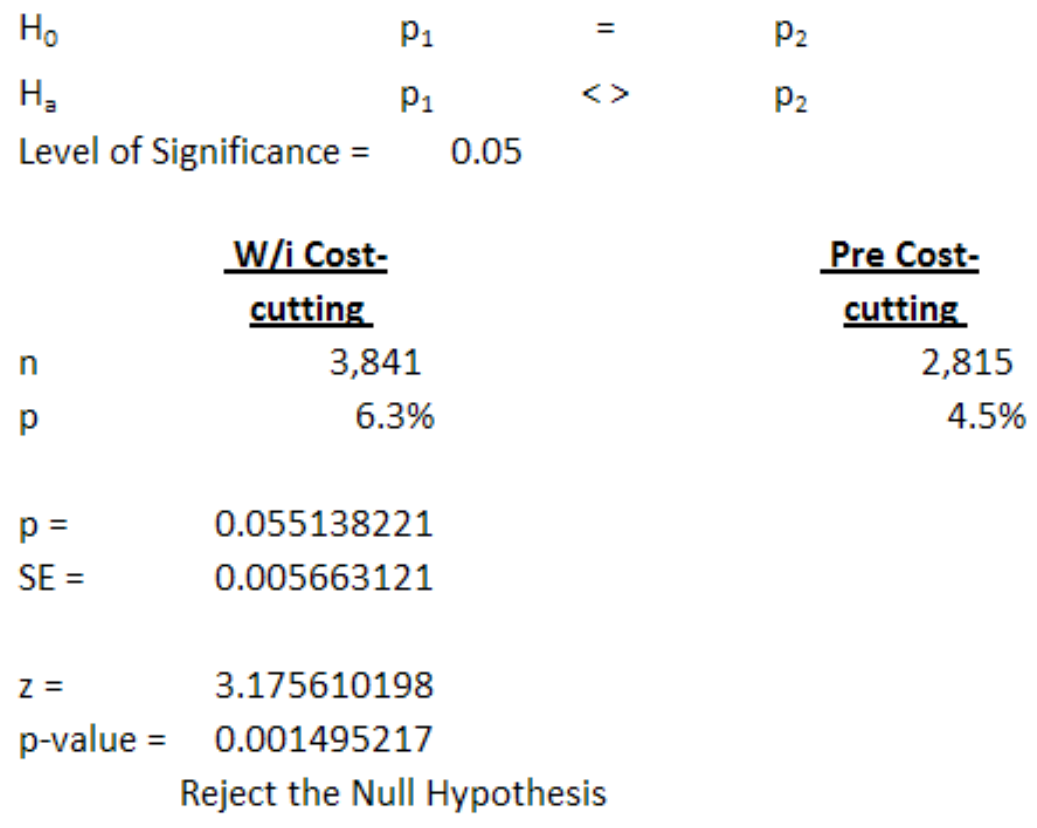

W/i Cost-

Pre Cost-

cutting

cutting

3,841

2,815

n

$6.3 \%$

$4.5 \%$
$p=\quad 0.055138221$
$\mathrm{SE}=\quad 0.005663121$
$z=\quad 3.175610198$
p-value $=0.001495217$
Reject the Null Hypothesis

Figure 4-21: Before and During Cost Cutting Binomial Two-proportion Significance Test Calculations

In figure 4-22 below, the confidence interval diagram illustrates the range of values that estimate the proportion of 1 st-year terminations before and during the cost cutting activities. 


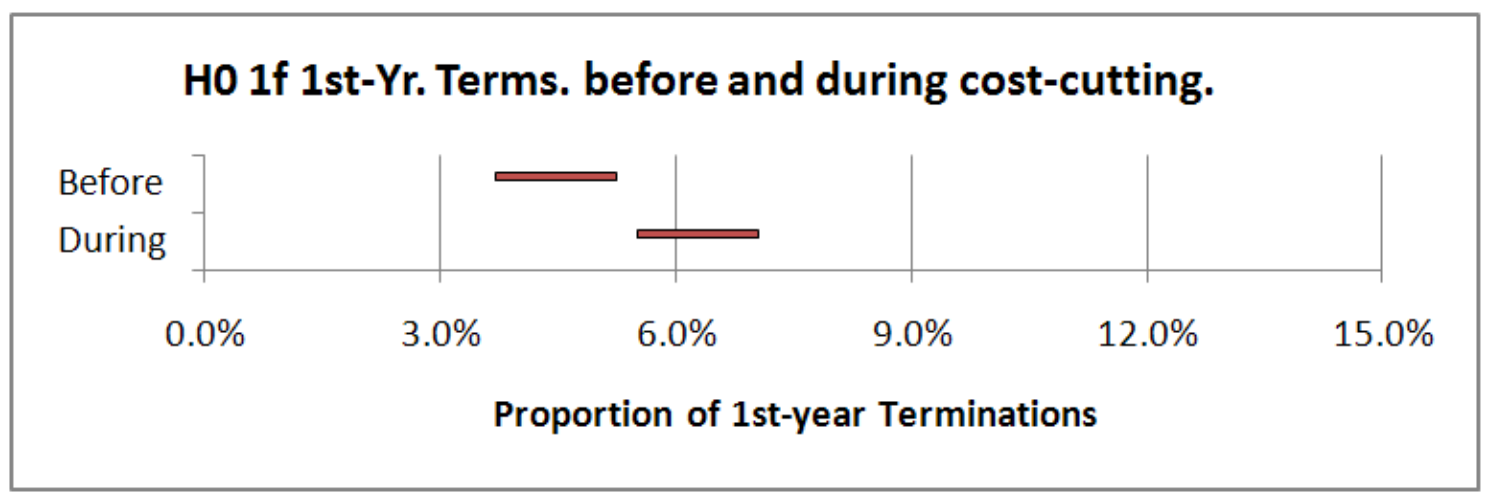

Figure 4-22: Before-During Cost Cutting $1^{\text {st }}-$ Year Terminations Confidence Intervals $\left(\mathrm{n}_{\text {During }}=3,841 ; \mathrm{n}_{\text {Before }}=2,815\right)$

Rejecting $\mathrm{H}_{0} 1 \mathrm{f}$ established that the proportion of $1^{\text {st }}$-year terminations increased significantly (loyalty decreased) during the cost-cutting period from the same measure taken before the cost-cutting activities. The effect of the cost-cutting policy upon customer loyalty necessitated adjustment of the field experiment to control for this confounding factor. The next test seeks to establish if the cost-cutting effect continued to erode customer loyalty in the period after. The next hypothesis test determined if the proportion of 1st-year terminations during the cost-cutting policy differed significantly from the period after it.

Customer Loyalty During and After the Cost-cutting Policy

$\mathbf{H}_{\mathbf{0}}$ 1g: The proportion of 1st-year terminations of all new customers during the costcutting is equal to the proportion of 1st-year terminations of all new customers after the cost-cutting. Figure 4-23 below illustrates the periods tested: 


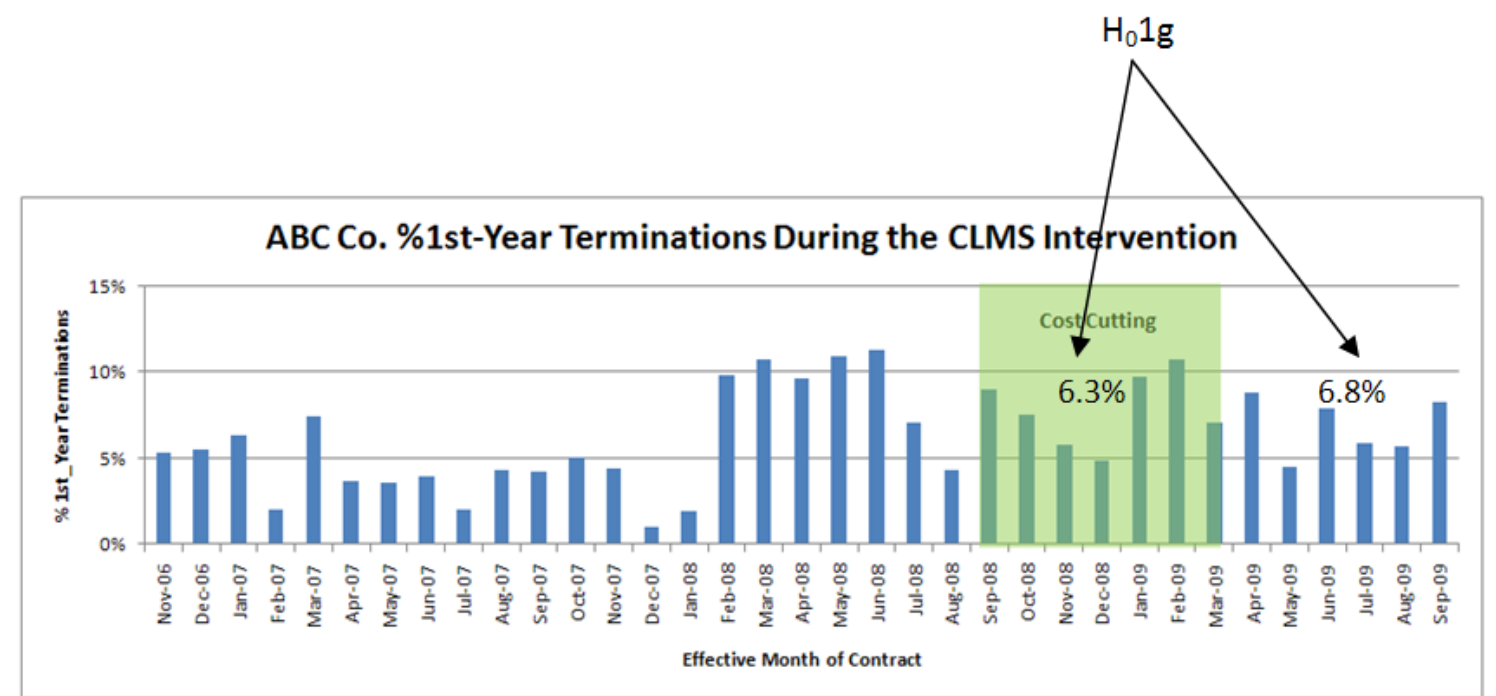

Figure 4-23: Proportion of $1^{\text {st }}$-Year Terminations After and During Cost Cutting, H01g, Test Periods

Findings: The null hypothesis is not rejected. The analysis finds that there is not a statistically significant difference in the metric during the cost-cutting period and after it. The proportion of 1 st-year terminations in the period after cost cutting is $\hat{p}==6.8 \%$. During the cost-cutting policy, the proportion of 1st-year terminations is $\mathrm{PH}_{0}=6.3 \%$. This was not a statistically significant difference. The |Test Statistic| is 1.05 . This is less than the critical z-value 1.96, the level of a statistical significance with a $95 \%$ confidence interval for a two-tail tests (figure 4-24, below). 


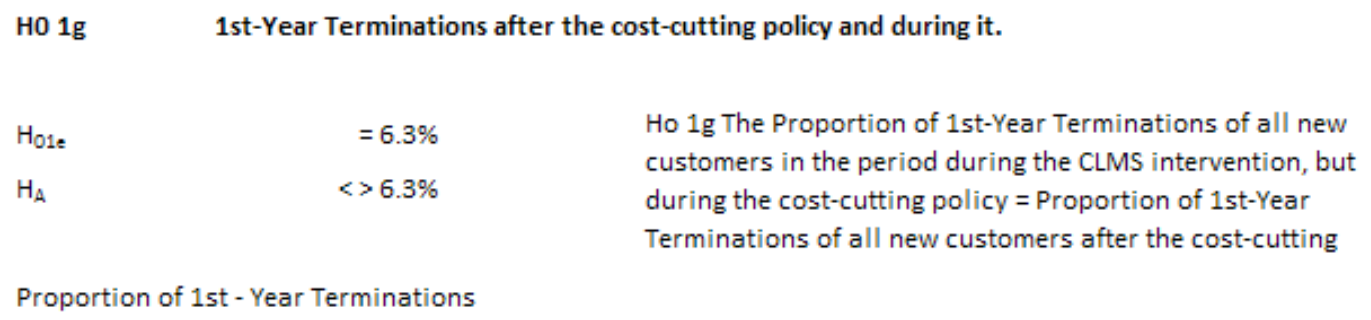

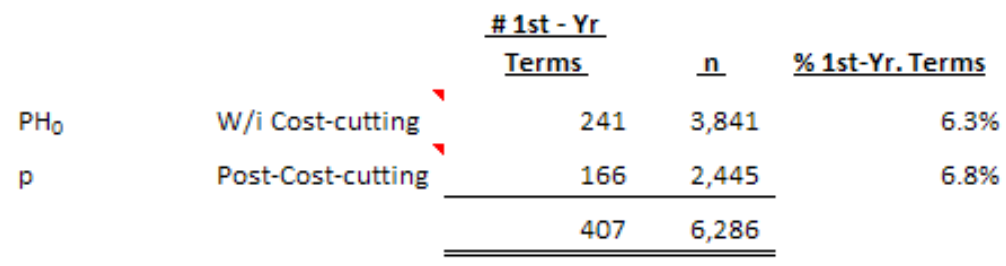

Database Total

$\begin{array}{lc}\text { Z Critical Value, two tailed, df }=\infty, \text { and } \\ \text { @ 95\% Confidenct } & 1.96 \\ \text { Test Statistic = } & 1.05 \\ \text { p-value = } & 0.294\end{array}$

The null hypothesis not rejected because I test statistic I, 1.04980161899725, is not greater than 1.96 the Z Critical Value. two tailed. df = $=\infty$. and@

Figure 4-24: After and During Cost Cutting Binomial Single-proportion Significance Test Calculations

Because the data from both after and during the cost cutting activities contain variability, a second binomial proportion z-test is applied that accounts for variability within the proportions taken from two independent samples (figure 4-25, below). 


\section{Two-proportion z-test}

$\begin{array}{llll}\mathrm{H}_{0} & \mathrm{p}_{1} & = & \mathrm{p}_{2} \\ \mathrm{H}_{\mathrm{a}} & \mathrm{p}_{1} & < & \mathrm{p}_{2} \\ \text { Level of Significance = } & 0.05 & & \end{array}$

$\begin{array}{lrr} & \frac{\text { W/i Cost- }}{\text { cutting }} & \frac{\text { Post-Cost- }}{\text { cutting }} \\ \mathrm{n} & 3,841 & 2,445 \\ \mathrm{p} & 6.3 \% & 6.8 \% \\ \mathrm{p}= & 0.064747057 & \\ \mathrm{SE}= & 0.006366491 & \\ \mathrm{z}= & -0.808857359 \\ \mathrm{p}-\mathrm{value}= & 0.418597199 \\ & \text { Cannot Reject the Null Hypothesis }\end{array}$

Figure 4-25: After and During Cost Cutting Binomial Two-proportion Significance Test Calculations

In figure 4-26 below, the confidence interval diagram illustrates the range of values that estimate the proportion of 1 st-year terminations before and during the cost cutting policy.

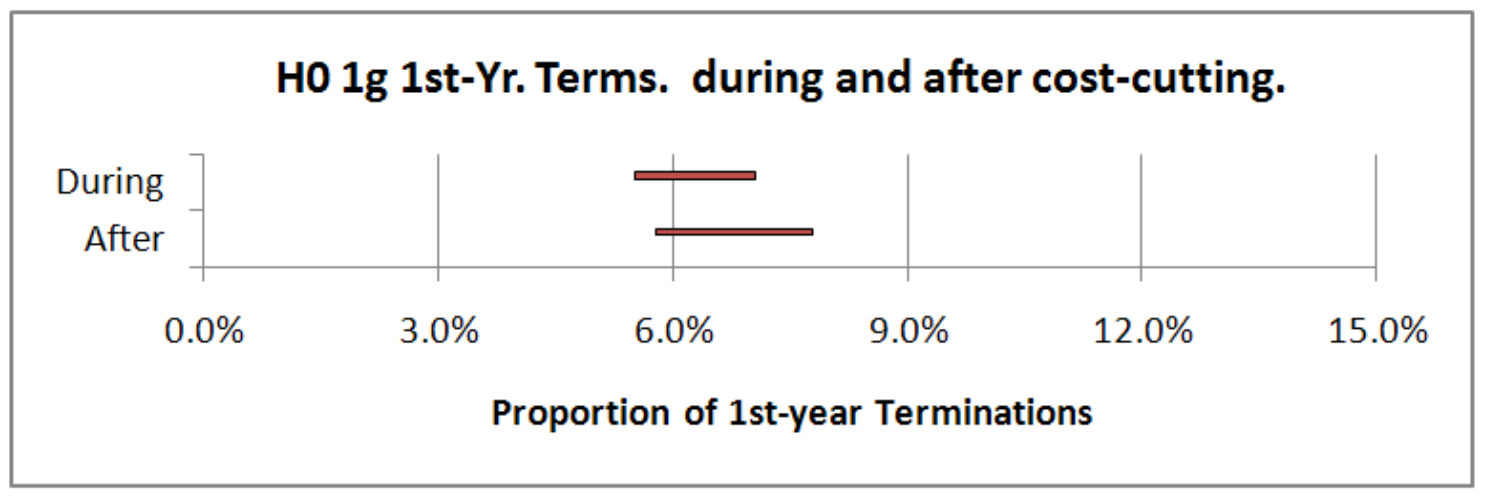

Figure 4-26: During-After Cost Cutting $1^{\text {st }}$-Year Terminations Confidence Intervals $\left(\mathrm{n}_{\text {During }}=3,841 ; \mathrm{n}_{\text {After }}=2,445\right)$ 
Failing to reject $\mathrm{H}_{0} 1 \mathrm{~g}$ indicates that the effects of the cost-cutting policy persisted after the policy implementation period. Because there was a statistically significant difference between the periods before and after the cost cutting actions, $\mathrm{H}_{0} 1 \mathrm{~h}$, the test aggregating the before and after periods and then testing that proportion of $1^{\text {st }}$-year terminations against the metric during the cost-cutting period was not necessary.

\section{$\underline{\text { Summary }}$}

The preceding analysis of confounding factors finds that the Great Recession and ABC Company management's cost-cutting actions are both confounding factors. There is a statistically significant increase in the proportion of $1^{\text {st }}$-year terminations (reduction in customer loyalty) during the recession as well as during and after the cost-cutting actions from the measure taken before both periods. This requires an adjustment to control for the effects of these confounding factors for the field experiment. Figure 4-27 illustrates the study period before and after the intervention with the confounding factor periods highlighted. 


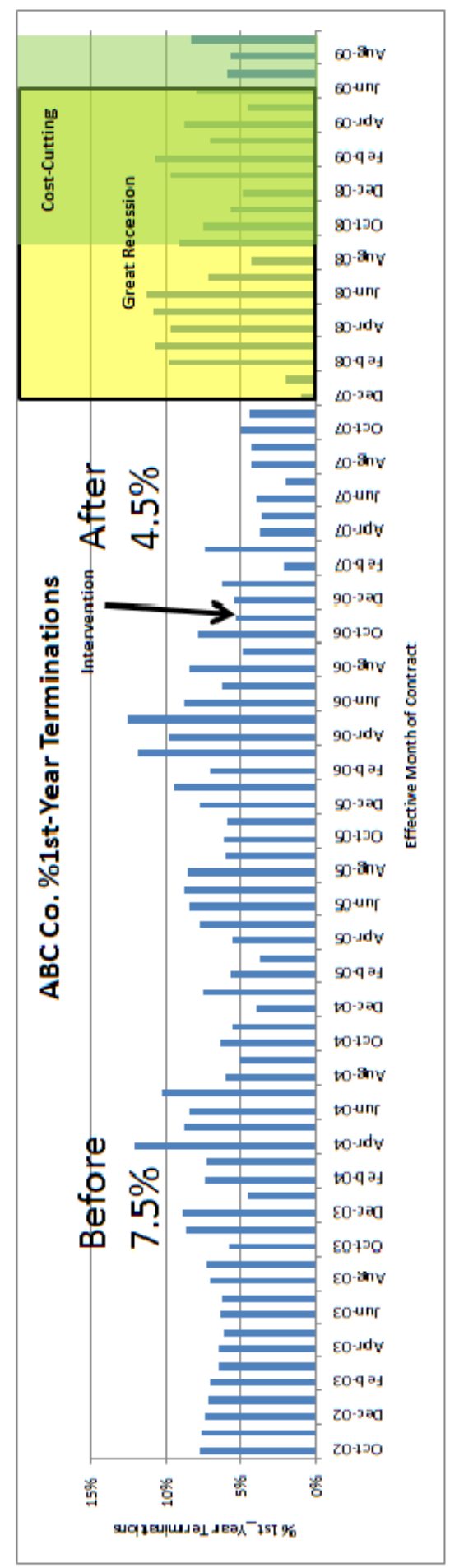

Figure 4-27: Study period with Confounding Factors 
The data in the period during the recession 12/1/2007 - 6/30/2009 is removed. Also, the data during and after the cost-cutting 9/1/2008 - 9/30/2009 was removed from the analysis. Data from 10/1/2009 - 9/30/2010 was removed because the $1^{\text {st }}$-Year Termination ratio requires twelve full consecutive months. The analysis of hypothesis $\mathrm{H}_{0} 1$ was adjusted accordingly, as described in section 4-2.

\section{4-4 Test Results for Research Question 2}

Research Question 2: Does CLSM decrease defections of targeted customers over that of all other, non-targeted customers?

Two hypothesis tests were applied to answer this question. The first reports the pre-post intervention differences for targeted customers, the second, for non-targeted customers. The first hypothesis test is as follows:

$\mathbf{H}_{\mathbf{0}}$ 2a: The proportion of 1 st-year terminations in the pre-intervention period for new targeted customers is less than or equal to the proportion of 1 st-yr. terminations of post-intervention period for new targeted customers controlled for confounding factors.

Findings: The null hypothesis is not rejected. The analysis found that there was no statistically significant difference in the metric before and after the intervention. The 
proportion of 1st-year terminations from the CLSM intervention period is $\hat{p}=4.4 \%$. Before the intervention, the proportion of 1 st-year terminations is $\mathrm{P}=5.8 \%$. This was not a statistically significant difference. The |Test Statistic| is 1.01 . This is less than the critical z-value 1.64; the level of a statistical significance with a 95\% confidence level for one-tail tests.

Figure 4-28, below, presents the calculations for the single proportion binomial significance test for both the targeted and non-targeted customers before and after the intervention. These two groups are presented together because their sum total equals the total number of new contract data points from the entire population. 


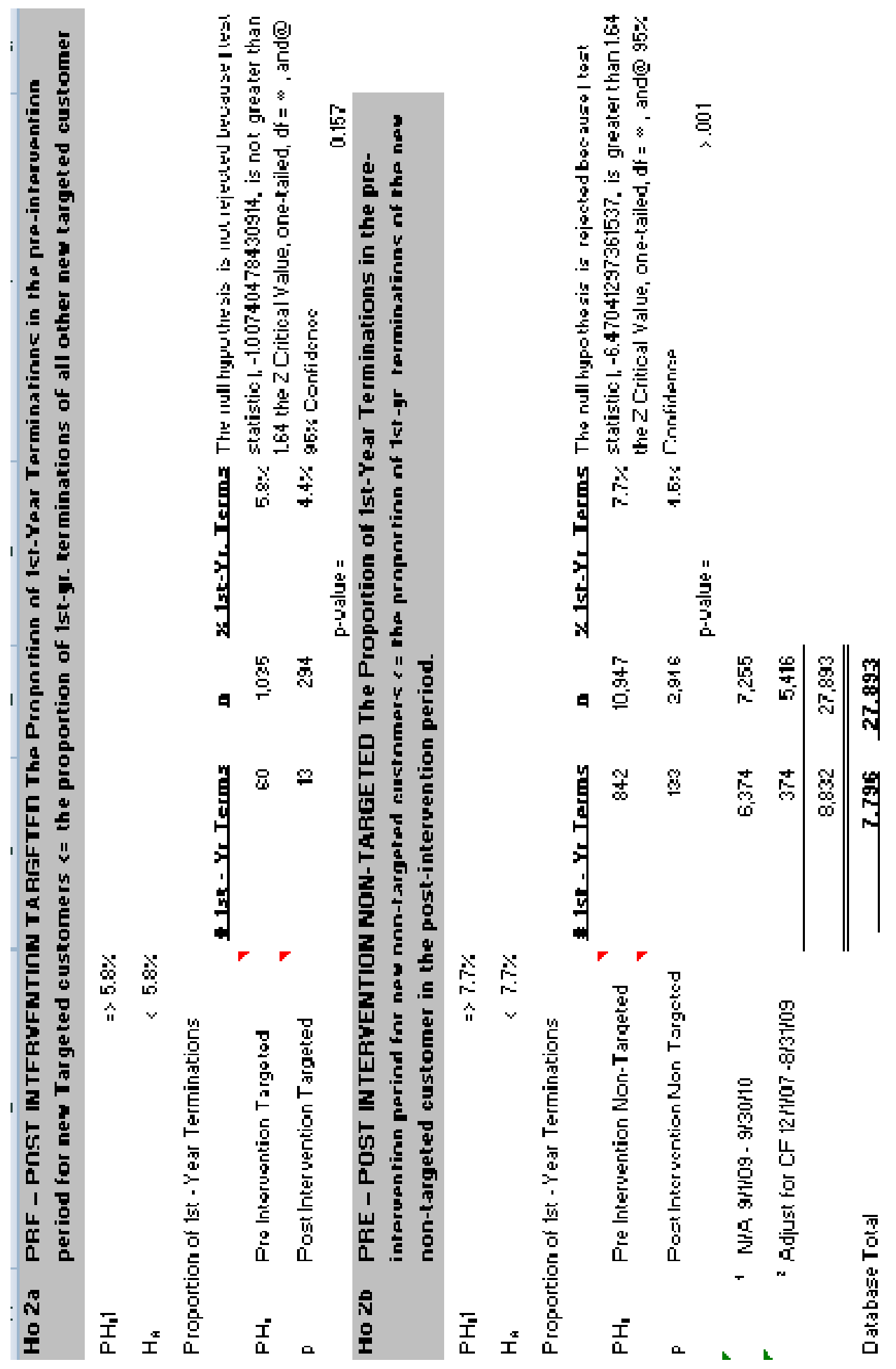

Figure 4-28: Targeted and Non-targeted Before and After CLMS Intervention Binomial Single-proportion Significance Test Calculations 
Because the targeted customer data from both before and after the CLMS intervention contain variability, a second binomial proportion z-test is applied that accounts for variability within the proportions taken from two independent samples (figure 4-29, below).

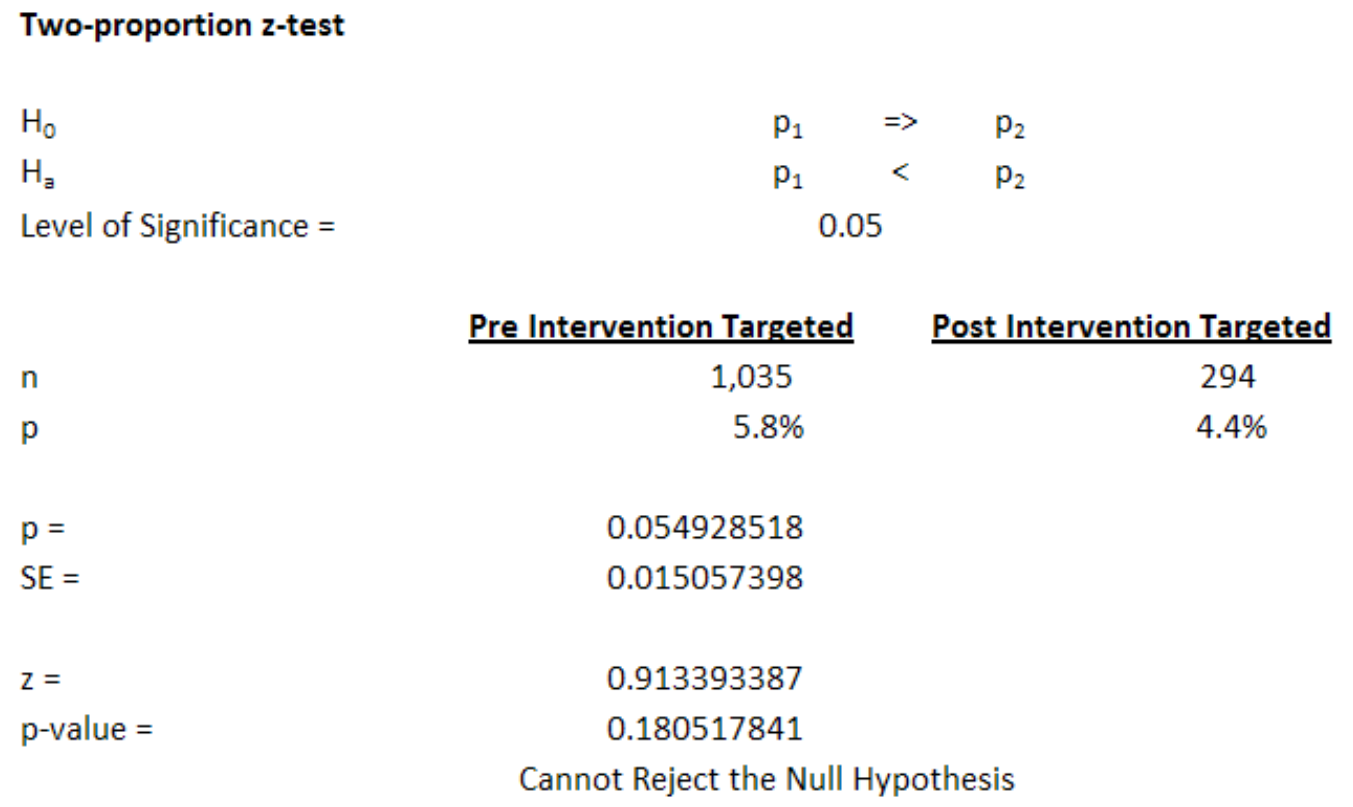

Figure 4-29: Targeted Customers Before and After CLMS Intervention Two-proportion Significance Test Calculations

In figure 4-30 below, the confidence interval diagram illustrates the range of values that estimate the pre-post-intervention (CLSM) proportion of 1st-year terminations for targeted customers. 


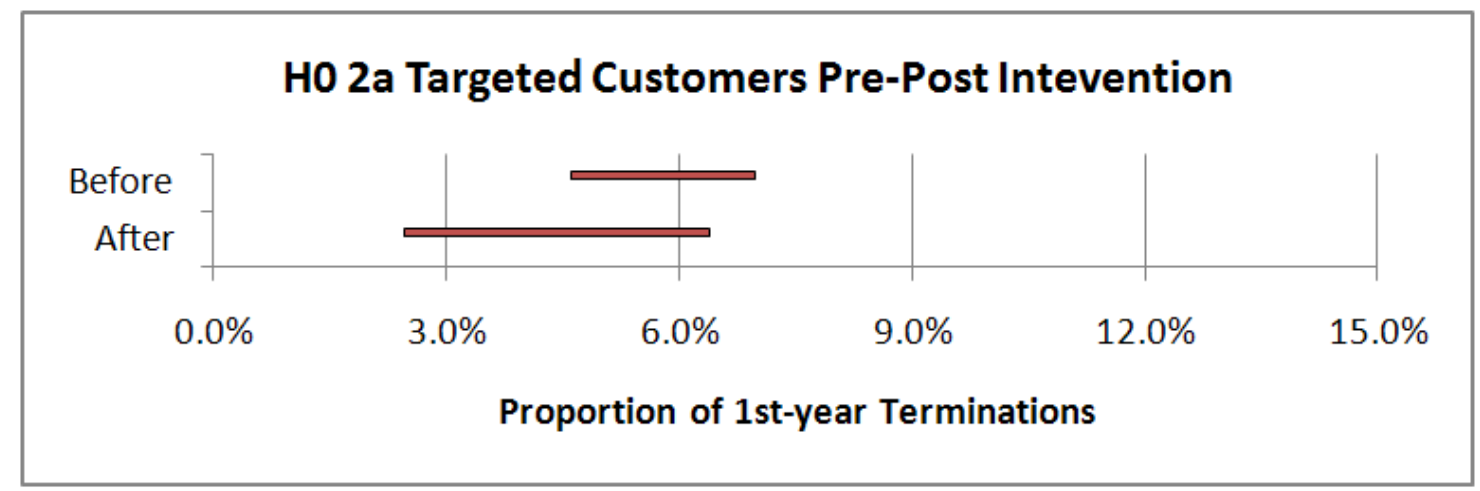

Figure 4-30: Pre-Post Intervention Confidence Intervals for Targeted Customers $\left(\mathrm{n}_{\text {Before }}=1,035 ; \mathrm{n}_{\text {After }}=294\right)$

$\mathbf{H}_{\mathbf{0}}$ 2b: The proportion of 1st-year terminations in the pre-intervention period for new non-targeted customers is less than or equal to the proportion of 1 st-yr. terminations of post-intervention new non-targeted customers controlled for confounding factors.

Findings: The null hypothesis is rejected. The analysis found that there was a statistically significant difference in the metric for non-targeted customers before and after the intervention. The proportion of 1 st-year terminations from the post-intervention period is $\hat{p}=4.5 \%$. Before the intervention, the proportion of 1 st-year terminations is $\mathrm{P}=7.7 \%$. This was a statistically significant difference. The $\mid$ Test Statistic $\mid$ is 6.47 . This is greater than the critical z-value 1.64; the level of a statistical significance with a $95 \%$ confidence level for one-tail tests (figure 28, above).

Because the non-targeted customer data from both before and after the CLMS intervention contain variability, a second binomial proportion z-test is applied that 
accounts for variability within the proportions taken from two independent samples (figure 4-31, below).

\section{Two-proportion z-test}

Pre Intervention Non-Targeted Post Intervention Non-Targeted

$\mathrm{p}$

$\mathrm{p}=$

$\mathrm{SE}=$

$\mathrm{z}=$

p-value $=$
10,947

$7.7 \%$

0.070179227

0.005301979

5.99211911

1.03562E-09

Reject the Null Hypothesis

Figure 4-31: Non-targeted Customers Before and After CLMS Intervention Two-proportion Significance Test Calculations

In figure 4-32 below, the confidence interval diagram illustrates the range of values that estimate the pre-post-intervention (CLSM) proportion of 1st-year terminations for nontargeted customers.

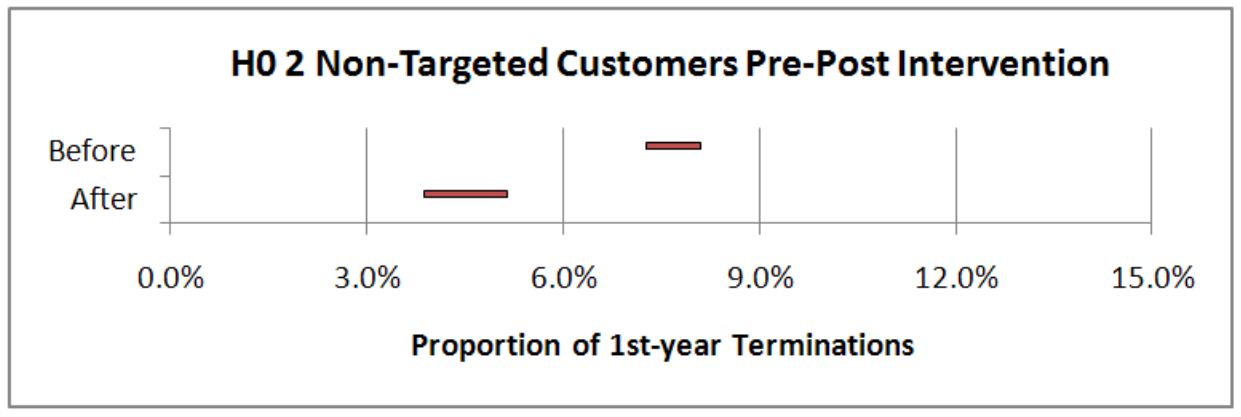

Figure 4-32: Pre-Post Intervention Confidence Intervals for Non-Targeted Customers

$$
\left(\mathrm{n}_{\text {Before }}=10,947 ; \mathrm{n}_{\text {After }}=2,946\right)
$$




\section{$\underline{\text { Summary }}$}

The preceding analysis did not find a statistically significant difference between the effect of the intervention on the loyalty of targeted customers, but did find a difference between the effects of the intervention on the loyalty of non-targeted customers.

\section{4-5: Test Results for Research Question 3}

Research Question 3: Does the successful use of CLSM to resolve customer problems decreases customer defections below that of those before the intervention?

Recall from chapter 4 that front-line personnel are required to contact customer survey respondents whose scores determine them to be less-than-satisfied. If the employee is able to resolve the customer issues satisfactorily, a "Resolution" status is recorded in the CLSM database. The hypothesis test used to answer this research question is as follows:

$\mathbf{H}_{\mathbf{0}}$ 3: The proportion of 1st-year terminations in the pre-intervention period is less than or equal to the proportion of 1 st-year terminations of contacted survey respondents in the post-intervention period, controlled for confounding factors, whose issues were reported as resolved in the CLSM database. 
Findings: The null hypothesis is rejected. The analysis found that there was a statistically significant difference in the metric before the intervention and after the intervention for "Resolution" customers. The proportion of 1 st-year terminations of contacted customers whose status in the CLSM database is "Resolution" from the postintervention period is $\hat{p}=4.4 \%$. Before the intervention, the proportion of 1 st-year terminations is $\mathrm{P}=7.5 \%$. This was a statistically significant difference. The $\mid$ Test Statistic| is 1.70 . This is greater than the critical z-value 1.64; the level of a statistical significance with a 95\% confidence level for one-tail tests (figure 4-33, below).

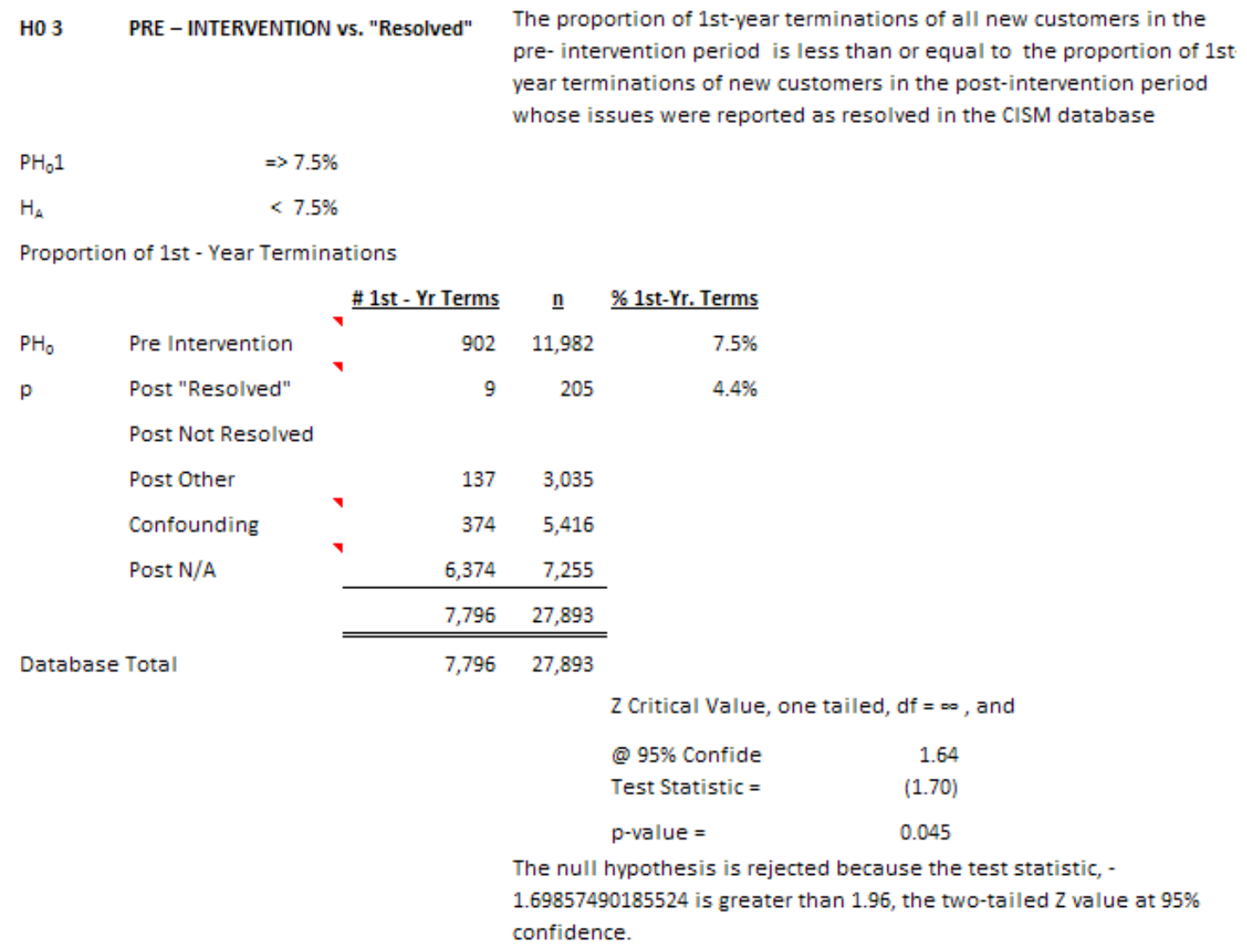

Figure 4-33: Before CLMS Intervention and "Resolved" After Binomial Single-proportion Significance Test Calculations 
Because both the pre-intervention benchmark data and the "Resolved" data from the CLMS database contain variability, a second binomial proportion z-test is applied that accounts for variability within the proportions taken from two independent samples (figure 4-34, below).

\section{Two-proportion z-test}

$\begin{array}{lcc}\mathrm{H}_{0} & \mathrm{p}_{1}=\mathrm{p}_{2} \\ \mathrm{H}_{\mathrm{a}} & \mathrm{p}_{1}<\mathrm{p}_{2} \\ \text { Level of Significance }= & 0.05 & \end{array}$

$\begin{array}{lcr} & \text { Pre Intervention } & \text { Post "Resolved" } \\ & 11,982 & 205 \\ \mathrm{p} & 7.5 \% & 4.4 \% \\ \mathrm{p}= & 0.074751785 & \\ \mathrm{SE}= & 0.01852451 & \\ & & \\ \mathrm{z}= & 1.693817924 \\ \mathrm{p} \text {-value }= & 0.045149944\end{array}$

Figure 4-34: All Customers Before and "Resolved" Customers After CLMS Intervention Two-proportion Significance Test Calculations

In figure 4-35 below, the confidence interval diagram illustrates the range of values that estimate the pre-intervention proportion of 1 st-year terminations for all customers 
(Before) and the post-intervention (After) metric for customers whose status is "Resolution" in the CLSM database.

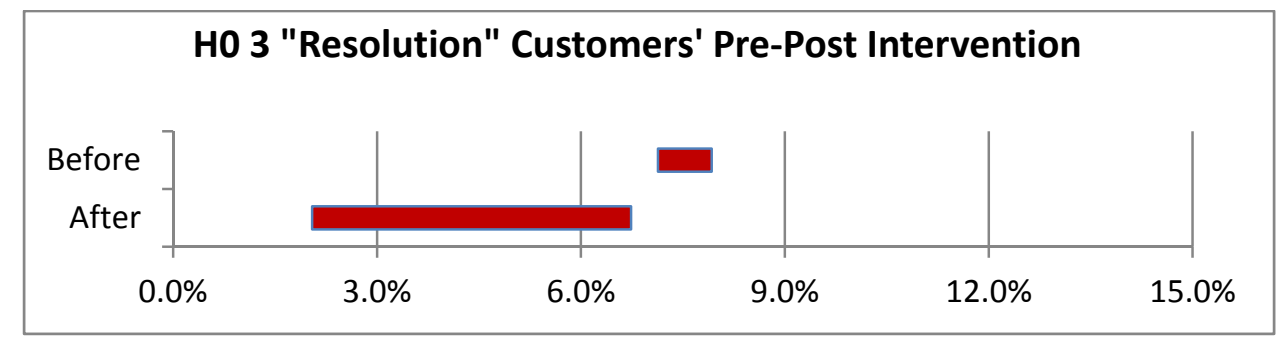

Figure 4-35: Pre-Intervention and Post-Intervention "Resolution" Customers Confidence Intervals $\left(\mathrm{n}_{\text {Before }}=11,982 ; \mathrm{n}_{\text {After }}=205\right)$

\section{4-6: Test Results for Research Question 4}

Research Question 4: Does the unsuccessful use of CLSM to resolve customer problems increases customer defections?

Front-line personnel are required to contact customer survey respondents whose scores determine them to be less-than-satisfied and record the status "Resolution" if the employee is able to resolve the customer issues satisfactorily. The employees, however, are not required to record the status for no-resolution. In order to identify non-resolved customer issues, the researcher assumed that less-than-satisfied respondents whose status is "Contacted" and not "Resolution" on the CLSM database are customers whose issues were not resolved.. The hypothesis test used to answer this research question is as follows: 
$\mathbf{H}_{\mathbf{0}}$ 4: The proportion of 1 st-year terminations in the pre- intervention period is less than or equal to the proportion of 1 st-year terminations of contacted survey respondents in the post-intervention period, controlled for confounding factors, whose issues were not reported as resolved in the CLSM database.

Findings: The null hypothesis is not rejected. The analysis found that there was not a statistically significant difference in the metric before the intervention and after the intervention for non-resolution customers. The proportion of 1st-year terminations of contacted customers whose status in the CLSM database is not "Resolution" is $\hat{p}=9.4 \%$. Before the intervention, the proportion of 1 st-year terminations is $\mathrm{P}=7.5 \%$. This was not a significant difference. The $\mid$ Test Statistic $\mid$ is .68. This is less than the critical z-value 1.64; the level of a statistical significance with a $95 \%$ confidence level for one-tail tests (figure 4-36, below). 


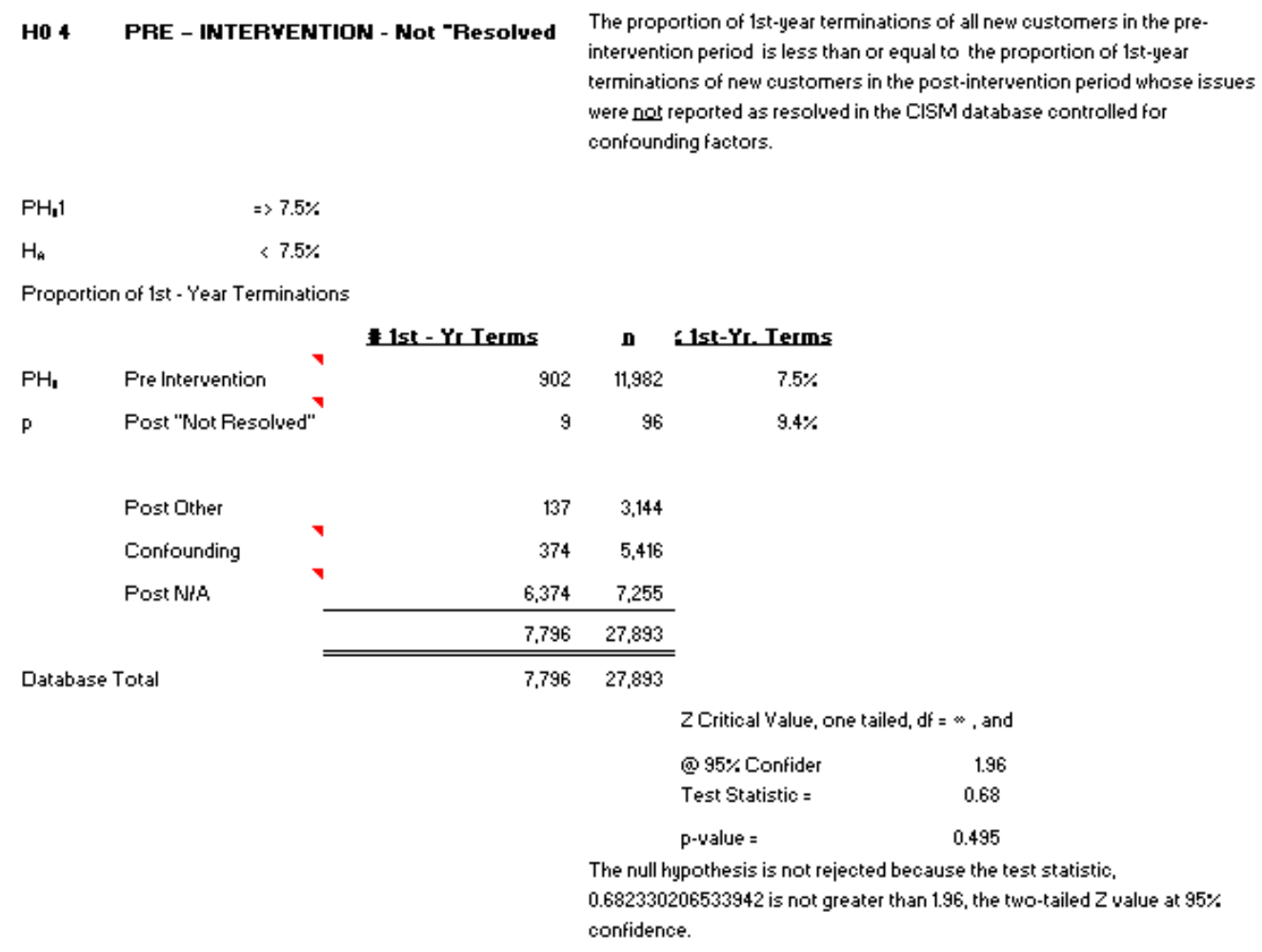

Figure 4-36: Before CLMS Intervention and "Not Resolved" Binomial Single-proportion Significance Test Calculations

Because both the pre-intervention benchmark data and the "Not Resolved" data from the CLMS database contain variability, a second binomial proportion z-test is applied that accounts for variability within the proportions taken from two independent samples (figure 4-37, below). 


\section{Two-proportion z-test}
$\mathrm{H}_{0}$
$\mathrm{H}_{\mathrm{a}}$
$\mathrm{p}_{1}=\mathrm{p}_{2}$
$\mathrm{p}_{1} \quad \ll \quad \mathrm{p}_{2}$
Level of Significance $=$
0.05

$\begin{array}{lcc} & \text { Pre Intervention } & \text { Post "Not Resolved" } \\ & 11,982 & 96 \\ \mathrm{p} & 7.5 \% & 9.4 \% \\ \mathrm{p}= & & \\ \mathrm{SE}= & 0.075426395 & \\ & 0.027060116 & \\ \mathrm{z}= & & \\ \mathrm{p} \text {-value }= & -0.682569643 & \\ & 0.494878822\end{array}$

Figure 4-37: All Customers Before and "Not Resolved" Customers After CLMS Intervention Twoproportion Significance Test Calculations

In figure 4-38 below, the confidence interval diagram illustrates the range of values that estimate the pre-intervention proportion of 1st-year terminations for all customers (Before) and the post-intervention (After) metric for contacted customers whose status is not "Resolution" in the CLSM database.

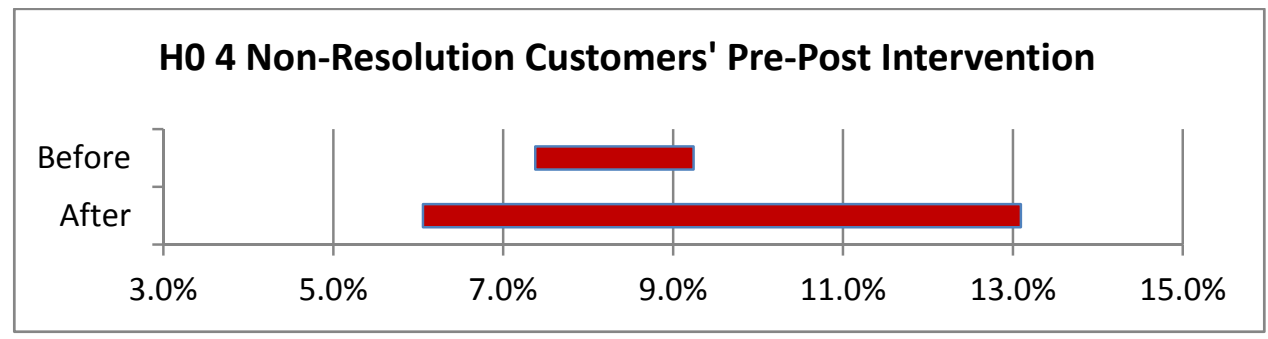

Figure 4-38: Pre-Intervention and Post-Intervention Non-resolution Customers Confidence Intervals $\left(\mathrm{n}_{\text {Before }}=11,982 ; \mathrm{n}_{\text {After }}=96\right)$ 


\section{4-6: Test Results for Research Question 5}

Research Question 5: Does the successful use of CLSM to resolve customer problems decreases customer defections below that of satisfied customers? The hypothesis test used to answer this research question is as follows:

$\mathbf{H}_{\mathbf{0}}$ 5: The proportion of 1st-year terminations of all satisfied customers is less than or equal to the proportion of 1st-yr. terminations of post intervention less-than satisfied customers who were contacted by employees to proactively resolve potential problems and whose issues were considered resolved in the CLSM database.

Findings: The null hypothesis is rejected. The analysis found that there was a statistically significant difference in the metric for satisfied customers (score > 8) and for "Resolution" customers after the intervention. The proportion of 1st-year terminations of contacted customers whose status in the CLSM database is "Resolution" from the postintervention period is $\hat{p}=4.4 \%$. For satisfied customers, the proportion of 1 st-year terminations is $\mathrm{P}=8.4 \%$. This was a statistically significant difference. The $\mid$ Test Statistic| is 2.06. This is greater than the critical z-value 1.64; the level of a statistical significance with a $95 \%$ confidence level for one-tail tests (figure 4-39, below). 


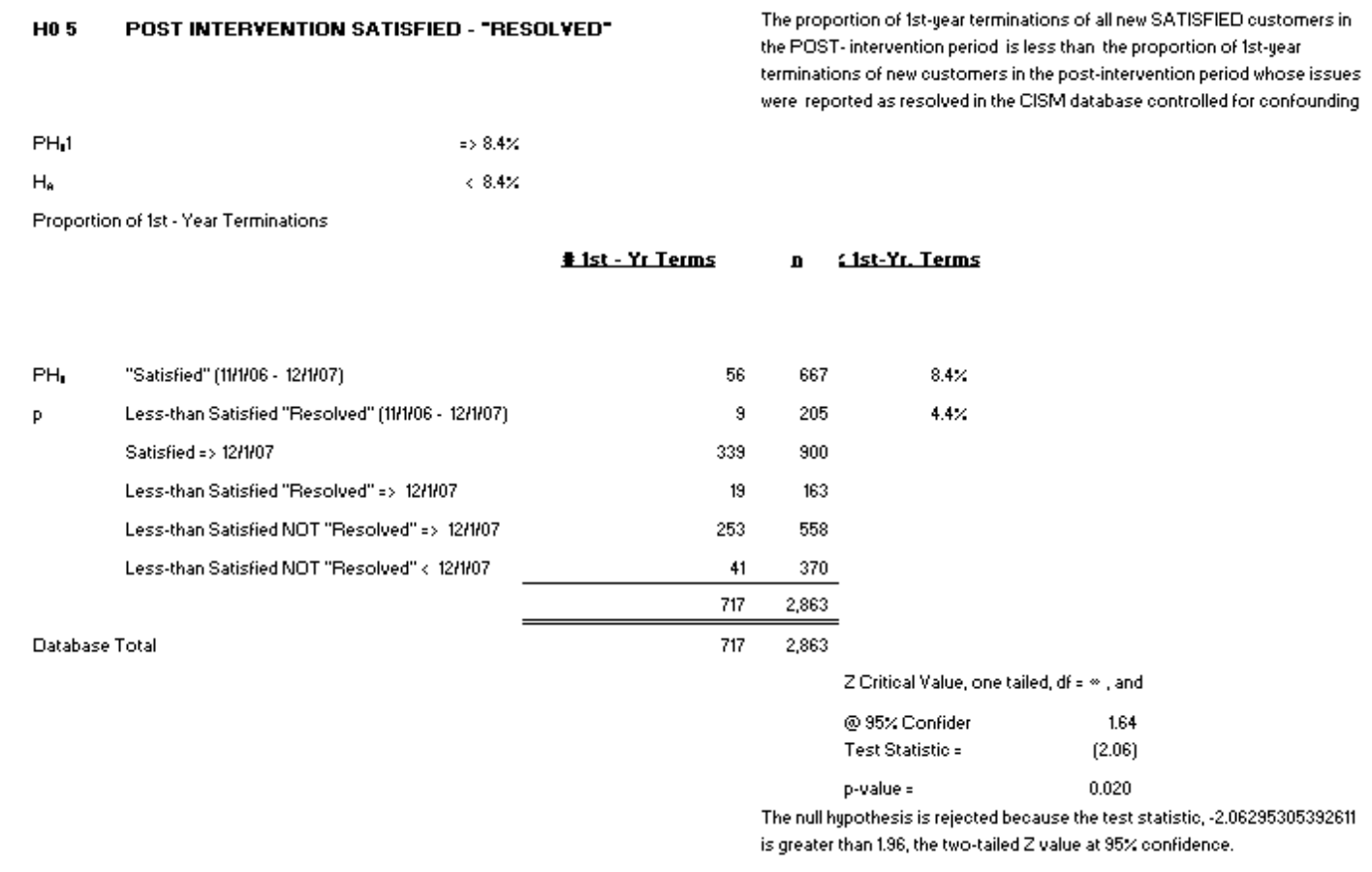

Figure 4-39: "Satisfied" and "Resolved" Binomial Single-proportion Significance Test Calculations

Because both the "Satisfied" and "Resolved" data from the CLMS database contain variability, a second binomial proportion z-test is applied that accounts for variability within the proportions taken from two independent samples (figure 4-40, below). 


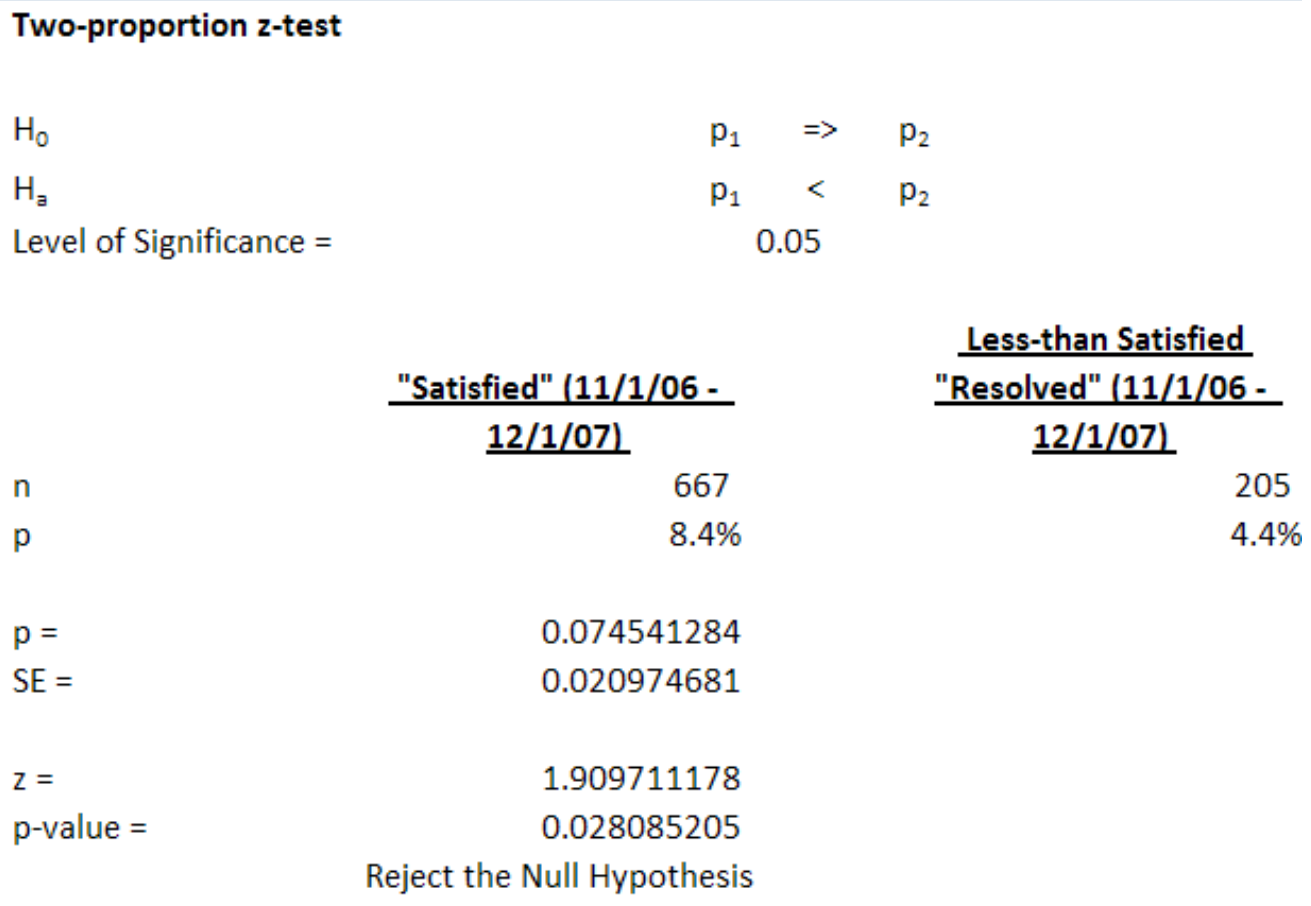

Figure 4-40: "Satisfied" and "Not Resolved" Customers After CLMS Intervention Two-proportion Significance Test Calculations

In figure 4-41 below, the confidence interval diagram illustrates the range of values that estimate the pre-intervention proportion of 1st-year terminations for all customers (Before) and the post-intervention (After) metric for customers whose status is "Resolution" in the CLSM database. 


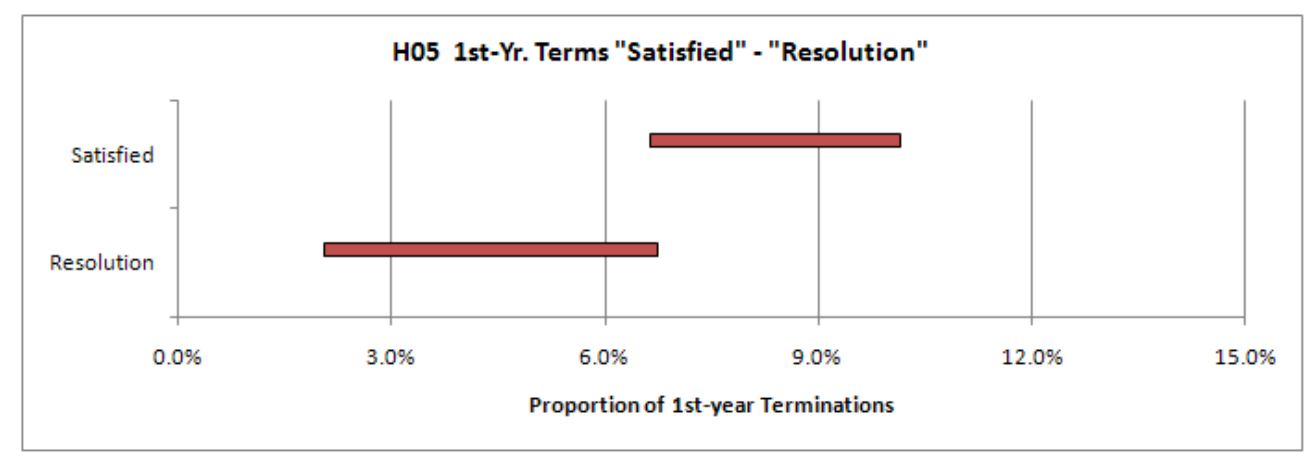

Figure 4-41: Post-Intervention "Satisfied" and "Resolution" Customers Confidence Intervals $\left(\mathrm{n}_{\text {Satisfied }}=667 ; \mathrm{n}_{\text {Resolution }}=205\right)$

\section{4-7: Summary}

The application of proportional z-tests of hypotheses found that the proportion of $1^{\text {st }}$-year terminations after the CLSM intervention decreased (loyalty increased). The Great Recession and the cost-cutting activities were both confounding factors and necessitated the elimination of all data from December, 2007 and thereafter from the field experiment. The proportion of $1^{\text {st }}$-year terminations of targeted customers did not decrease, whereas the proportion of $1^{\text {st }}$-year terminations of non-targeted customers decreased significantly (loyalty increased). The proportion of $1^{\text {st }}$-year terminations of survey respondents reported as "Resolution" in the CLSM database decreased (loyalty increased) from the metric taken before the intervention for all customers and after the intervention for satisfied customers. Whereas, there was not a statistically significant decrease in the proportion of $1^{\text {st }}$-year terminations for respondents whose issues were not resolved. Table 4-1 below provides a summary of the hypothesis tests. 


\begin{tabular}{|c|c|c|}
\hline$\frac{\text { Research Question / }}{\text { Hypothesis }}$ & Description & Findings \\
\hline $\begin{array}{l}\text { Question 1/ } \mathrm{H}_{0} 1 \\
\text { All Customers }\end{array}$ & $\begin{array}{l}\text { Defections before the intervention are less than or equal } \\
\text { to defections after the intervention. }\end{array}$ & $\begin{array}{l}\text { Null Hypothesis } \\
\text { is Rejected }\end{array}$ \\
\hline $\begin{array}{l}\text { Question 2/ } \\
\mathrm{H}_{0} 2 \mathrm{a} \\
\\
\text { Targeted } \\
\text { Customers }\end{array}$ & $\begin{array}{l}\text { Defections of targeted customers before the intervention } \\
\text { are less than or equal to defections of targeted customers } \\
\text { after the intervention. }\end{array}$ & $\begin{array}{l}\text { Null Hypothesis } \\
\text { is Not Rejected }\end{array}$ \\
\hline $\begin{array}{l}\text { Question 2/ } \\
\mathrm{H}_{0} 2 \mathrm{~b} \\
\text { Non-Targeted } \\
\text { Customers }\end{array}$ & $\begin{array}{l}\text { Defections of non-targeted customers before the } \\
\text { intervention are less than or equal to defections of } \\
\text { targeted customers after the intervention. }\end{array}$ & $\begin{array}{l}\text { Null Hypothesis } \\
\text { is Rejected }\end{array}$ \\
\hline $\begin{array}{l}\text { Question 3/ } \mathrm{H}_{0} 3 \\
\text { “Resolution” } \\
\text { Customers }\end{array}$ & $\begin{array}{l}\text { Defections before the intervention are less than or equal } \\
\text { to defections of respondents whose issues were resolved. }\end{array}$ & $\begin{array}{l}\text { Null Hypothesis } \\
\text { is Rejected }\end{array}$ \\
\hline $\begin{array}{l}\text { Question } 4 / \mathrm{H}_{0} 4 \\
\text { Non-Resolution } \\
\text { Customers }\end{array}$ & $\begin{array}{l}\text { Defections before the intervention are greater than or } \\
\text { equal to defections of respondents whose issues were not } \\
\text { resolved. }\end{array}$ & $\begin{array}{l}\text { Null Hypothesis } \\
\text { is Not Rejected }\end{array}$ \\
\hline $\begin{array}{l}\text { Question 5/ } \mathrm{H}_{0} 5 \\
\text { “Resolution” } \\
\text { Customers }\end{array}$ & $\begin{array}{l}\text { Defections of satisfied customers (score }>8 \text { ) are less than } \\
\text { or equal to defections of respondents whose issues were } \\
\text { resolved. }\end{array}$ & $\begin{array}{l}\text { Null Hypothesis } \\
\text { is Rejected }\end{array}$ \\
\hline
\end{tabular}

Table 4-1: Summary of Hypothesis Tests 


\section{CHAPTER 5: DISCUSSION}

\section{5-1: Introduction}

Today business strategies emphasize customer loyalty. The availability of alternatives that technology and the internet have brought to consumers from the global market place has intensified competition making retaining customers a priority. This research provides empirical evidence of how a closed loop use of customer satisfaction surveys reduced customer defections and improved loyalty in one financial services firm. This chapter provides an interpretation of the research findings, a discussion of the unexpected outcomes, a recommendation for future work, and an assessment of the strengths and weaknesses of this research.

This chapter is organized as follows:

- Section 5-2 Interpretation

- Section 5-3 Unexpected Outcomes

- Section 5-4 Strengths and Limitations

- Section 5-5 Future Research

- Section 5-6 Contribution to the Literature

\section{5-2: Interpretation}

This research provides evidence that the implementation of CLSM improves the loyalty of customers. Providing customer satisfaction feedback to front-line personnel and empowering them to act proactively to prevent potential defections results in significantly less defections. Figure 5-1 is a summary of the before and after changes in the proportions of $1^{\text {st }}$-year terminations for six of the customer groups examined, including whether or not the change was determined to be statistically significant. 


\begin{tabular}{|c|c|c|c|}
\hline No. & Customer Group & Change in Defection & $\begin{array}{c}\text { Statistical } \\
\text { Significance }\end{array}$ \\
\hline 1 & All Customers & From $7.5 \%$ to $6.0 \%$ & Significant \\
\hline 2 & All Customers (Controlled) & From $7.5 \%$ to $4.5 \%$ & Significant \\
\hline 3 & Targeted Customers & From $5.8 \%$ to $4.4 \%$ & Not Significant \\
\hline 4 & Non-Targeted Customers & From $7.7 \%$ to $4.5 \%$ & Significant \\
\hline 5 & "Resolution" Respondents & From $7.5 \%$ to $4.4 \%$ & Significant \\
\hline 6 & "No Resolution Respondents & From $7.5 \%$ to $9.4 \%$ & Not Significant \\
\hline
\end{tabular}

Table 5-1: Summary of Research Findings from the CLSM Intervention

Following is an interpretation of the results for the research findings.

\section{5-2.1: CLMS Improves Retention in Spite of Recessionary Pressures}

1. The proportion of $1^{\text {st }}$-year terminations decreases significantly for all customers following the CLMS intervention from $7.5 \%$ to $6.0 \%$ even though a major recession occurred during the intervention.

Although the proportion of $1^{\text {st }}$-year terminations where much higher during the Great Recession, the metric still decreased significantly for all customers following the CLMS intervention from $7.5 \%$ to $6.0 \%$ without adjusting for confounding factors. These decreases were achieved although customers' decisions to remain with ABC Company were made during the Great Recession. 
Additionally, after removing data affected by confounding factors, the resulting postintervention period included customers with new contracts beginning 10/1/06-11/30/07. These contracts are for one-year. Customers who terminate their contracts within one year, for the most part, do so at the first annual renewal month. Figure 5-2 illustrates the frequency of the number of months that $1^{\text {st }}$-year terminations remain effective during the pre-intervention benchmark period.

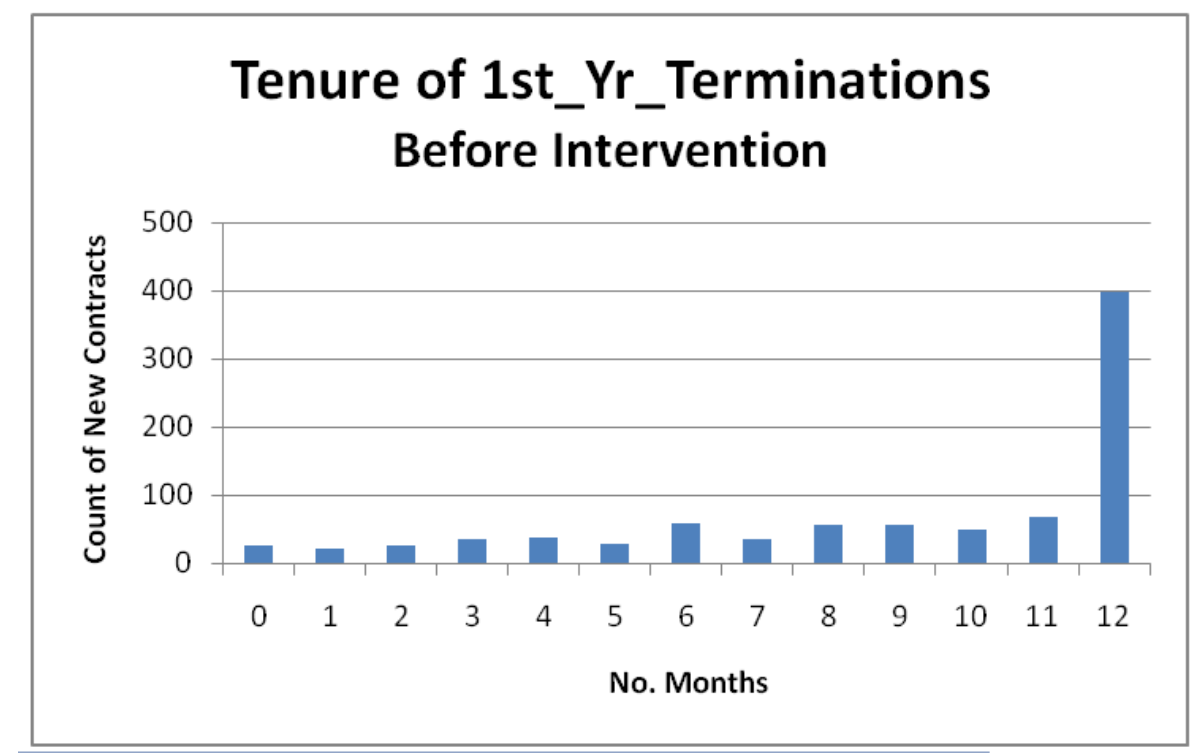

Figure 5-1: Counts of $1^{\text {st }}$-Year Termination by the Number of Months from a Contract's Beginning

Figure 5-2 illustrates the number of months during the four-year benchmark period before the CLMS intervention in which ABC Company's customers terminated in the first year. The $\mathrm{x}$-axis represents the month in which customers terminated their contracts. Zero represents the frequency that customers terminate their contract in the first month while twelve represents the frequency that customers terminate in their first-year anniversary 
month. Over $70 \%$ terminated after six months and more than $40 \%$ terminated in the final renewal month.

Based upon this termination frequency analysis of the benchmark period and because elimination of periods affected by confounding factors reduced the study period to November '06 - November '07, it is evident that most (approximately 90\%) of customers, in the 13-month post-intervention period, made their decision to terminate after the Great Recession began. This means that, despite the increased economic pressures on customers to terminate during the recession period, the CLSM intervention never-the-less succeeded in significantly reducing defections from the benchmark rate.

\section{5-2.2: Practical Contribution of Improving Customer Loyalty}

2. The proportion of $1^{\text {st }}$-year terminations decreased significantly for all customers following the CLMS intervention after controlling for confounding factors.

The CLMS intervention reduced the proportion of $1^{\text {st }}$-year terminations from $7.5 \%$ to 4.5\%, a decrease of 3 percentage points. According to Reichheld and Sasser (1990), firms can increase profits $75 \%$ by reducing defections 5 percentage points. They refer to profits that accrue over the life expectancy of a customer and their estimate is based on the opportunity costs from: lost purchases, forfeited referrals, unrealized efficiency gains, 
and uncollected price premiums. However, there is a substantial short-term financial benefit provided as well. A conservative analysis of the increase in the first year's sales revenue at $\mathrm{ABC}$ Company illustrates that the reduction in the proportion of $1^{\text {st }}$-year terminations increased sales revenue that otherwise would have been lost due to defections.

The average tenure of a $1^{\text {st }}$-year termination is 8.7 months. Thus, ABC Company loses about 3.3 months $(12-8.7)$, or $28 \%$, of its annual sales of new contracts from those contracts which terminate in a given year. In 2007, the annual sales revenue from new contracts was $\$ 162.8$ million. The following calculations estimate the savings delivered by CLSM.

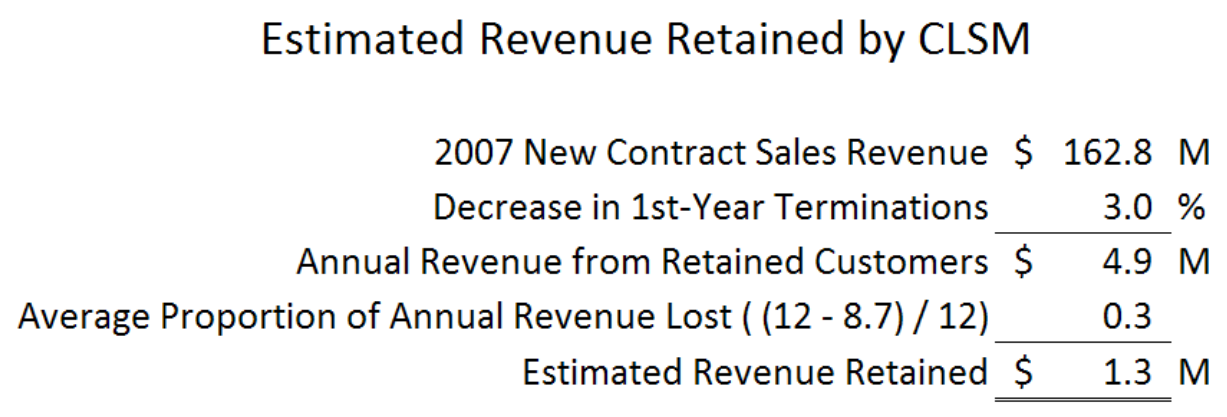

This is an extremely conservative estimate, since the following year should benefit by close to $\$ 4.9$ million if the retained customers remain loyal. 


\title{
5-2.3: Why didn't CLMS Improve Results for Targeted Customers?
}

3. The proportion of $1^{\text {st }}$-year terminations did not decrease significantly for strategically targeted customers.

\begin{abstract}
Although the data shows an improvement in the loyalty of targeted customers from 5.8\% to $4.4 \%$ after the CLSM intervention, binomial proportion tests determine that the difference is not statistically significant. This is explained by the preferential relationship that strategically targeted customers already receive that other, non-targeted, customers do not prior to the intervention.
\end{abstract}

At ABC Company targeted customers frequently rely on problem-solving, a core competency, which is one of ABC Company's competitive advantages. ABC Company has dedicated staff for responding to customer questions pertaining to the financial products the company sells and services. The types of problems that customers inquire about are often complex and require specialists that ABC Company has on staff. In most cases, the cost of these professionals, and the problem resolution services performed, are provided without additional charge to the customer. It is a strategic differentiation (Porter, 2008) and core competency (Prahalad, 1990) that was only available to the company's targeted customers before the intervention.

ABC Company has long competed in its market by leveraging these problem-solving services, but only its strategically targeted customers had benefited from them before the 
CLMS intervention. This accounts for the higher loyalty among targeted customers. The ratio of 1 st-year terminations prior to the CLSM intervention was is $5.8 \%$ for targeted customers compared to $7.7 \%$ for non-targeted customers.

It is not only the value that customers receive from the problem-solving services that result in lower defection rates of strategically targeted customers. The time taken to request these services, explain a problem and seek resolution results in an investment in the relationship with the service provider. Problem resolution services create a dependence upon these services that deepens customers' relationships with the service provider. This commitment to the relationship represents an investment in switching costs that has been associated with customer retention (Bell, Auh, \& Smalley, 2005).

\section{5-2.4: CLMS and the Service Recovery Paradox}

4. The proportion of $1^{\text {st }}$-year terminations did decrease significantly for "Resolution" respondents.

This research also provides evidence for the Service Recovery Paradox proposed by McCollough and Bharadwaj (1992) that, customers who experience service issues followed by superior recovery, rate their satisfaction as high as or even higher than they would have if no service failure occurred. In this research, "Resolution" respondents demonstrate higher satisfaction after a successful recovery due to the significant 
reduction in their proportion of $1^{\text {st }}$-year terminations compared to both the benchmark from before the intervention and satisfied customers (score > 8) after the intervention.

\section{5-2.5: Small Sample Size Impacts Ability to Answer Q4}

5. The proportion of $1^{\text {st }}$-year terminations did not decrease significantly for "No Resolution" respondents.

The literature suggests (Hart, Heskett, and Sasser, 1990; McCollough, et al. 2000) that dissatisfaction is greater when attempts of service recovery are unsuccessful. However, the present study fails to support this assertion. In section $4-6 \mathrm{H}_{0} 4$ tests the defection rate of less-than-satisfied customers whose issues are not resolved against the benchmark. This comparison did not find a statistically significant difference.

This is most likely due to the small sample size. There were only 96 respondent contacts where less-than-satisfied whose issues were not resolved satisfactorily. The

resulting proportion of $1^{\text {st }}$-year terminations confidence interval range was from $4.5 \%$ to $14.3 \%$ and the null hypothesis was not rejected. The small number of contacts in the analysis results from the limitation to the volume of data imposed by the controls for confounding factors. Confounding factors reduce the examination period to only thirteen months. This short period and small sample create the broad confidence interval resulting in the difference not to be significant. 


\section{5-3: Unexpected Outcomes}

The researcher was surprised that the proportion of $1^{\text {st }}$-year terminations of strategically targeted customers did not improve significantly. However, as explained above, closer investigation reveals that the customer relationship improvements that the CLMS encourages are already practiced by employees working with this group of customers; therefore, the intervention creates less of an impact on these strategically targeted customers. Another surprise was the substantial improvement derived from the CLMS intervention. The researcher did not expect to find a decrease in the percentage of $1^{\text {st }}$ year defections from $7.5 \%$ to $4.5 \%$.

\section{5-4: Strengths and Limitations}

This research is strengthened by its sample size and time horizon. The study analyzes the defection behavior of 20,638 customers and spans seven years 10/1/2002-9/30/2009. It also is strengthened by its use of empirical evidence to measure customer defections, the use of the proportion of $1^{\text {st }}$-year terminations rather than use surveys that measure customer intent to recommend or re-purchase, which are considered less robust (Morgan and Rego, 2006; Keiningham, et al. 2007). Although it is not a long-term metric the proportion of $1^{\text {st }}$-year termination metric is completely objective, and is also very relevant to the management at the host organization. 
This research is also strengthened by its careful treatment of confounding factors. Identification and elimination of data tainted by confounding factors enhanced the research reliability and its potential for replication by other researchers.

A limitation to this research is that it is a field experiment and as such, although much effort is taken to identify all confounding factors, influential variables may still be present in the data and can prevent replication of the experiment and / or invalidate the results. Perhaps the greatest limiting outcome affecting this research was the loss of nineteen months of post-intervention data to the effect of the two confounding factors, the Great Recession and cost cutting activities. The research project started out to measure effect of the CLMS intervention on a long-term loyalty metric that is based upon customer tenure, but the Great Recession necessitated the use of a shorter-term metric.

Another limitation to this research is that it is not a longitudinal study where the loyalty intentions of individual customers are observed repeatedly before and after the intervention. Longitudinal studies exclude time-invariant, unobserved, individual differences by observing the temporal order of events. This research instead relies on the size of the sample to mitigate the variability and enhance the precision and accuracy of the results. Lastly, this research is limited because it is confined to a single company. Consequently the results may not be generalizable to the broader business community. 
Lastly, this research is applied within only one company from the financial services industry. This is a very narrow application of the CLSM model and substantially limits generalizing the research results to firms of different sizes and in different industries.

\section{5-5: Future Research}

An opportunity for future research is found in the replication of this experiment where the long-term effects of the intervention can be measured. It is unlikely (one hopes) that another significant macro-economic event such as the Great Recession will recur in the coming years. It would be useful to replicate the study over a time horizon that permitted the use of a long-term loyalty metric.

Because customer survey data is available at many companies in a multitude of industries, and because very little investment is required to implement CLSM, it would be useful and practical to replicate this intervention in other firms and industries. The results of such studies are expected to validate the findings of the present study and thereby would enhance the generalizing of the results.

\section{5-6: Contribution to the Literature}

The service-recovery literature has defined service recovery as 1) taking place after customers complain and 2) measuring the success of the service recovery by asking the customers about their loyalty intent. The present research contributes to this literature by: 
1. Redefining service recovery is proactive instead of reactive: Instead of reacting to customer complaints, front-line employees investigate the potential for defections by using customer survey feedback to identify "less-than-satisfied" customers in order to proactively prevent defections and promote customer loyalty.

2. Evidence of loyalty is empirical and not subjective: Instead of measuring customer loyalty intent by surveying customers after a service recovery attempt, this research measures loyalty by analyzing customers' actions following the intervention.

This research also answers a call to use customer surveys to influence customers. According to McColl-Kennedy and Schneider (2000) customer satisfaction surveys are predominantly used for performance measurement, but they point out that customer satisfaction measurement is not a neutral act, but an intervention. As the use of surveys to solicit customer satisfaction is a method to learn about customers, it is also a means to influence customers as to a firm's vision and strategy. The CLMS intervention provides evidence as to the use of customer satisfaction surveys as a tool to reach out to customers and not as a mere measurement device.

This research also contributes an effective, low cost, methodology for businesses seeking to retain customers. Unlike Customer Relationship Management that requires large investments in technologies such as databases, interactivity, and mass customization, 
customer satisfaction surveys are ubiquitous. Most companies already have this data. It is a small and practical investment to dust off these "old bottles" of customer satisfaction survey data, apply the proactive methodology of CLSM, and then enjoy the significant rewards from the "new wine" of increased loyalty by retaining more customers through proactive, closed loop customer feedback. 


\section{REFERENCES CITED}

Ahearne, Michael; Mathieu, John; Rapp, Adam. (2005) Journal of Applied Psychology, September 2005, Vol. 90 Issue 5

Ambler, Tim (2002) Comment: Customer lifetime values-credible, or utterly incredible? Journal of Targeting, Measurement \& Analysis for Marketing, February 2002, Vol. 10 Issue 3, p201

Anderson, Eugene and Mittal, Vikas, (2000) Journal of Service Research, November 2000

Anderson, Eugene, Sullivan Mary, (1993) Marketing Science, Vol 12 No 2 Spring 1993

Andreasen, Alan R, (1977)A Taxonomy of Consumer Satisfaction/Dissatisfaction Measures, Journal of Consumer Affairs, Winter77, Vol. 11 Issue 2, p11

Banker, R. A., G Potter, and D. Srinivasan. (2000) An empirical investigation of an incentive plan that includes non-financial performance measures. The Accounting Review 75 (1): p65-92

Barber, L. Hayday, S, Bevan, (1999) From people to profits, The Institute for Employment Studies Report, \#355

Battista, Paul; Verhun, Darcy, (2000) Customer Relationship Management, CMA Management, May 2000, Vol. 74 Issue 4, p34

Bell, S. J., Auh, S., \& Smalley, K. (2005) Customer relationship dynamics: Service quality and customer loyalty in the context of varying levels of customer expertise and switching costs, Journal of the Academy of Marketing Science, 33, p169-183

Blodgett, Jeffrey G. and Stephen S. Tax (1993), "The Effects of Distributive and Interactional Justice on Complainants' Repatronage intentions and Negative Word of Mouth Intentions," Journal of Consumer Satisfaction, Dissatisfaction and Complaining Behavior, 6, p100-110

Boshoff, Christo (1997), "An Experimental Study of Service Recovery Options," International Journal of Service Industry Management, 8 (2), p110-30

Boulding, W., Staelin, R., Ehret, M., \& Johnston, W.J. (2005). A customer relationship management roadmap: What is known, potential pitfalls, and where to go. Journal of Marketing, 69(5), p155-166

Brown, Stephen W., Deborah L. Cowles, and Tracy L. Tuten (1996), “Service 
Recovery: Its Value and Limitations as a Retail Strategy," International Journal of Service Industry Management, 7 (5), p32-46

Bruhn, Manfred, Grund, Michael A (2000) Total Quality Management, September, 2000

Carpenter, Phil. (1995) Customer lifetime value: Do the math , MC: Marketing Computers, January 1995, Vol. 15 Issue 1, p18

Chakrapani, Chuck, (1998), How to Measure Service Quality \& Customer Satisfaction, The Informal Field Guide for Tools and Techniques, American Marketing Association, Chicago, Ill

Chandon, P., Morwitz, V.G. and Reinartz, W.J. (2005) Do intentions really predict behavior? Self-generated validity effects in survey research, Journal of Marketing, Vol. 69 No. 2, p1-14

Chen, Injazz J ; Popovich, Karen (2003) Understanding customer relationship management (CRM): People, process and technology, Business Process Management Journal, 2003, Vol. 9 Issue 5, p672-688

Chung, Beth; Hoffman, K. Douglas (1998) Critical incidents, Cornell Hotel \& Restaurant Administration Quarterly, June 1998, Vol. 39 Issue 3, p66

Cohen, Susan G, Chang, Lei and Ledford, Gerald E. (1997) A hierarchical construct of self-management leadership and its relationship to quality of work life and perceived work group effectiveness, Personnel Psychology, Summer, 1997

Colgate, M. (2001), Developing a comprehensive picture of service failure, International Journal of Service Industry Management, Vol. 12 No. 3, p215-33

Connolly, T. and Ashworth, G. (1994) 'Managing customers for profit', Management Accounting, Vol. 72, No. 4, p34-40

Davidow, M. (2003), "Organisational responses to customer complaints: what works and what doesn't", Journal of Service Research, Vol. 5 No. 3, p225-50

Davis, Tom and Landa, Michael, (2000) The Story of Mary: How the organization culture can erode bottom-line profitability, The Canadian Manager, Winter, 2000

Deng, Zhaohua; Lu, Yaobin; Wei, Kwok Kee; Zhang, Jinlong (2010) International Journal of Information Management, August 2010, Vol. 30 Issue 4, p289-300

Donio, Jean; Massari, Paola; Passiante, Giuseppina (2006) Journal of Consumer Marketing, Vol. 23 Issue 7

Edvardsson, Bo; Johnson, Michael D.; Gustafsson, Anders; Strandvik, Tore (2000) The effects of satisfaction and loyalty on profits and growth: products versus services, Total 
Quality Management, September 2000, Vol. 11 Issue 7, p918

Flint, Daniel J.; Blocker, Christopher P.; Boutin, Philip J (2011) Industrial Marketing Management, February 2011, Vol. 40 Issue 2, p219-230

Forrester, Jay W., (1968), Principles of Systems: Text and Workbook, Wright-Allen Press, Cambridge, Mass

Goodwin, Cathy and Ivan Ross (1992), "Consumer Responses to Service Failures: Influence of Procedural and Interactional Fairness Perceptions," Journal of Business Research, 25, p149-63

Gostick, Adrian, (2000) They do recognition right, Workspan, October, 2000

Gronroos, Christian (1984) A Service Quality Model and its Marketing Implications, European Journal of Marketing, 1984, Vol. 18 Issue 4

Gronroos, Christian (1990) Relationship Approach to Marketing in Service Contexts: The Marketing and Organizational Behavior Interface, Journal of Business Research, January 1990, Vol. 20 Issue 1, p3-11

Gupta, Sunil; Zeithaml, Valarie (2007) Customer Metrics and Their Impact on Financial Performance, Marketing Science, November / December 2006, Vol. 25 Issue $6, \mathrm{p} 718-739$

Hallowell, Roger (1996) The relationships of customer satisfaction, customer loyalty, and profitability: an empirical study, International Journal of Service Industry Management, Vol. 7 Issue 4

Hallowell, Roger, Schlesinger, Leonard A., Zornitsky, Jeffrey, (1996) Internal Service Quality, Customer and Job Satisfaction: Linkages and Implications for Management, Human Resource Planning, 1996, Vol. 19 Issue 2

Halstead, D., Droge, C., Cooper, M.B. (1993) Product warranties and post-purchase service. Journal of Services Marketing 7 1., p33-40

Halstead, Diane; Morash, Edward A.; Ozment, John (1996) Comparing Objective Service Failures and Subjective Complaints: An Investigation of Domino and Halo Effects, Journal of Business Research, June 1996, Vol. 36 Issue 2, p107-115

Harrington, James H, (1991), Business Process Improvement, McGraw-Hill, New York Hart, Christopher W. L., James L. Heskett, and Earl W. Sasser (1990) The Profitable Art of Service Recovery, Harvard Business Review, 68 (July / August), p148-156

Harvard Management Update (2000) A crash course in customer relationship management, March 2000, Vol. 5 Issue 3, p3 
Heskett, James L. Sasser, Jr., W. Earl, Schlesinger, Leonard A. (1997) The Service Profit Chain: how leading companies link profit and growth to loyalty, satisfaction, and value, The Free Press, New York, NY

Heskett, James, Jones, Thomas, Loveman, Gary, Sasser, Jr., W. Earl, Schlesinger, Leonard A (2008) Putting the Service-Profit Chain to Work, Harvard Business Review; July - August 2008, Vol. 86 Issue 7/8, p118-129

Hoffman, K. Douglas, and Beth G. Chung (1999) Hospitality Recovery Strategies: Customer Preference versus Firm Use, Journal of Hospitality and Tourism Management, 23 (1), p71-84

Homburg, Christian; Annette Giering (2001) Psychology \& Marketing, January 2001, Vol. 18 Issue 1, p43-66, 24p

Huselid, Mark A. (1995) The impact of human resource management practices on turnover, productivity, and corporate financial performance, Academy of Management Journal, June, 1995

Johnson, Julian (2004) Manager: British Journal of Administrative Management, Making CRM technology work, January / February 2004, Issue 39, p22-23

Johnston, R. and Mehra, S. (2002), "Best practice complaint management", The Academy of Management Executive, Vol. 16 No. 4, p145-55

Jones, Thomas O., Sasser, W. Earl (1995) Why Satisfied Customers Defect, Harvard Business Review, November - December 1995

Jones, M. A., Mothersbaugh, D. L., \& Beatty, S. E. , (2000) Switching barriers and repurchase intentions in services, Journal of Retailing,, 76, p259-274

Kaplan, Robert S, and Cooper, Robin (1998), Cost \& Effect: Using Integrated Cost Systems to drive profitability and Performance, Harvard Business School Press, Boston, MA

Kaplan, Robert S., and Norton, David P. (1996) Linking the Balanced Scorecard to Strategy, California Management Review, Fall 1996 Vol 39, No 1, p53-79

Keating, E.K., Oliva, R., Repenning, N., Rockart, S.F., Sterman, J.D. (1999) Overcoming the improvement paradox, European Management Journal, 1999 Vol. 17 No.2,, p120-34

Keiningham, Timothy L. ; Cooil, Bruce ; Aksoy, Lerzan ; Andreassen, Tor W. ; Weiner, Jay , (2007) The value of different customer satisfaction and loyalty metrics in predicting customer retention, recommendation, and share-of-wallet., Managing Service 
Quality, July 2007, Vol. 17 Issue 4, p361-384

Keiningham, Timothy L.; Aksoy, Lerzan; Cooil, Bruce; Andreassen, Tor Wallin, (2008) The Galileo Effect, Marketing Management, January / February 2008, Vol. 17 Issue 1, p48-51

Kelley, S.W. (1994) Antecedents to customer expectations for service recovery. Journal of the Academy of Marketing Science 22 1., p52-61

Kelley, Scott W., K. Douglas Hoffman, and Mark A. Davis (1993) A Typology of Retail Failures and Recoveries, Journal of Retailing, 69 (4), p429-52

Kelley, Scott W.; Davis, Mark A. (1994) Antecedents to Customer Expectations for Service Recovery, Journal of the Academy of Marketing Science, Winter94, Vol. 22 Issue 1, p52-61

Kessler, Sheila, (1996) Measuring and managing customer satisfaction: going for the gold, ASQC Quality Press, Milwaukee, WI

Koys, Daniel J. (2001) The Effects of employee satisfaction, Organizational citizenship Behavior, and Turnover on Organizational effectiveness: A Unit-Level Longitudinal study, Personnel Psychology, Vol 54, 2001, p101-114

Kumar, V, Rajan, Bharath (2009) Profitable Customer Management: Measuring and Maximizing Customer Lifetime Value, Management Accounting Quarterly, Spring 2009, Vol. 10 Issue 3, p1-18

Maister, David H. (2000), Practice What You Preach: What Managers Must Do to Create a High Achievement Culture, The Free Press, New York

Maxham, J.G. III and R.G. Netemeyer (2002) A Longitudinal Study of Complaining Customers' Evaluations of Multiple Service Failures and Recovery efforts, Journal of Marketing, 66(4), p57-71

McColl-Kennedy, Janet; Schneider, Ursula (2000) Measuring customer satisfaction: why, what and how, Total Quality Management, 9/1/2000 Vol. 11 Issue 7, p882- 896

McCollough, M.A. and S.G. Bharadwaj (1992) The Recovery Paradox: An Examination of Consumer Satisfaction in Relation to Disconfirmation, Service Quality and Attribution based Theory, in C.T. Allen, et al. (Eds.), Marketing Theory and Applications, Chicago, IL: American Marketing Association

McCollough, M., Berry, L. and Yadav, M. (2000) An empirical investigation of customer satisfaction after service failure and recovery, Journal of Service Research, Vol. 3 No. 2, p121-37

McDaniel, Carl, Jr. and Gates, Roger (2005) Marketing Research, Sixth Edition, John 


\section{Wiley \& Sons}

Michel, S. (2001) Analyzing service failures and recoveries: a process approach, International Journal of Service Industry Management, Vol. 12 No. 1, p20-33

Miller, John A (1996) Implementing Activity-Based Management in Daily Operations, John Wiley and Sons, New York

Miller, Janis L. , Craighead, Christopher W. , Karwan, Kirk R. (2000) Service recovery: a framework and empirical investigation, Journal of Operations Management, June 2000, Vol. 18 Issue 4, p387-400

Mithas, S., Krishnan, M.S., \& Fornell, C. (2005). Why do customer relationship management applications affect customer satisfaction? Journal of Marketing, 69(4), p201-209

Morgan, Neil A.; Rego, Lopo Leotte (2006) The Value of Different Customer Satisfaction and Loyalty Metrics in Predicting Business Performance, Marketing Science, September / October 2006, Vol. 25 Issue 5, p426-439

Morwitz, Vicki G., (2005) The effect of survey measurement on respondent behavior, Applied Stochastic Models in Business \& Industry, July -October 2005, Vol. 21 Issue $4 / 5, \mathrm{p} 451-455$

Naumann, Earl, and Giel, Kathleen (1995) Customer Satisfaction Measurement and Management: Using the voice of the customer, Thomson Executive Press, Cincinnati, Ohio

Parasuraman, A., Zeithaml, Valarie A., and Berry, Leonard L. (1988) SERVQUAL: A Multiple-Item Scale for Measuring Consumer Perceptions of Service Quality, Journal of Retailing, Spring 1988, Vol. 64 No. 1, p5 - 40

Parasuraman, A.; Zeithaml, Valarie A.; Berry, Leonard (1985) L A Conceptual Model of Service Quality and Its Implications for Future Research, Journal of Marketing, Fall 1985, Vol. 49 Issue 4, p41-50

Pfau, Bruce n. and Kay Ira T. (2002) The Human capital Edge, McGraw Hill, New York

Pingitore, Gina; Morgan, Neil A.; Rego, Lopo L.; Gigliotti, Adriana; Meyers, Jay. (2007) The Single-Question Trap., Marketing Research, Summer 2007, Vol. 19 Issue 2, p4-5

Pont, Marcin; McQuilken, Lisa (2005) Journal of Financial Services Marketing, June 2005, Vol. 9 Issue 4, p344-359

Porter, Michael E, (2008) On Competition, Harvard Business School Publishing, Boston, Massachusetts 
Porter, Michael E. (1985) Competitive Advantage: Creating and Sustaining Superior Performance, The Free Press, New York, NY

Porter, Michael E.(1985) Competitive Advantage, Free Press, New York

Prahalad, C.K.(1990) The Core Competence of the Corporation, Harvard Business Review, May - June 1990

Reichheld, F.F., Sasser Jr., W.E. (1990) Zero Defections: Quality comes to Services, Harvard Business Review, September / October 1990, Vol. 68 Issue 5

Reichheld, Fred, (2006) The Ultimate Question, Driving Good Profits and True Growth, Harvard Business School Press, Boston, MA

Reichheld, Frederick F. (1996) The Loyalty Effect: The Hidden Force Behind Growth, Profits, and Lasting Value, Bain and Company

Reichheld, Frederick F. (2003) The One Number you Need to Grow, Harvard Business Review, p364-94

Repenning, Nelson P. and Sterman, John D. (2001) Nobody ever gets credit for fixing problems that never happened: creating and sustaining process improvement, California Management Review, Vol. 43 No. 4 Summer 2001

Repenning, Nelson P. and Sterman, John D. (2002) Capability Traps and SelfConfirming Attribution Errors in the Dynamics of Process Improvement, Administrative Science Quarterly, Vol. 47, p265

Richins, Marsha L. (1983) Negative Word-of-Mouth by Dissatisfied Consumers: A Pilot Study, Journal of Marketing, Winter 1983, Vol. 47 Issue 1, p68-78

Richmond, Barry (1993) Systems Thinking: Critical Thinking Skills for the 1990's and Beyond, System Dynamics Review, 9, p113-33

Roth, Aleda V. (1993) Performance Dimensions in services: An empirical investigation of strategic performance, Advances in Services marketing and management, Vol 2, p1 47

Ryals, Lynette (2005) Making Customer Relationship Management Work: The Measurement and Profitable Management of Customer Relationships, Journal of Marketing, 69 (October), p252-61

Schlesinger, Leonard A, Zornitsky, Jeffrey (1991) Job Satisfaction, Service Capability, and Customer Satisfaction: An Examination of Linkages and Management Implications, Human Resource Planning, Vol 14, No. 2, p414-149 
Schlesinger, Leonard A.; Heskett, James L., (1991) e Service-Driven Service Company., Harvard Business Review, September / October 1991, Vol. 69 Issue 5, p71-81

Schneider, B. and Bowen, D. (1985) Employee and Customer Perceptions of Service in Banks: Replication and Extension, Journal of Applied Psychology, 1985, Vol. 70 , p423-33

Schneider, Benjamin and Bowen, David E., (1999) Understanding Customer Delight and Outrage, Sloan Management Review, Fall 1999

Schneiderman, A. , (1988) Setting quality goals, Quality Progress, April 1988, p55-57

Sharp, Byron, (2008) The Net Promoter Score Fails the Test, Marketing Research, Winter 2008, Vol. 20 Issue 4, p28-30

Singh, Jagdip (1990) Identifying Consumer Dissatisfaction Response Styles: An Agenda for Future Research, European Journal of Marketing, 1990, Vol. 24 Issue 6, p55-72

Smith, A.K. and R.N. Bolton (1998) An Experimental Investigation of Customer Reactions to Service Failure and Recovery Encounters: Paradox or Peril? Journal of Services Research, 1(1), p65-81

Smith, Amy K, Ruth N. Boltonand Janet Wagner (1999), A Model of Customer Satisfaction with Service Encounters Involving Failure and Recovery, Journal of Marketing Research, 36 (3), p356-72

Srinvasan, R., \& Moorman, C. (2005). Strategic firm commitments and rewards for customer relationship management in online retailing. Journal of Marketing, 69(5), p193-200.

Sterman, John D. (2000) Business Dynamics: Systems thinking and modeling for a complex world, McGraw Hill, Boston, MA

Stone, Merlin; Woodcock, Neil; Wilson, Muriel (1996) Managing the Change from Marketing Planning to Customer Relationship Management, Long Range Planning, October 1996, Vol. 29 Issue 5, p675-683

Stratton, William O; Desroches, Denis; Lawson, Faefa; Hatch, Toby (2009) ActivityBased Costing: Is It Still Relevant?, Management Accounting Quarterly, Spring 2009, Vol. 10 Issue 3, p31-40

Sui-Hua Yu (2007) Total Quality Management \& Business Excellence, Jul2007, Vol. 18 Issue 5, p555-569

Swanson, Richard A. (1998) Demonstrating the financial benefit of human resource development: Status and update on the theory and practice, Human resource 
development Quarterly, Fall 1998

Tax, Stephen S.; Brown, Stephen W.; Chandrashekaran, Murali (1998) Customer Evaluations of Service Complaint Experiences: Implications for Relationship Marketing, Journal of Marketing, April 1998, Vol. 62 Issue 2, p60-76

Vavra, Terry G. (1997) Improving Your Measurement of Customer Satisfaction, ASQ Quality Press, Milwaukie, WI

Wang, Chung-Yu (2010) Service quality, perceived value, corporate image, and customer loyalty in the context of varying levels of switching costs, Psychology \& Marketing, March 2010, Vol. 27 Issue 3, p252-262

Wann-Yih Wu; Cheng-Hung Tsai (2007) The empirical study of CRM, International Journal of Commerce \& Management, 2007, Vol. 17 Issue 3, p194-210

Wisner, Priscilla S. and Feist, Hollace A. (2001) Does teaming pay off?, Strategic Finance, February, 2001

Wright, Len Tiu; Stone, Merlin; Abbott, Juli (2002), The CRM imperative - Practice vs. theory in the telecommunications industry, Journal of Database Marketing, July 2002, Vol. 9 Issue 4, p339

Yang, Ching-chow (2003) Improvement actions based on the customers' satisfaction survey, Total Quality Management \& Business Excellence, October 2003, Vol. 14 Issue $8, \mathrm{p} 919$

Yee, Rachel W. Y.; Yeung, Andy C. L.; Cheng, T. C. Edwin; Kee-Hung Lai. (2009) The service-profit chain: A review and extension, Total Quality Management \& Business Excellence, June 2009, Vol. 20 Issue 6, p617-632

Zeithaml, Valarie A.; Bolton, Ruth N.; Deighton, John; Keiningham, Timothy L.; Lemon, Katherine N.; Petersen, J. Andrew (2006) Forward-Looking Focus: Can Firms Have Adaptive Foresight? Journal of Service Research, November 2006, Vol. 9 Issue 2, p168-183, 16p 